(2) norden 



\section{EU REACH \\ Enforcement project}

Final report 2008 


\section{EU REACH Enforcement project}

Final report 2008

TemaNord 2008:561

(C) Nordic Council of Ministers, Copenhagen 2008

ISBN 978-92-893-1717-7

Print: Ekspressen Tryk \& Kopicenter

Printed on environmentally friendly paper

This publication can be ordered on www.norden.org/order. Other Nordic publications are available at www.norden.org/publications

Printed in Denmark

Nordic Council of Ministers

Store Strandstræde 18

DK-1255 Copenhagen K

Phone (+45) 33960200

Fax (+45) 33960202

www.norden.org

\author{
Nordic Council \\ Store Strandstræde 18 \\ DK-1255 Copenhagen K \\ Phone (+45) 33960400 \\ Fax (+45) 33111870
}

\section{Nordic co-operation}

Nordic cooperation is one of the world's most extensive forms of regional collaboration, involving Denmark, Finland, Iceland, Norway, Sweden, and three autonomous areas: the Faroe Islands, Greenland, and Åland.

Nordic cooperation has firm traditions in politics, the economy, and culture. It plays an important rol in European and international collaboration, and aims at creating a strong Nordic community in a strong Europe.

Nordic cooperation seeks to safeguard Nordic and regional interests and principles in the global community. Common Nordic values help the region solidify its position as one of the world's most innovative and competitive. 


\section{Content}

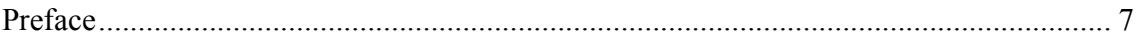

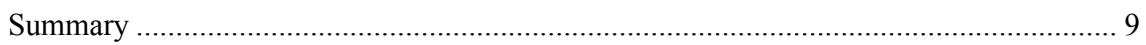

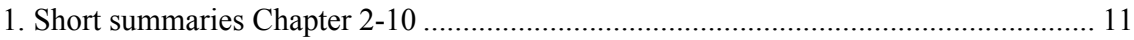

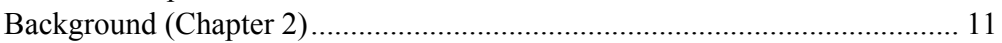

REACH Enforcement Priorities (Chapter 3) ................................................ 11

Competence/Education (Chapter 4) ........................................................... 11

Methods/Tools (Chapter 5) ...................................................................... 11

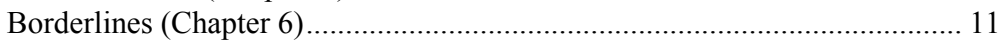

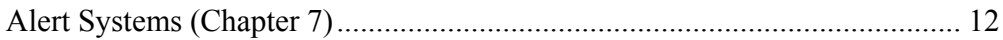

REACH-IT (Chapter 8) ..................................................................... 12

Proposals for Forum Projects (Chapter 9) .................................................. 12

Draft Proposal for Forum Rules of Procedure (Chapter 10).......................... 12

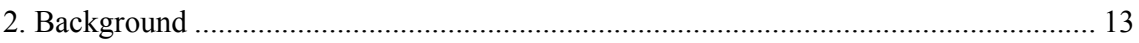

2.1 REACH requirements on Member States (MS) with respect to enforcement....... 13

2.2 Role of European Chemicals Agency (ECHA) in relation to enforcement............ 13

2.3 Preparatory work made by the EU project and relation to subCWG enforcement and $\mathrm{COM}$

3. REACH Enforcement Priorities - a short analysis of prioritisation needs, problems and information needs......

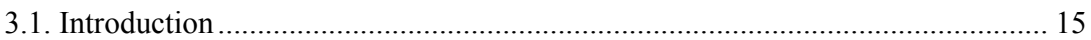

3.2 Registration (title II), Data sharing and avoidance of unnecessary testing (Title

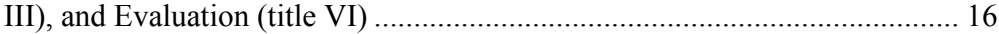

3.3 Information in the supply chain (title IV) - new parts........................................ 22

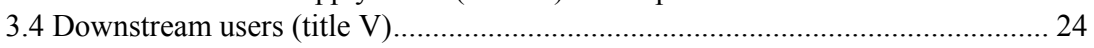

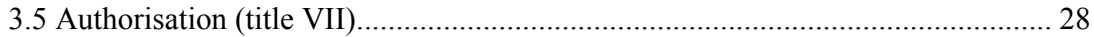

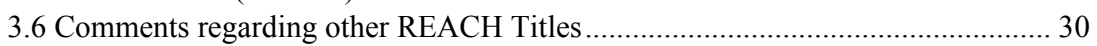

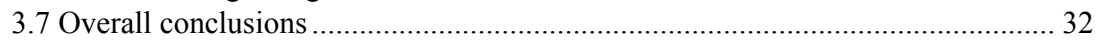

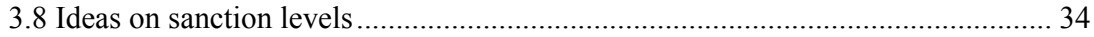

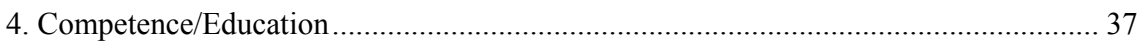

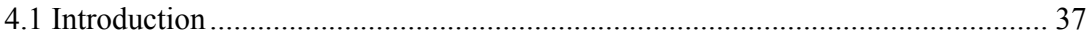

4.2 Preliminary Analysis of competence needs with respect to some "typical" REACH

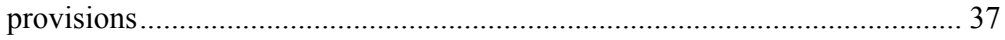

4.3 Results and suggestions done by member states................................................ 38

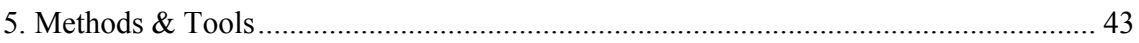

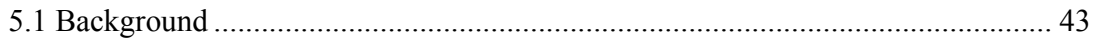

5.2 Results of the input of other MS in the discussion workshop September 2007 .... 44

5.3 Structure and work process of the Compendium ............................................... 45

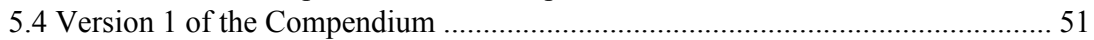

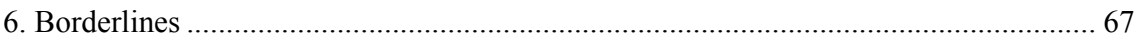

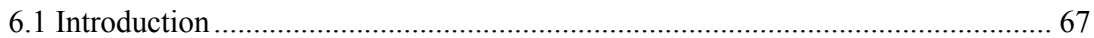

6.2 Borderlines between work by ECHA and by National Enforcement Authorities. 67

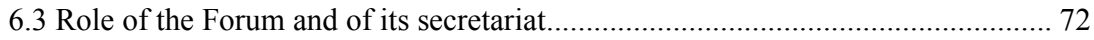

6.4 Interfaces between enforcement fields ............................................................... 77

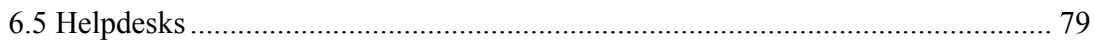


7. Alert System.

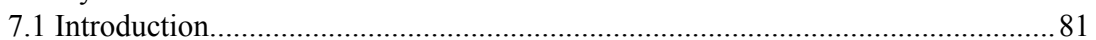

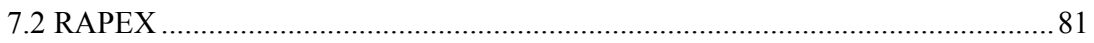

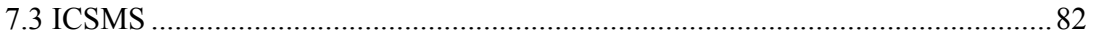

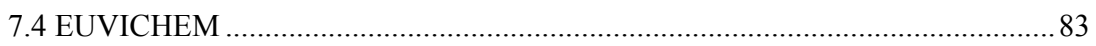

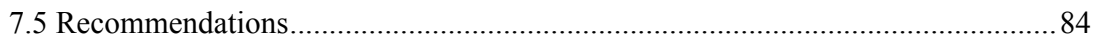

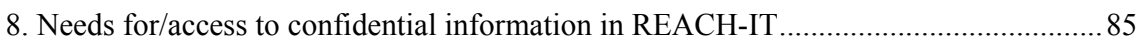

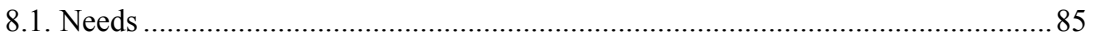

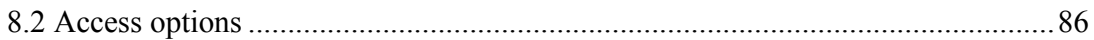

8.3. Interrelation between organisational structure and access.................................. 88

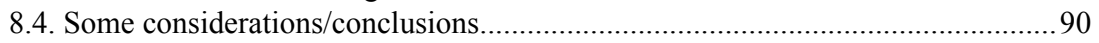

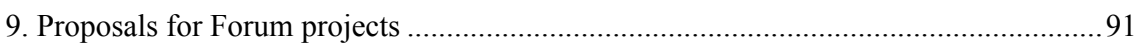

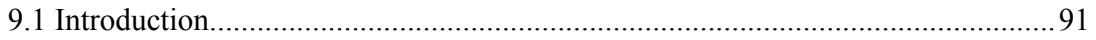

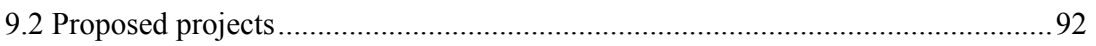

10. Draft Proposal for Forum Rules of Procedure (31 October, 2007)............................ 95

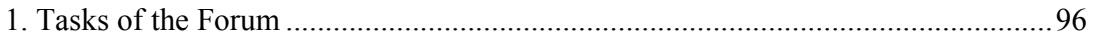

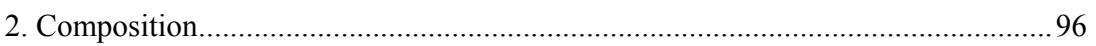

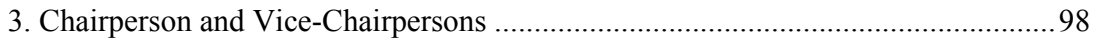

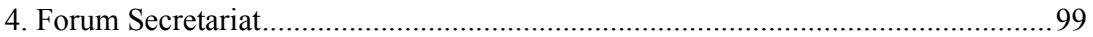

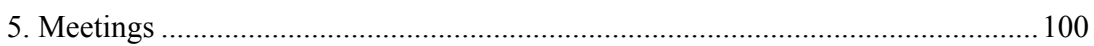

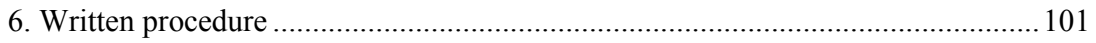

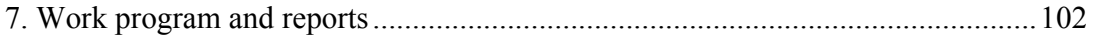

8. Working groups and Projects......................................................................... 102

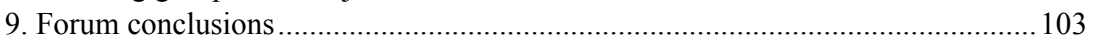

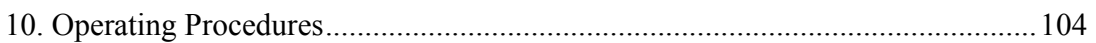

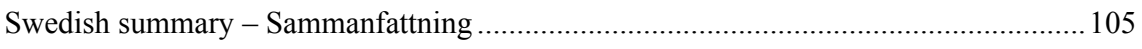

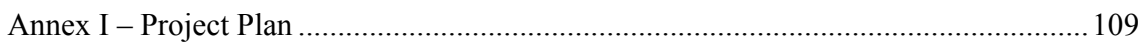

Annex II - Minutes from workshop 14-15 December 2006 - Report "Preparing for

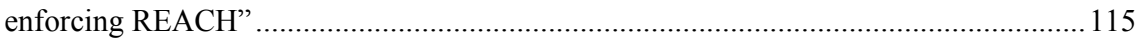

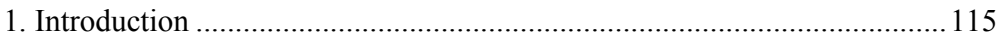

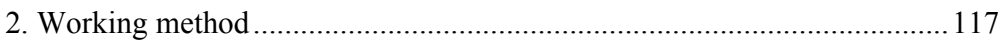

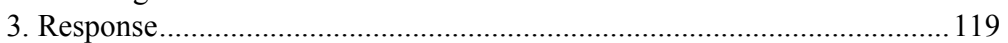

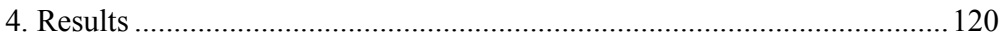

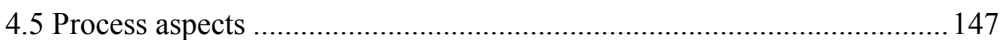

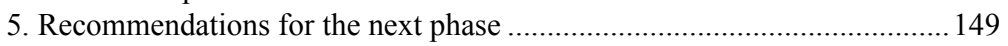

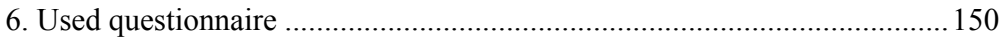

Annex III - Minutes from workshop 24-25 September 2007 ....................................... 153

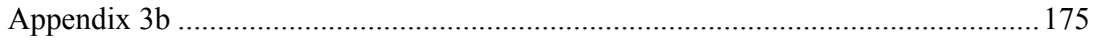

Annex IV - Presentation of the project at 1st Forum meeting 11 December 2007.......... 177

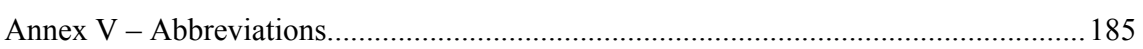




\section{Preface}

This is a report of a EU project aimed to identify present enforcement and new needs due to the new EU regulation on chemicals, REACH, investigate the state of preparation of the Member States and start preparing for the operative work of the Forum for enforcement. The project has also aimed to elaborate work division, co-operation and information exchange, prepare a draft proposal for Rules of Procedure for the Forum and develop a compendium of useful enforcement methods.

The project has been carried out by a project group consisting of Denmark, Ireland, the Netherlands, and Sweden (lead). To support the project a consultant, Royal Haskoning (from the Netherlands), was hired. Austria, Belgium, Latvia, Norway, Slovenia, Spain, and United Kingdom have acted as referral group and sub-CWG Enforcement as steering group.

Financial support for the project has been arranged by Member States (Nordic Council of Ministers and Netherlands), since enforcement is within the competence of the Member States. Commission though has been able to give indirect support (meeting rooms, travel costs), since project workshops and sub-CWG meetings have been held back-to back. 



\section{Summary}

The new EU regulation on chemicals, REACH, implies a significant restructuring and enlargement in the field of chemicals regulation, and thus also of enforcement. The importance of the Forum for enforcement included in REACH for a good implementation of REACH was early recognised.

Thus, at the CWG (Commission Working Group for the implementation of REACH) meeting in November 2005, a REACH Implementation Project on enforcement was proposed (by Sweden). The initiative lead to the start of a REACH EU Enforcement Project in March 2006, and also to the Commission setting up a subgroup under the CWG in order to prepare for the enforcement of REACH.

Aims of the project (c.f. the project plan attached as Annex I) were to:

- Identify present enforcement and new needs due to REACH

- Investigate the state of preparation of the Member States and start preparing for the operative work of the Forum

- Elaborate work division, co-operation and information exchange

- Prepare a draft proposal for Rules of Procedure for the Forum

- Develop a compendium of useful enforcement methods

To achieve the objectives of the project several activities were carried out through workshops, investigations, interviews etc, with the purpose to give the Forum a "flying start".

The project has resulted in, among others, several independent reports included in this final report as chapters 3-10: REACH Enforcement Priorities, Competence/Education, Methods/Tools, Borderlines, Alert Systems, REACH-IT, Proposals for Forum Projects, and Draft Proposal for Rules of Procedure for Forum. Chapter 1 presents short summaries of the individual reports. Annexed to the report is the project plan, minutes from workshops and presentation of the project at first Forum meeting in December 2007. 



\section{Short summaries Chapter $2-10$}

\section{Background (Chapter 2)}

Description of REACH requirements on Member States and the role of ECHA with respect to enforcement, and the preparatory work made by the project.

\section{REACH Enforcement Priorities (Chapter 3)}

This report goes through REACH with the aim to contribute to identification of the provisions most important to enforce, in order to make REACH work appropriately. It also tries to analyse factors (e.g. interpretation problems) that may make enforcement difficult or impossible, and to identify some needs for information from REACH-IT. A draft version was used as a thought starter for discussions during the $2^{\text {nd }}$ project workshop, the results of which have been incorporated.

\section{Competence/Education (Chapter 4)}

This report comprises a short analysis of the various enforcement situations/questions enforcers will meet, and gives some preliminary reflections and conclusions on the needs for competences and education for various kinds of REACH enforcement. It is based e.g. on discussions at workshops organized by the project. The aim is to try to assist the Member States in the start-up phase of enforcement of REACH.

\section{Methods/Tools (Chapter 5)}

This report provides a very first version of a Compendium of Methods \& Tools, which might be made a very useful item according to interviews and workshops of the project. A process to make/update it is proposed. Such a compendium might be used as a reference book/framework for exchange of information on good practices in enforcement.

\section{Borderlines (Chapter 6)}

This report describes and discusses the so far partly unclear borderlines between ECHA and the national Enforcement Authorities in relation to 
enforcement of REACH. It also discusses the role of Forum, and the borderlines between enforcement authorities within a Member State.

\section{Alert Systems (Chapter 7)}

This report describes some relevant existing alert systems; RAPEX, ICSMS and EUVICHEM. The aim is to prepare for discussions on the need for and existing alternatives for an alert system, to complement other ways for information exchange between enforcement authorities.

\section{REACH-IT (Chapter 8)}

This report contains some first thoughts on enforcers' needs for and access to confidential information in REACH-IT, and on the interrelation between organisational structure and access. It is intended to function merely as a thought starter for work by Forum on this critical issue.

\section{Proposals for Forum Projects (Chapter 9)}

This report contains a number of project proposals from the $2^{\text {nd }}$ project workshop and has been handed over to Forum to assist in the start-up phase. Examples: development of a report template according to Article 127, development of training kit for inspectors, and a project on SDS.

\section{Draft Proposal for Forum Rules of Procedure (Chapter 10)}

This report contains a draft proposal for Forum Rules of Procedure. During the process towards this proposal other RoPs were studied and relevant issues and demands were determined. The draft proposal was handed over to ECHAs Forum secretariat in November 2007, i.e. before the $1^{\text {st }}$ meeting of Forum. 


\section{Background}

\subsection{REACH requirements on Member States (MS) with respect to enforcement}

REACH (Title XIV) requires the Member States to maintain an appropriate control system. Member States must also set up an appropriate framework for penalties, with a view to impose effective, proportionate and dissuasive penalties for non-compliance, and notify these to the Commission no later than 1 December 2008. Results of inspections, monitoring and penalties are to be reported to the Commission by 1 June 2010 , and after that every five years.

REACH also recognises the need for good cooperation, coordination and exchange of information between the Member States, the Agency and the Commission regarding enforcement, to make REACH operate effectively. A "Forum for Exchange of Information on Enforcement" under the Agency will spread good practice and highlight problems at Community level, coordinate harmonised enforcement projects and joint inspections, develop working methods/tools for inspectors, identify enforcement strategies and best practice in enforcement, develop an electronic information exchange procedure, liaising with industry and other stakeholders, and examine proposals for restrictions (c.f. Art 76-77).

\subsection{Role of European Chemicals Agency (ECHA) in relation to enforcement}

The tasks of ECHA include ensuring effective management of the technical, scientific and administrative aspects of the REACH Regulation at Community level. Among other things, ECHA will perform completeness checks of registrations and assign a registration number to (seemingly) complete registrations, or where necessary reject registrations. Furthermore, ECHA will carry out two evaluation tasks - compliance checks of registrations and examination of test proposals (Note: were in 1st REACH proposal to be carried out by MS).

When ECHA performs compliance checks, it will now and then become necessary to require registrant(s) to submit more information. And when it comes to examination of test proposals, there will in a large number of cases set times when test results have to be reported. ECHA hereby has to rely on the national enforcement authorities with the help of sanctions to ensure that companies submit the information. It's not made clear 
in REACH whether ECHA, in the case the registrant does not give in the information required, may cancel a registration number given out at an earlier stage.

Furthermore, ECHA provides a secretariat for the Forum for enforcement, and will have access to the enforcement reports from MS. ECHA shall also provide technical and scientific guidance and tools for implementing the legislation, in particular to assist the development of Chemical Safety Reports (CSR)s.

As can be understood from the above, a great deal of interaction on enforcement-related tasks will be needed between ECHA and national enforcement.

\subsection{Preparatory work made by the EU project and relation to subCWG enforcement and COM}

In the spring of 2006, a questionnaire prepared by the project was distributed by COM to the CLEEN (Chemical Legislation European Enforcement Network) members. There were questions on the state of preparation for enforcement under REACH, including national projects, identification of appropriate enforcement tools and strategies, education of enforcers, changes to the organisation for enforcement etc. 21 out of 28 countries answered. The results were presented at the $1^{\text {st }}$ sub CWG meeting in Vienna June 2006. The conclusion was that very few countries at that time had started preparations for the enforcement of REACH.

During autumn 2006 the consultant contracted by the project interviewed some 20 MS to find out in more detail their view on how to perform harmonized enforcement of REACH in EU. Results were presented at the $2^{\text {nd }}$ sub CWG meeting in December 2006, and back-to-back a workshop on the results was organised by the project. A report from this work and workshop, "Preparing for enforcing REACH", is attached to this report as Annex II.

During 2007 the project work comprised investigation of different titles of REACH), drafting rules of procedures for the Forum, and identifying methods/tools and competence/education needs for REACH enforcement. Certain results were reported to the $4^{\text {th }}$ and last subCWG 24 September 2007, and other results were discussed at a workshop back-to back with the $4^{\text {th }}$ sub-CWG. Minutes from that workshop is attached to this report as Annex III.

At the $1^{\text {st }}$ meeting with the Forum for enforcement 11 December 2007, a presentation of the results was given by the project and is attached to this report as Annex IV. 


\section{REACH Enforcement Priorities - a short analysis of prioritisation needs, problems and information needs}

\subsection{Introduction}

This report has been written within the framework of the REACH EU Enforcement Project and was used as a thought starter for discussions during a workshop organised by the project in Brussels 24-25 September 2007. The outcome from the workshop has been incorporated in this report.

The specific aim of the report is to contribute to identification of those provisions in REACH which seems most important to enforce in order to make REACH work appropriately. This may also give some ideas on the need for sanctions for non-compliance. Furthermore, the report tries to analyse problems, e.g. interpretation problems, that may make enforcement difficult or impossible, and finally to identify some of the needs for information - especially confidential information - from REACH-IT in order to enable enforcement.

During the review work to produce the report, primarily the following questions were asked:

- Is enforcement of the article crucial for the functioning of REACH?

- Is it a complicated/unclear article, difficult to enforce? Why?

- Is confidential (or at least "non-public") information required from REACH IT, in order to make enforcement of the article possible/efficient? Which information?

Only selections of all the articles that have to be enforced are mentioned. The review focuses on certain articles in REACH Titles II-VII, which in the review work were considered the most important ones for the functioning of REACH, since they contain new and extensive obligations for Industry. There is also a section on some other Titles in REACH with a brief analysis. Chapter 3.8 lists some rough ideas on the level of sanctions non-compliance of the articles might require, with respect only to the importance for the functioning of REACH. 


\subsection{Registration (title II), Data sharing and avoidance of unnecessary testing (Title III), and Evaluation (title VI)}

\section{Introduction}

The above three Titles of REACH are dealt with together here because they all deal with - directly or indirectly - with registration, which can be said to be the cornerstone of REACH.

Registration contains a core provision on "no data, no market" and a number of detailed provisions on what, how, and when to register, including to perform a Chemical Safety Assessment (CSA) and complete a Chemical Safety Report (CSR) for all substances in quantities of 10 tonnes or more/year/ registrant. Registrants then - in safety data sheets /exposure scenarios they supply - have to recommend appropriate measures to control the risks adequately. This build up of more information, and identification and recommendation of how to adequately control the risks, is one of the main aims with REACH.

Data-sharing and avoidance of unnecessary testing contains an important provision on pre-registration, which is a possibility for registrants to submit just some information before 1 December 2008, in order to be allowed to register not until 2010/2013/2018 depending on volume.

However, pre-registration is not an obligation in it-self, registrants can choose to register early instead. If they neither pre-register, nor register, the "no data - no market" provision in Title II will apply. Pre-registration of "phase-in substances" will facilitate formation of so called Substance Information Exchange Fora (SIEF).

One aim of evaluation is, to put it very simply, to check registrations, and there are duties for registrants to provide more "registration information" to the Agency: 1) results from animal tests proposed in the registration dossier, and 2) further information as found necessary in the compliance check. Another aim is to allow for generation of more information, during substance evaluation, in order to reveal needs for actions at EU level (such as restrictions).

In a number of cases where a registration number has been assigned to a substance at a very early stage (after just a simple completeness check) it will later on during evaluation become obvious that much of the necessary information is still missing or invalid, and thus has to be given in by the registrant. To ensure registration in the end leads to the intended better information on chemicals, identification of appropriate safety measures, etc, it thus seems crucial that MS strictly enforce evaluation decisions telling the registrants to submit the required information.

Furthermore, it seems crucial that ECHA considers any possibility to establish a procedure by which a registration number might be cancelled if a registrant doesn't comply with evaluation decisions regarding test 
plans or decisions taken after compliance check, at least in severe cases. REACH does not state anything on this matter, but only that registrations can be rejected if a registrant fails to complete his registration after the completeness check.

\section{Priorities}

"Core" registration articles

Articles 5 and 6 are the most important articles and of highest priority, all other articles in Title II may be seen as complementary to these two. Article 5 says "no market or manufacture if not registered according to the provisions in Title II", and Article 6 contains a general duty to register substances as such or in preparations. Enforcement of Article 5 and 6 will be most crucial to prevent manufacturing, import, marketing, and use of substances without the appropriate registration. One important early task for enforcement will be to check violations of art 5 for phase-in substances still on the market but neither pre-registered (art 28), nor registered (art 6). It is also important to check that the non-phase in substances (the very new substances) are registered according to the requirements, as they can't be pre-registered and consequently can't benefit from transitional regime provided for in Article 23. Stocks will probably be rather difficult to inspect as there is a need to prove time of manufacture/importation. Included is also a need to check supply chain and tonnage. It could also be difficult to get information from companies (especially from importers) as the definition of substance could be difficult to interpret (e.g. mono-constituents, multi-constituent, reaction products)

Many exemptions and time-limits will make enforcement difficult in the beginning. Pre-registration should not be seen isolated and is a part of the registration requirements in Article 5 and 6. In future when most of the registrations are done, it can be a problem with false information in the database as only $5 \%$ of registrations will be evaluated. This is also a reason why access to REACH-IT is necessary for enforcers for controlling if the data in REACH-IT is in correlation with the data presented at an inspection and that there is a system to give feedback to the ECHA.

As the REACH regulation covers many competences, cooperation between enforcement authorities dealing with $\mathrm{REACH}$ and those dealing with environment and work environment is needed (often different CAs) as different backgrounds of inspectors will be needed (environment/health etc). Most countries have not yet decided if administrative and/or criminal penalties will be used for sanctions. Probably threat of withdrawal of the product might help in getting the companies to comply with the regulation. Many countries considers that the first year should more consist of information and guidance/education rather than sanctions and to focus on small companies since the larger often already know their 
obligations. A problem can be that companies that do not comply today with the legislation will probably act in the same way in future.

Article 7 seems for the moment rather difficult to prioritise. It is expected that there will be very few registrations according to 7.1, since in many cases "objects" that suppliers so far have considered to be articles will instead have to be dealt with as substances/preparations in containers, in accordance with REACH and a newly elaborated guidance. It is also believed that not the least because of the exemption in 7.6, there will be very few notifications/registrations according to 7.2 and 7.5 of Substances of Very High Concern (SVHCs) in articles, For the sake of knowledge of the presence of SVHCs in articles; it might be more efficient to instead strictly enforce the duties in Article 33 for suppliers to inform recipients and consumers on SVHC contents. However, present disagreements on how to interpret and implement Article 33 imply that it is unclear to what extent the article may be effectively enforced (c.f. section 4.3.). If the Customs will enforce Article 7 there is a need to define their role and bring out guidelines, especially concerning the relation to the custom codes.

\section{Complementary/Subordinated" registration articles}

There is an obvious need to further analyse and discuss to what extent prioritisation of Art. 5 and 6 imply checking compliance also with the "complementary" articles, and to what extent they should and could be prioritised as such for enforcement. This also relates to the evaluation provisions (c.f. below) by which missing registration information may be required from registrants. However, at least some of the "complementary" articles, such as Art 9, 17, 18 and 22, contain very specific provisions which seem crucial to enforce as such.

- Article 10, 12, 14: Tells which information that has to be provided with the registration, including for various manufactured/imported volumes (art 10,12) and requires $\mathrm{M} / \mathrm{I}$ to compile a CSR if the volume is 10 tonnes or more (art 14). These articles connect closely to the evaluation part, as it concerns the CSR and tonnage, and is a part of ECHA controls. Tonnage also relates to Article 6.

- Article 20.2: Requires Manufacturers/Importers (M/I) to complement registrations if asked by ECHA to do so during completeness check. Failure to do so will lead to ECHA rejecting the registration, but giving false information might be enforced.

- Article 22: Requires Manufacturers/Importers (M/I) to update previous registrations with new information. Enforcement is crucial in order to ensure that the information in REACH-IT does not get outdated and less useful or quite incorrect. This will be rather simple 
to enforce as it is easy to create a simple checklist, but of low priority. New uses can probably be identified when DU is inspected.

- Article 23: Tells when registration has to be made depending on volume (deadlines). Has to be enforced together with articles 5 and 6

- Article 9,17 and 18: Offers exemptions from registration for product- and process oriented research and development (if a notification instead is made, and any conditions decided by ECHA are fulfilled) and for on-site as well as transported isolated intermediates (if a simplified registration instead is made and a number of conditions are fulfilled). Enforcement is considered important to decrease any risk for these provisions to be used as "loopholes" from registration.

Pre-registration and other articles in Title III:

Further analysis and discussion of this Title is needed - it may be that many of the articles in this Title as such have a character that makes them difficult to enforce. It though should be noted that Art 30 specifically states - in order to ensure data sharing - that if an owner of a study refuses to provide either proof of the cost of the study or the study itself, he shall be penalized. One early and important task for enforcers will be to check if phase-in substances have been either pre-registered - Art 28 - or registered - Art. 6 (and 7), to reveal if the "no data - no market" provision in Art 5 has to be enforced.

\section{Evaluation articles in Title VI:}

Further analysis is needed with respect to procedures and co-operation between ECHA, CAs, and enforcement authorities to enable effective enforcement of provisions in this Title. Besides, the relation between this Title and Title II Registration needs to be analysed more.

- Article 40.4: Duty to submit results of tests on vertebrates in accordance with decisions on test plans proposed in the registrations

- Article 41.4: Duty to submit further information in accordance with decisions during compliance check of registrations

- Article 46.2: Duty to submit further information in accordance with decisions during substance evaluation. Can partly be compared with the provisions regarding substances on the Existing Substances Regulation lists of substances.

- Article 49: Duty for registrants, if required, to submit information to the MSCA for evaluation. This concerns on-site isolated intermediates that are used in strictly controlled conditions.

- Article 50: Duty for registrants to inform ECHA if manufacture/import has ceased and for a DU if he ceased the use. 
Duty for the Agency to inform the competent authority of the MS in which the registrant or DU is located.

- Article 53.4: Prohibition to manufacture, import or placing a substance on the market by decision of a national court or by an arbitration order.

Since art 5 don't refer to Title VI, it seems possible to stay on the market without e.g. submitting test results according to art 40.4 that are necessary to know the risks. Therefore, enforcement of the evaluation articles seems crucial, in order to ensure that REACH will result in the intended build up of new information. For all kind of evaluation, enforcement has to be triggered by ECHA (via MS CA). The national CA will only be contacted in those cases where ECHA does not get a response in the communication with the company. Otherwise the correspondence is only between ECHA and the company. A high number of evaluation decisions are foreseen by the Commission.

\section{Comments}

Enforcers will have to control that the substances above 1 tonne/year/manufacturer either has been registered and has got a registration number, or has been pre-registered and the deadline for registration has not been passed yet. A big challenge for enforcers will be to conclude whether the substance needs to be registered or if it is outside the scope of REACH or covered by any of the many exemptions. This requires knowledge of the other EC legislation mentioned in REACH as well as rather deep knowledge of chemistry and process technology.

Another challenge will be to identify companies that are obliged to pre-register/register their substances but have not done so. This may be especially difficult with respect to SMEs and to importers from third countries.

Registration and notification of substances in articles can be most difficult to enforce (c.f. above). To get information on substances incorporated in articles from manufacturers and importers might be difficult. This has been concluded from earlier inspection projects.

\section{Information required from REACH IT}

When controlling if substances are registered or if the correct information has been submitted by the registrant, the enforcement authorities need access to information about registered substances and responsible companies. For preparations imported from $3^{\text {rd }}$ countries, enforcement may require access to confidential information e.g. of the full composition of a preparation, as well as the tonnage/tonnage band registered by a specific registrant. The precise tonnage is confidential information, but informa- 
tion of total tonnage band for the substance is not confidential. According to recent drafts from the Commission, Enforcement bodies (those which are not part of the CA) will be seen upon as external parties not allowed on-line access to REACH-IT. Instead, for their information needs they will have to rely on special reports drawn out of the system by the CA. This may lead to more work for the CA:s and delays for the enforcement authorities needing the information.

Even though the CSR shall be available at the company who has a duty to compile it, the enforcers might have to check with the CSR sent to ECHA. Therefore access to the CSR in REACH-IT is also needed. The CSR is considered confidential and thus not available over the Internet for the enforcement bodies.

According to Article 41.2, a list of dossiers being checked for compliance by ECHA shall be made available to MS competent authorities, but not publicly available over the Internet. This could be a problem if the enforcement authorities, who often are not a part of the competent authority, need to ask companies to provide more information without having access to this list. This means that the Competent Authorities need to have a national system to inform all the enforcement authorities (work, environment, health etc.) in their own MS if there is any requirement for a specific company to submit more information to the Agency and if there is a need for any enforcement authority to take any action.

\section{Conclusions}

The Registration and Evaluation titles can be seen as the basis for the functioning of REACH. Enforcement is needed to prevent manufacture, import, marketing and use of non-registered substances.

Evaluation makes sure that the information is correct and fulfills the requirements. These two titles are tightly connected since the substances are getting the registration numbers before the compliance check of the submitted data. The task for the enforcement authorities in the Member States will be to make sure that the companies submit requested information to the Agency in the evaluation process. The sanctions for not submitting this information need to be stringent and comparable between the MS, in order not to cause market disruptions.

For the function of registration and evaluation a lot of information is required from REACH IT, confidential as well as non-confidential information, e.g.:

- Registrants and the registration number for the substance they have registered - the connection between registrant and registration number is crucial for enforcement authorities to control if a company has registered the substance 
- The CSR that the registrant has submitted for the substance - to control that the CSR used by an individual company is identical and when controlling that the data in the SDS is in line with the CSR

- The tonnage/tonnage band for the substance - when controlling that the requirements regarding information in the registration are followed and if more information due to higher tonnage should be submitted.

\subsection{Information in the supply chain (title IV) - new parts}

\section{Introduction}

The most important new parts here are considered to be the obligation to attach an annex with exposure scenarios (ES) to the SDS (if $>10$ tonnes) and the obligation to pass on information on SVHC contents in articles to recipients as well as to consumers at request. Registration itself is of little value unless the information gathered is communicated appropriately along the supply chain to ensure that suitable risk management measures can be taken.

\section{Priorities}

Within title IV Article 31 is the main priority. This article states the obligation to provide the recipient with safety data sheet with exposure scenarios that is consistent with the information in the CSA/CSR (if required). This is important since this is the only instrument to provide information through the supply chain. The article has some new requirements - e.g. SDS for PBT/vPvB and added exposure scenarios.

When controlling the SDS the content shall be in compliance with Annex II which describes how the SDS should be compiled. Results from earlier controls are that $>50 \%$ of SDS content is incorrect and future controls will show if this will be better with REACH. If the SDS should be compared with the CSR, there is a need to have access to the CSR via REACH-IT in some way. If the MS/CA will give information of CSR to enforcement authorities, they will become some kind of "gatekeepers". A question is if the requirements to deliver a SDS are fulfilled with links in an e-mail to customer to available SDS on the company's website. As there is no clear answer, guidance is needed.

Other articles of importance in this title are:

- Article 32: Obligation to provide the recipient with certain information also for substances for which there is no obligation for a safety data sheet. If the format for SDS is used for information according to this article - there is a need to state in the SDS that this is information according to Article 32. 
- Article 33: requirement to communicate information on substances in articles to allow safe use to suppliers and on demand, also to consumers. Important information for the recipients to get, so that they can ensure that the article can be handled safely. This article is of high priority but very difficult to enforce as there so far is nearly no guidance on what information besides the substance name to give to ensure safe use, and on how to transmit the information. Besides, there are still differing views on how to apply the $0.1 \%$ limit for when to give information.

- Article 36: Obligation for M/I and DU to assemble and keep all the information required by the regulation for 10 years, and to submit it or make it available upon request. Checking that this obligation is complied with might reveal how well the companies have organised their work with REACH, and contribute to that such work is organised better. This checking might be done when enforcing various duties the companies have to comply with. However, most MS do not seem to prioritise enforcement of this article, maybe e.g. because it at least in the beginning could be difficult to enforce.

\section{Comments}

Enforcement of the obligation to provide the recipient with a SDS and the obligation to communicate information on substances in articles is needed. The exposure scenarios (ES) are a new part of the product information, and both the information in the SDS and in the ES has to be controlled. This may lead to a need to check with the CSR, and also the registration dossier in some cases, if there is e.g. contradictory information in the SDS and in the ES.

In a note in conjunction with the work with RIP 3.5 on guidance for DUs, the Commission has stated as its view that if an actor in the supply chain (i.e. a DU who is a formulator) has developed a CSA for a preparation, it is sufficient if the SDS is consistent with the CSA for the preparation instead of the CSAs developed for the individual substances. This may offer a complication for enforcement, since it may very well be that the formulator in both his CSA and his SDS has not taken enough regard to the risks with an individual substance contained in the preparation, and has recommended to less restrictive measures with respect to that substance. Enforcement in such a case may have to spot the formulators CSA rather than his SDS, and a check with the CSAs for the individual substances may have to be made.

The information on substances in articles needs also to be enforced. This will be complicated since there is so far no format or language requirement for this information. Furthermore, there is no agreement between the Commission and the Member States on how to interpret the 
$0.1 \%$ weight limit for when to give information (apply on parts or the whole article).

Here, it is considered that art 31 and 33 are the core articles to generally enforce, while art 32 and 36 in individual cases can be important to enforce.

Checking SDS has been an enforcement duty for many years, but since REACH has entered into force, no member state has punished any company for not having changed place on headings 2 and 3 .

\section{Information required from REACH IT}

Here, it might e.g. be relevant in certain cases to check the SDS found at DUs against the CSR given to ECHA by the supplier. If /when finding faulty/incorrect SDS there is a need to control if the SDS correspond with the CSR. As the CSR is considered to be confidential, this could lead to a problem if different enforcement authorities should control the CSR (e.g. work, environment, health etc.) and not having access to the CSR in the database.

\section{Conclusions}

Inspection of safety data sheets (SDS) has been carried out for many years, so this is not a new task for enforcement authorities. The articles concerning information when a SDS is not needed and information about substances in articles are new, and also that an ES has to be annexed to the SDS. The form for information about substances in articles is not yet stipulated and guidance in this issue will be needed.

\subsection{Downstream users (title V)}

\section{Introduction}

REACH places the heaviest burden for chemicals control on manufacturers/importers $(\mathrm{M} / \mathrm{I})$, in that they will have to:

- gather/produce all data necessary to assess the properties of the substances,

- identify and assess which uses/use conditions/exposure scenarios that will lead to adequate control, and

- recommend this to the downstream users (DU).

For uses of substances supplied in a volume of more than 10 tonnes by an individual $\mathrm{M} / \mathrm{I}$, the $\mathrm{M} / \mathrm{I}$ also in a CSR have to identify so called DNELs and PNECs. These tell how low the exposure level has to be, not to cause 
any health and environmental effects, respectively (c.f. Annex I to $\mathrm{REACH}$ ). This can be said to define what adequate control means. However, REACH also - unlike earlier legislation on chemicals control in practice require DUs to either stick to the uses/exposure scenarios which $\mathrm{M} / \mathrm{I}$ consider leads to adequate control, or to take over the responsibility to ensure adequate control.

As a basis, REACH states that a DU shall identify and apply appropriate measures to adequately control risks identified in a SDS supplied to him, his own CSR, or any information supplied to him. Where the DU does not prepare an own CSR, he shall apply any appropriate measures needed to ensure that the risks are adequately controlled. (c.f. Art 37.537.6).

Further, a DU has to report to ECHA any use outside conditions described in an exposure scenario - or if appropriate a use or exposure category - communicated to him in a SDS, or for any use his supplier advises against (c.f. Art 38 and 37.4 taken together) (note: "conditions" is those which according to the $\mathrm{M} / \mathrm{I}$ lead to adequate control). Besides, if such a use "outside the conditions" amounts to one tonne or more, the DU also himself has to prepare a CSR, and keep it up to date and available (c.f. Art 37.4 and 37.7).

Where DUs don't stick to the M/I recommendations on how to ensure adequate control, DUs thus both have to report this and apply other measures that still lead to adequate control.

When there is a DNEL/PNEC, checking of if the DU keeps exposure at or below these levels may reveal whether the DU has ensured adequate control, even if his use/use conditions is outside the conditions for adequate control as recommended by the supplier.

To ensure that REACH functions as intended, it will obviously be necessary with extensive enforcement directed to the DUs, to make sure e.g. that the safe exposure scenarios elaborated by M/I will not only be "paper products" but are also "implemented" in real life by the DUs, or that DUs ensure adequate control in another way and report/make CSR as REACH require.

\section{Priorities}

Within title $\mathrm{V}$, the following articles have been prioritised and for the following reasons:

\section{- Article 37:}

- Duty (art 37.4) for DUs to prepare a CSR for any use of 1 tonne or more outside conditions described in an exposure scenario - or if appropriate a use or exposure category - communicated to him in a 
SDS or for any use his supplier advises against.

- Duties (art 37.5-37.6) for DUs to apply appropriate measures to adequately control risks identified in a SDS supplied to him, his own CSR, or any information supplied and, if the DU does not prepare a CSR, that he considers the use(s) of the substance and identify and apply any appropriate risk management measures needed.

\section{- Article 38:}

- Duty for DUs to report to ECHA any use outside conditions described in an exposure scenario - or if appropriate a use or exposure category - communicated to him in a SDS, or for any use his supplier advises against (c.f. Art 38 and 37.4 taken together).

In this group of DUs the formulators should be prioritised as they have more responsibilities than e.g. the end-user. For example they have to prepare SDS and sometimes ES for preparations.

\section{Comments}

DUs consists of a variety of companies, therefore compliance with the above duties will probably in many MS have to be monitored and where appropriate enforced by a combination of enforcement authorities responsible for work environment, environment, chemicals control, etc. This in itself may constitute a difficulty. There could also be some problem if there are different requirements in different legislation - should you follow the highest level of protection? (example: DNEL - OHS limit).

Furthermore, enforcement may be difficult or impossible if the descriptions in the SDS/exposure scenarios of uses/conditions/risk management measures are too general or ambiguous. In such cases, it will be problematic to decide if the DUs use is inside the conditions described in an exposure scenario, or if the use is outside the scenario and the DU thus is obliged to notify the use to ECHA and possibly also make his own CSR.

A question is what can be required of the DU if he has informed his supplier of his use but get no recommendations/reactions back? This may end up in difficulties for the enforcer to know who has the responsibility.

Special problems will arise when a DU buys a certain substance from various suppliers which submit different exposure scenarios for the same substance. It may even be that the DU stores the batches delivered by different suppliers in one and the same container. In such a case, it may be very difficult to decide whether all conditions for use of the substance are fulfilled at a given moment, if not the DU applies the most restrictive conditions for all the batches. 
A specific problem for DUs who are formulators will arise if they buy the same substance from different suppliers and in that case receive rather different quality of SDS:

- From suppliers manufacturing $>1000$ tonnes/year - the SDS should be consistent with the CSR and contain information of good quality. The SDS should also in certain cases be annexed with an ES

- From suppliers manufacturing 1-10 tonnes/year - SDS with less information than above (no requirement of a CSR) and without ES

- From suppliers manufacturing $<1$ tonne/year - only SDS with known information

The situation can also be more complex if the substance is classified differently by the suppliers. In the above cases it is difficult for the enforcers to judge if DU is in line with risk management measures recommended to him if he receive contradictory information from different suppliers. It will also be difficult or impossible to conclude if the SDS for the preparation manufactured by the formulator is in line with the substance information if the information is of different quality and not in line with each other.

\section{Information required from REACH IT}

There is an obvious need to know which DUs in the own MS who has reported a use "outside the conditions", and for which substances and uses, as well as who the supplier is and details of his CSR. This is to be able to check if the DUs still ensure adequate control.

\section{Conclusions}

The most important issue for enforcers regarding this title will be to make sure that a DU either stick (reasonable well..., this may constitute difficult/delicate considerations) to the conditions described in an exposure scenario communicated to him, or report the use to ECHA and if above 1 tonne make a CSR, and still ensure adequate control.

When conducting enforcement at DUs, it may also be relevant and necessary to check that the exposure scenario communicated to the DU is relevant in relation to the CSR in the registration the supplier has made (c.f. Art 31.7). Furthermore, there is a need to check that the scenario when implemented really leads to adequate control. If not, there may be a need to see to that the $\mathrm{M} / \mathrm{I}$ review his CSA/CSR, and/or that Restrictions on EU level are considered. 


\subsection{Authorisation (title VII)}

\section{Introduction}

The authorisation requirement for SVHCs is a new and demanding requirement that will require effective enforcement a few years from now, when the first applications arrive to ECHA and even more so when the first sunset dates are passed, as well as when there are authorisations with conditions the fulfilment of which may be checked at DUs.

The authorisation provisions shall assure that the risks from substances of very high concern are properly controlled or the substances substituted. SVHC are defined as:

- Carcinogenic, mutagenic or toxic for reproduction (CMRs), category 1 and 2

- Persistent, bioaccumulative and toxic or very persistent and very bioaccumulative (PBTs/vPvBs), or

- Substances, which do not fulfil the criteria for the above mentioned effects but are identified as causing serious and irreversible effects to humans or the environment equivalent to those mentioned above, such as endocrine disrupters, on a case-by-case basis.

SVHCs will step by step be included in Annex XIV to REACH. Once included in this Annex, the use(s) and placing on the market need to be authorised before a specific date, the sunset date. Manufacturers, importers or downstream users, who wish to continue to use the substance or place it on the market after the sunset date, have to send an application for authorisation to ECHA.

\section{Priorities}

Article 56 is the main priority in Title VII as it states the core provisions of authorisation. As authorisation will be a work in progress during many years and new authorisations or changed/withdrawn authorisations will occur continuously, it is necessary for an effective enforcement that the enforcers have access to updated information, preferably via REACH-IT or by MS/CA. Other articles of interest for enforcement, but of lower priority, are:

- Article 60.10: Duty for the holder of an authorisation to ensure that the exposure is reduced to low as a level as is technically and practically possible, notwithstanding any conditions of the 
authorisation. This will be (very) difficult to enforce as it needs very specific competence.

- Article 61.4: EQS might be monitored by those enforcing WFD (if needed - feedback to ECHA/COM)

- Article 62: Contains requirements on the application for authorisation. Enforcers should control applications only in extraordinary cases. False data in an application might lead to sanctions or a need to review authorisations but it is unclear what priority reviewing authorisations will be for COM.

- Article 65: Requires the holder of an authorisation to include the authorisation number on the label before placing the substance on the market for an authorised use. This is important information for the DU when checking if his use is within the authorisation for that substance. Will have to be enforced but could be difficult as it could be rather difficult to know when a label is needed e.g. for which substance, or for which substance in the preparation.

- Article 66: Requires a DU, using a substance according to his supplier's authorisation, to notify the Agency within three months of the first supply of the substance. This is crucial information for the enforcement authorities in MS, to be able to know where to check whether the conditions in authorisations are respected by the DU or not. Controlling DU notifications seems to be a rather simple duty, a better way is to first check the notification list of DUs that have notified that they use an "Annex XIV substance", and then control if they comply with the conditions and the notification made.

\section{Comments}

The authorisation conditions for a certain use of a certain substance may include e.g. risk management measures both for the work environment and for the environment, and may thus in many MS fall within the competence of enforcers from different enforcement authorities. This may in itself cause various problems and e.g. require substantial co-operation/coordination efforts.

Furthermore, problems will arise for enforcers if the use and the conditions are too vaguely described in the authorisation decision.

Besides, there will also be a need of various kinds of monitoring, e.g. of that exposure is reduced to as low a level as is technically and practically possible, and that environmental quality standards (according to Water Framework Directive) are met. If not, the authorisation may need to be reviewed (c.f. Art 61). 


\section{Information required from REACH IT}

Enforcers will need precise - and thus often confidential - information on the authorised uses and the prescribed conditions. They will also need to know e.g. which supplier has been granted authorisation for a certain use of a certain substance, as well as who are his customers down the supply chain (only they may use the substance according to the authorisation conditions).

Furthermore, access is needed to the register of DUs who have notified that they use a substance in accordance with an authorisation granted to an actor up his supply chain. According to Article 66.2 this register will only be accessible for Competent Authorities. When other authorities carry out the enforcement they will thus have to request the information from the CA.

\section{Conclusions}

The core task for enforcement related to this title is to control - for SVHCs for which the sunset date has been passed - that only authorised uses take place, and that these are in full compliance with the authorisation conditions. Inspectors will probably sometimes have to have knowledge of industrial processes in order to determine if the conditions in the authorisation are complied with.

In addition it has to be ensured that data in applications are correct, that SVHCs are labelled with the authorisation number, and that DUs notify their SVHC uses to ECHA. All this will contribute to an efficient authorisation regime.

\subsection{Comments regarding other REACH Titles}

\section{Introduction}

Other REACH Titles also need to be enforced, but are not new tasks for enforcement in the way that the Titles II+VI and parts of IV, V and VII are. Requirements to classify, label and compile safety data sheets have been a task for enforcement authorities for long time. This is also the case for restrictions, as the Restriction Directive has been into force since 1976. 


\section{Restrictions (title VIII)}

The title sets out general provisions for when a substance on its own, in a preparation or in an article must not be manufactured, placed on the market or used unless it complies with conditions given for that substance, in Annex XVII. New proposals for restrictions may be prepared by Member States or the Agency. The proposal should demonstrate that there is a risk to human health or the environment which needs to be addressed at European level. The restriction procedure shall act as a safety net in REACH.

- Article 67.1: This article is the only relevant article in this title for enforcement together with Annex XVII, which specifies the restrictions. The article states that "a substance on its own, in a preparation or in an article, subject to a restriction shall not be manufactured, placed on the market or used unless it complies with the conditions of that restriction". Enforcement of the restrictions is important since any deviation constitutes a potential risk to human health or to the environment.

Clearly formulated restrictions - including any exemptions and conditions - are crucial to make compliance easy and efficient enforcement possible. Experience shows that such clarity has not always been the case. Various enforcement authorities (work environment, environment, customs, etc) may have to be involved and co-operate, which in itself may give rise to problems. No specific needs for information from REACH-IT are foreseen.

\section{Classification and Labelling (title XI)}

The classification and labelling inventory ensures that hazard classifications (and consequent labelling) of all dangerous substances manufactured in, or imported into, the EU are available to all with the aim of promoting agreement on the classifications. The regulation stipulates that the companies shall make efforts to reach an agreement, but it is not clear if this can be enforced (c.f. Art 113.2). If there are any divergences between classifications of the same substance they should be removed over time through co-operation between notifiers and registrants. For certain substances (category 1 and 2 CMRs, respiratory sensitizers, and other substances if justified on a case-by-case basis), the divergences can be eliminated through EU harmonised classifications.

- Article 113: requires industry to submit all its classifications to the Agency by December 1, 2010. The Secretariat of the Agency shall, 
according to Article 77.2e, establish and maintain a database with both the classification and labelling inventory and the harmonised classification and labelling list. The inventory and the list will be made publicly available over the internet. This is information that enforcement authorities need.

\subsection{Overall conclusions}

\section{Enforcement}

From the review, it is obvious that certain articles will be more crucial to enforce than others, in order to ensure a good functioning of the core elements of REACH. The analysis made cannot claim to have identified precisely all the most important articles, but merely represents an attempt to identify such articles. This may be used as a basis for further discussions among the MS. It is hoped that such discussions may contribute to increased agreement between MS with respect to priorities for the enforcement of REACH.

Out of the articles/duties identified in this report as especially important, the following seem to be the most crucial ones to enforce stringently, to ensure that e.g. the "no data - no market" principle is followed, that the uses of all substances ${ }^{1}$ are adequately controlled, and that SVHCs are eventually substituted (c.f. 3.8 of this report):

- Art 5,6 - M/I core duties to register

- Art 31 - Supplier duties to pass on SDS

- Art 37, 38 - DU duties to implement exposure scenarios

- Art $56-\mathrm{M} / \mathrm{I}+\mathrm{DU}$ duties to obey the SVHC authorisation requirements

- Art 67/Annex XVII - Restrictions

One of the first Forum projects might be to have enforcers reporting back problems with some selected REACH articles, especially those connecting to the prioritised ones above. An optional tool could be to have a list (on ECHA/CA/other website?) with questions enforcers will ask during inspections. This list might have an influence on the behaviour of companies, i.e. if they have knowledge of what inspectors will ask during inspection, they might control in advance that they are in compliance with legislation.

\footnotetext{
${ }^{1}$ except for SVHC that in some cases could be used without adequate control if there is an authorization
} 


\section{Sanctions}

In 3.8 of this report, ideas on appropriate sanction levels (severe/medium/light) are given for listed articles, based mainly on the believed importance of the article for the function of REACH, but not on an analysis of what's legally possible and suitable going out from how the articles are formulated and legal and administrative possibilities in the MS. The latter differ among the MS, but it would be of great advantage if the sanction levels could be as similar as possible in the MS, to reduce any risks for market disruptions.

\section{Information from REACH-IT}

From the very brief and rough analysis made in this review of needs for confidential information from REACH-IT, it is obvious that there are substantial such needs.

Furthermore, it seems obvious that the fact that many of the responsible enforcement authorities in the MS will only have indirect access to such confidential information, via the CA who will have to retrieve the information from REACH-IT and pass on information in the form of special reports, may lead to problems. 


\subsection{Ideas on sanction levels}

\section{Articles prioritized for enforcement with ideas on sanction levels}

\begin{tabular}{|c|c|c|c|c|}
\hline $\begin{array}{l}\text { Priority } \\
\text { articles }\end{array}$ & Content of article & $\begin{array}{l}\text { Ideas of level } \\
\text { of sanctions }\end{array}$ & $\begin{array}{l}\text { Comments on reasons and/or } \\
\text { challenges }\end{array}$ & RIP \\
\hline 5,6 & $\begin{array}{l}\text { No data }- \text { no market } \\
\text { principle }+\mathrm{M} / \mathrm{l} \text { core } \\
\text { duty to register }\end{array}$ & Severe & $\begin{array}{l}\text { Substance identification cru- } \\
\text { cial, information from REACH- } \\
\text { IT necessary }\end{array}$ & $\begin{array}{l}3.1 \\
3.2 \\
3.10\end{array}$ \\
\hline 31 (31.7) & $\begin{array}{l}\text { M/I duty to attach } \\
\text { exposure scenarios to } \\
\text { the SDS }\end{array}$ & Severe & $\begin{array}{l}\text { Will require checking with the } \\
\text { CSR/CSA - info needed from } \\
\text { REACH-IT. Enforcement } \\
\text { difficult or impossible if am- } \\
\text { biguous exposure scenarios } \\
\text { and/or use descriptions are } \\
\text { stated in the SDS }\end{array}$ & $\begin{array}{l}3.2 \text { and } \\
3.5\end{array}$ \\
\hline 37,38 & $\begin{array}{l}\text { DU to implement } \\
\text { exposure scenarios or } \\
\text { notify ECHA } \\
\text { (and make a CSR) }\end{array}$ & Severe & $\begin{array}{l}\text { Control that DU implements } \\
\text { the exposure scenarios or } \\
\text { notifies ECHA/make CSR is } \\
\text { crucial for REACH to lead to } \\
\text { adequate control of risks. If } \\
\text { ambiguous ESs, enforcement } \\
\text { will be difficult/impossible. }\end{array}$ & 3.5 \\
\hline 56 & $\begin{array}{l}\text { Use of SVHCs listed } \\
\text { in Annex XIV only } \\
\text { according to authori- } \\
\text { zation conditions }\end{array}$ & Severe & $\begin{array}{l}\text { Efficient enforcement presup- } \\
\text { poses precisely defined au- } \\
\text { thorized uses as well as } \\
\text { unambiguous conditions for } \\
\text { use. }\end{array}$ & \\
\hline 67.1 & Restrictions & $\begin{array}{l}\text { Medium to } \\
\text { severe }\end{array}$ & $\begin{array}{l}\text { To vaguely written restrictions, } \\
\text { conditions, exemptions will } \\
\text { make enforcement difficult }\end{array}$ & \\
\hline
\end{tabular}




\section{Complementarylsubordinated articles with ideas on sanction levels}

\begin{tabular}{|c|c|c|c|c|}
\hline Article & Content of article & $\begin{array}{l}\text { Ideas of level } \\
\text { of sanctions }\end{array}$ & $\begin{array}{l}\text { Comments on reasons and/or } \\
\text { challenges }\end{array}$ & RIP \\
\hline 7 & $\begin{array}{l}\text { Duty notify/register } \\
\text { substances in articles }\end{array}$ & Severe & $\begin{array}{l}\text { Few cases, interpretation } \\
\text { problems, many exemptions. } \\
\text { Difficult to enforce. }\end{array}$ & 3.8 \\
\hline $\begin{array}{l}10,12,14, \\
23\end{array}$ & $\begin{array}{l}\mathrm{M} / \mathrm{I} \text { detailed duties } \\
\text { register, make CSR }\end{array}$ & Severe & $\begin{array}{l}\text { Lays down which information } \\
\text { shall be given and when for } \\
\text { which volumes + duty to make } \\
\text { a CSR }\end{array}$ & $3.2,3.3$ \\
\hline 22 & $\begin{array}{l}\mathrm{M} / \mathrm{I} \text { duty to update } \\
\text { registrations }\end{array}$ & Severe & $\begin{array}{l}\text { Ensures that registrations are } \\
\text { updated, not to become incor- } \\
\text { rect in relation to what's mar- } \\
\text { keted }\end{array}$ & \\
\hline $9,17,18$ & $\begin{array}{l}\mathrm{M} / \mathrm{l} \text { exemptions from } \\
\text { registration }\end{array}$ & $\begin{array}{l}\text { Medium to } \\
\text { severe }\end{array}$ & $\begin{array}{l}\text { Could turn out to be used as } \\
\text { loopholes, }\end{array}$ & \\
\hline & & & if not appropriately enforced & \\
\hline 33 & $\begin{array}{l}\text { Supplier duty inform } \\
\text { recipient + consumer } \\
\text { on SVHC in articles }\end{array}$ & Severe & $\begin{array}{l}\text { So far, there is no agreement } \\
\text { on how to interpret the } 0.1 \% \\
\text { limit, and there is no guidance } \\
\text { on which information to give, } \\
\text { and how to transmit it }\end{array}$ & 3.8 \\
\hline 36 & $\begin{array}{l}\text { M/I/DU duty keep } \\
\text { REACH info } 10 y, \\
\text { submit on request }\end{array}$ & $\begin{array}{l}\text { Medium to } \\
\text { severe }\end{array}$ & $\begin{array}{l}\text { Enforcement of this provision } \\
\text { offers a possibility to see to } \\
\text { that } \mathrm{M} / \mathrm{I} \text { and DU keeps track of } \\
\text { all their duties and do a sys- } \\
\text { tematic work }\end{array}$ & \\
\hline $\begin{array}{l}40(40.4) \\
41(41.4) \\
46(46.2)\end{array}$ & $\begin{array}{l}\mathrm{M} / \mathrm{I} \text { duties to send in } \\
\text { info according to } \\
\text { evaluation decisions }\end{array}$ & $\begin{array}{l}\text { Medium to } \\
\text { severe }\end{array}$ & $\begin{array}{l}\text { Enforcement crucial, to ensure } \\
\text { that } \mathrm{M} / \mathrm{I} \text { send the requested } \\
\text { info, not the least results from } \\
\text { proposed tests on vertebrates, } \\
\text { to } \mathrm{ECHA} \text {. }\end{array}$ & \\
\hline 62 & $\begin{array}{l}\text { Requirements au- } \\
\text { thorization application }\end{array}$ & Severe & $\begin{array}{l}\text { Important to enforce incor- } \\
\text { rect/false data in the applica- } \\
\text { tions, to make the system work }\end{array}$ & 3.7 \\
\hline 65 & $\begin{array}{l}\text { Duty to label with } \\
\text { authorization number }\end{array}$ & $\begin{array}{l}\text { Medium to } \\
\text { severe }\end{array}$ & $\begin{array}{l}\text { Important information which } \\
\text { tells DUs and enforcers that at } \\
\text { least, there is an authorization }\end{array}$ & \\
\hline 66 & $\begin{array}{l}\text { DU notify SVHC uses } \\
\text { to ECHA }\end{array}$ & Severe & $\begin{array}{l}\text { Enforcement authorities need } \\
\text { this info to be able to know } \\
\text { where to check that DUs use } \\
\text { SVHCs according to conditions }\end{array}$ & \\
\hline
\end{tabular}





\section{Competence/Education}

\subsection{Introduction}

The aim of this paper is to try to assist the Member States in the start-up phase of enforcement of REACH. The paper comprises a short analysis of the difficulties to enforce various kinds of provisions, summaries of results from discussions at workshops organized by the REACH EU Enforcement project in Brussels in December 2006 and September 2007, and some preliminary reflections and conclusions on the needs for competences as well as the need for education for various kinds of REACH enforcement.

\subsection{Preliminary Analysis of competence needs with respect to some "typical" REACH provisions}

Just to give an idea what REACH means for an inspector a short analysis of the inspection work is given. This analysis is not exhaustive, but as an illustration.

In order to ensure that the requirements of REACH are complied, the enforcer should address the following questions:

- Is the company obliged to register taking into account its roles under $\mathrm{REACH}\left(\mathrm{M} / \mathrm{I}^{2}\right)$ (article 5)?

- Does the tonnage level as mentioned in the registration correspond to the real situation (article 12)?

- In case an "only representative" is appointed, are the criteria for an only representative met (article 8)?

- Is a notification justified in the framework of PPORD ${ }^{3}$ or as an exemption (article 7 and 9)?

- Is the substance used according to its notified use in the registration (article 37)?

- Is the registration dossier up-to-date (article 22)?

- Is a phase-in registration applicable and has a pre-registration been carried out for that particular substance (article 23-24)?

- Is a Safety Data Sheet (SDS) prepared and adequately communicated down the supply chain (article 31 )?

\footnotetext{
${ }^{2}$ Manufacturer/Importer

${ }^{3}$ Product and Process Orientated Research and Development
} 
- Is the SDS in agreement with the information from the Chemical Safety Report (CSR) (article 31.2)?

The above stated questions indicate that basic knowledge is needed to even identify a possible problem. A thorough knowledge of the enforcer is required, specifically in the interpretation of REACH, for specific inspections. Each situation may be very diverse per company (e.g. number of substances, legal entities, production/import and use related requirements). This requires expertise to verify the information of the company. This would imply choice procedures for the selection of substances to be checked, auditing/accountancy skills and knowledge of Enterprise Resource Planning (ERP) systems ${ }^{4}$ in order to verify the actual amount of substance-use.

The role of the enforcer may also be of importance. Will the enforcer also be involved in provision of procedures? This requires specific training.

The greatest challenge will be to determine if an M/I has the obligation to register or not. Specific (chemical) knowledge of an enforcer (inspector) is required to identify substances (e.g. monomers in polymers) and to derive the correct REACH obligations. Finally, the enforcer (inspector) needs to have access to up-to-date information regarding substances (e.g. radioactive substances, biocides, pesticides) which are exempted from REACH registration.

\subsection{Results and suggestions done by member states}

Workshop in Brussels December 2006 Brussels

In order to identify the competences, the perspective of all disciplines concerned should be taken into account. The task within REACH should be analyzed from all these perspectives.

For the training it is expected that different levels of training will be needed: a more basic training for a large number of inspectors and a more specialist training for a smaller group. The basic training could perhaps be done through so-called 'webinars'. This would save valuable travelling time. For the specialist training, however a more intensive interaction through workshops or even direct guidance will still be needed.

\footnotetext{
${ }^{4}$ This encompasses software systems installed for an automated and integrated dealing with logistic, administrative and financial aspects of an enterprise > it contains information on stock of raw materials, production planning, stock of products et cetera (examples are: SAP and Microsoft Dynamics)
} 
The idea was that the training program involves the training of trainers per country. These trainers should then do the training towards their National situation.

Workshop in Brussels September 2007

The workshop in September 2007 started with the following thought starter to facilitate the discussion:

What needs a good enforcer?

- Knowledge of the REACH legislation

- Knowledge of processes and companies

- Knowledge and skills to inspect a company

- Knowledge and skills to check administrative processes

- Knowledge and skills to issue penalties (administrative and criminal law)

Which needs are there for education?

- Depends on the existing knowledge and experiences (custom-made education)

- Examples for education:

- Detailed information of the regulation

- Development of inspection skills

- Development of behaviour skills

From the discussion Workshops the following suggestions were made:

- Depends on tasks/ national approach

- Use information from the past (e.g. info about polymers)

- Exchange of inspectors (as done for Seveso)

- Support of ECHA for training the trainers

- Service from ECHA to assist

- One MS gives a training open for other MS

- Attention for chemistry/ engineering process

- Specialist support is necessary

- Legal advisors - Toxicology

- Training on the job/ not only theoretical

- Different approach in different countries:

- Country 1: Inspectors from 3 different authorities trained to enforce all titles of REACH

- Country 2: To inspect SDS you need to ask 5 different authorities to enforce the different sections 
- Knowledge in detail of REACH

- Knowledge of Legal affairs

- Knowledge how to inspect a company

- Knowledge of processes and companies

- Knowledge of chemistry (especially title V)

- Knowledge of administrative and criminal law

- Auditing skills (specialists)

- Training to use checklists

- Use of database (short)

Final overall suggestions for competences

Based on the results of the workshops and analysis of function descriptions and Impel publications on the qualifications of Inspectors. The following overview of competences is derived:

\begin{tabular}{|c|c|c|c|c|}
\hline & \multirow{2}{*}{$\begin{array}{l}\text { Explanation of the level and } \\
\text { description of the type of } \\
\text { inspector }\end{array}$} & \multicolumn{3}{|c|}{ Competences (end terms) } \\
\hline & & Knowledge & Skills & Experience \\
\hline $\begin{array}{l}1^{\text {st }} \text { level } \\
\text { Basic } \\
\text { inspector }\end{array}$ & $\begin{array}{l}\text { The } 1^{\text {st }} \text { level inspectors are } \\
\text { every inspector that visits } \\
\text { establishments, inspects } \\
\text { products or issues permits } \\
\text { of operators on adjacent } \\
\text { and overlapping work } \\
\text { fields. It concerns inspec- } \\
\text { tors in: } \\
\text { Customs } \\
\text { Occupational Health \& } \\
\text { Safety } \\
\text { IPPC / Environment } \\
\text { Water Framework Directive } \\
\text { Product / Consumer Health }\end{array}$ & $\begin{array}{l}\text { Minimum BSc- } \\
\text { level } \\
\text { Chemistry/ engi- } \\
\text { neering process } \\
\text { Basic knowledge } \\
\text { of administra-tive } \\
\text { and criminal law } \\
\text { Basic knowledge } \\
\text { of REACH } \\
\text { Knowledge of the } \\
\text { target group } \\
\text { Emission stan- } \\
\text { dards }\end{array}$ & $\begin{array}{l}\text { Strong observa- } \\
\text { tion skills } \\
\text { Hands on } \\
\text { mentality } \\
\text { Good commu- } \\
\text { nica-tion skills } \\
\text { Convincing } \\
\text { Dealing with } \\
\text { obstructions } \\
\text { and negotiation } \\
\text { techniques } \\
\text { Software skills }\end{array}$ & \\
\hline $\begin{array}{l}2^{\text {nd }} \text { level } \\
\text { REACH } \\
\text { inspector }\end{array}$ & $\begin{array}{l}\text { The } 2^{\text {nd }} \text { level inspector is } \\
\text { the inspector of the Na- } \\
\text { tional Enforcement Author- } \\
\text { ity designated specifically } \\
\text { to enforce REACH. } \\
\text { They are comparable to the } \\
\text { inspectors which formerly } \\
\text { inspected the Former } \\
\text { chemicals legislation like: } \\
\text { Ozon depleting substances } \\
\text { SDS } \\
\text { Biocides } \\
\text { Etc. }\end{array}$ & $\begin{array}{l}\text { MSc level in } \\
\text { Science or engi- } \\
\text { neering or BSc } \\
\text { with experience at } \\
\text { MSc level } \\
\text { Chemistry/ engi- } \\
\text { neering process } \\
\text { Basic knowledge } \\
\text { of administra-tive } \\
\text { and criminal law } \\
\text { Detail knowledge } \\
\text { of REACH } \\
\text { Knowledge of the } \\
\text { target group } \\
\text { Emission and } \\
\text { Immision stan- } \\
\text { dards } \\
\text { Sampling }\end{array}$ & $\begin{array}{l}\text { Strong observa- } \\
\text { tion skills } \\
\text { Hands on } \\
\text { mentality } \\
\text { Good commu- } \\
\text { nica-tion skills } \\
\text { Convincing } \\
\text { Project man- } \\
\text { age-ment, } \\
\text { Capable of } \\
\text { setting up and } \\
\text { carrying out } \\
\text { projects } \\
\text { Software skills } \\
\text { Basic auditing } \\
\text { skills }\end{array}$ & $\begin{array}{l}\text { Minimum } 5 \\
\text { years experi- } \\
\text { ence } \\
\text { Minimum } 2 \\
\text { years experi- } \\
\text { ence in } \\
\text { industry }\end{array}$ \\
\hline
\end{tabular}




\begin{tabular}{|c|c|c|c|c|}
\hline & \multirow{2}{*}{$\begin{array}{l}\text { Explanation of the level and } \\
\text { description of the type of } \\
\text { inspector }\end{array}$} & \multicolumn{3}{|c|}{ Competences (end terms) } \\
\hline & & Knowledge & Skills & Experience \\
\hline \multirow[t]{9}{*}{$\begin{array}{l}3^{\text {rd }} \text { level } \\
\text { Specialist } \\
\text { inspector }\end{array}$} & $\begin{array}{l}3^{\text {rd }} \text { level specialist supports } \\
\text { the other level inspectors } \\
\text { on in-depth compliance- } \\
\text { checks. } 3^{\text {rd }} \text { specialists are } \\
\text { required in different fields } \\
\text { of knowledge. It concerns: }\end{array}$ & MSc level & See $2^{\text {nd }}$ level & $\begin{array}{l}\text { Minimum } 5 \\
\text { years experi- } \\
\text { ence }\end{array}$ \\
\hline & Legal specialists & $\begin{array}{l}\text { LM in Administra- } \\
\text { tive Law, Special- } \\
\text { ized in Chemicals } \\
\text { legislation }\end{array}$ & & \\
\hline & Toxicologists & $\begin{array}{l}\text { M.SC in Humane } \\
\text { or Eco-toxicology }\end{array}$ & & \\
\hline & Auditing & M.SC-level & & \\
\hline & & $\begin{array}{l}\text { Lead Auditor in } \\
\text { OHSAS } 18001 \text { or } \\
\text { ISO } 14001\end{array}$ & & \\
\hline & Accountants & M.SC & & \\
\hline & & $\begin{array}{l}\text { Registered Ac- } \\
\text { countant }\end{array}$ & & \\
\hline & Information tech- & B.SC-level & & \\
\hline & nology & ERP -systems & & \\
\hline
\end{tabular}

Note that it is possible that even lower level inspectors have some role in the entire process of enforcing REACH. This possibility however is so different between member states or specific enforcement situations and also their significance is limited. Therefore such a level is not described.

Also note that the designation 'level' does not automatically imply having the described title. But that one also can prove this competence in other ways.

For every Member State this overview will have different implications considering their organization and the starting level of the current inspectors. To implement the competences every member states will have to establish the gaps to be overcome. On the actual training we can therefore only roughly describe possible training modules. In the next paragraph we therefore describe a general process for the implementation.

Reflections and conclusions on the need for education to Forum and MS

The first step in the process is to identify the involved organizations and the current level on the described competences. Then a Member State will have to assess the gaps in competence. After establishing the gap, a tailor made training program can be made. 
Possible training modules are:

- Basic REACH Knowledge (for 1st level inspectors)

- Detail REACH knowledge (for 2nd level inspector)

- Sub modules

- Substance identification

- Registration, Evaluation and Authorization process

- Assessing CSR's and Exposure scenarios

- C\&L and SDS inspections

- Auditing Manufacturers and Importers

- Administrative inspections Accountants (for specialist)

- ERP -systems in relation to registration (for specialist)

- Working of SIEFs and Sole representatives

- Setting up Harmonized projects for the Forum

In the development of these modules the following methods should be taken into considerations:

- Use of webinars

- Training on the job / direct application in real-life situations

- Exchange of inspectors with a training project

From the workshops we can conclude that the Member States consider it a good idea to let ECHA develop a training program which involves the training of trainers per country. These trainers should then do the training towards their National situation. 


\section{Methods \& Tools}

\subsection{Background}

Article 77 paragraph 4 of the REACH-Regulation state that the Forum shall take care of specific tasks to achieve the greater goal of exchange of information. Sub a, d and e set out the following tasks

- Spreading good practice and highlighting problems at Community level;

- Identifying enforcement strategies, as well as best practice in enforcement;

- Developing working methods and tools of use to local inspectors.

From this starting point several discussions took place to get a grip on how to implement these tasks. Out of interviews and workshops it was concluded that a 'Compendium of Methods \& Tools' would be a very useful item. This compendium would be a sort of reference book (or framework) to exchange information between inspectors (and management of inspectors) on good practices in enforcement.

The REACH EU Enforcement Project has therefore prepared a paper setting out proposals for a compendium of methods and tools for the enforcement of REACH.

The aim of this paper is to provide for a first version of the compendium and a description of the process to make in a continuous evolving toolbox for inspectors through out the EU. In this first version it was not chosen to use a specific definition of the terms 'good practice' and 'best practice'. This is done because these definitions all contain an element of proven success for the specific field. Considering the fact that REACH has just come into force, such proven success is an impossible goal. When the compendium and the enforcement of REACH is further developed a good working definition will however be needed.

This paper is a recommendation / proposal towards the Forum as a starting point for the implementation of (part of) these tasks. 


\subsection{Results of the input of other MS in the discussion workshop September 2007}

In the workshop of September 2007 possible information sources as well as specific needs or preconditions were stated.

\section{Information sources:}

- Use good practice from ECLIPS - a CLEEN project concerning Classification \& Labelling (CL) and Safety Data Sheets (SDS);

- Info out of NONSE/ SENSE Project (Eurex);

- REACH Implementation Projects 3.5.

Needs:

- Methods:

- Site visit versus desk study (depends on subject of inspection)

- - Specific branch checklists

- Need for checklists on CL and SDS

- Tools for selection of companies

- The use of information from different sources:

- Site permits

- Registration for taxes

- Risk approach

- Trade registration/ product registration

- Information from other MS (about trades)

- Other inspectorates/ stakeholders

- Need for a list of authorizations

- Importer needs to have their own inventory of substances contained

- in products from outside EU

- Information to China and other countries outside EU about REACH

- Information to inspectors that they have a duty to enforce REACH

- Monitoring effective control to learn for the future

- Monitoring the behavior of the companies

- Make an inventory of companies that don't follow the regulations

- Guidance document on programming of inspection work

- Decision support system to help inspectors to easily interpret the scope and the exemptions of (examples are similar systems in (Lv) cosmetics, biocides (SE))

- Accountancy like tools to check tonnage bands (like the chemical weapons inspectors form the UN do)

- Methods on sampling and analyzing

- Tools to verify communication in the supply chain (auditing tools) 
- Checklist for inspection of downstream users

- Methods for integrated / coordinated inspection (on both inspection level as program level)

- A method to make a good link with activities on IPPC and WFD

- Overall guidance on inspection

- Compilation (example: Seveso).

\section{Preconditions:}

- Information should be in English (this however narrows the possibilities)

- Use CIRCA for upload information about good practices

- A proper treatment of confidential information.

These needs and preconditions form the basis for the design of the compendium.

\subsection{Structure and work process of the Compendium}

\section{Structure of the Compendium}

The structure of the Compendium is based on the needs and preconditions stated earlier. For the design the following angles of approach were considered.

The design is started for the perspective of the different user groups. The appreciation of the compendium by a 'user' should be the main goal.

\begin{tabular}{ll}
\hline User group & Use \\
\hline Enforcers & $\begin{array}{l}\text { Enforcers are the primary user group. They use the toolbox for the execu- } \\
\text { tion of inspection or inspection projects. Inspector would have an interest to } \\
\text { hear from specific experience with these tools. } \\
\text { It is likely thinkable that there will be different levels of inspectors. These } \\
\text { different levels will probably have interest in different tools. } \\
\text { Managers are also a primary user group. They may use the toolbox for their } \\
\text { programming. They also have an interest in specific experiences. } \\
\text { The Forum is responsible for the compendium. They can also be a user, } \\
\text { when they use the compendium to evaluate the status of their tasks under } \\
\text { sub a, d and e of article 77. It is conceivable that the Forum assigns a } \\
\text { working group for the development and maintenance of the compendium. } \\
\text { The Forum secretariat is a secondary user. They will either maintain the } \\
\text { compendium or support a workgroup maintaining the compendium. Their } \\
\text { interest would be that the structure is in such a way that maintenance is } \\
\text { fairly easy to carry out and that it fits in the IT-systems and web applications } \\
\text { used by ECHA. It should be noted that the structure of the CIRCA site has } \\
\text { not yet been determined. }\end{array}$ \\
\hline
\end{tabular}


In order for all the different user groups, with changing interest, we propose to create a database-like structure. This means that any tool or method is labelled according to the following items (a possible selection):

- User group (Inspector, Specialist, Manager. Forum Member etc)

- Phase in the process (Programming, planning inspection, execution of inspection, Sanctioning, monitoring etc)

- Target group (Manufacturer/ Importer / Downstream Users / SME etc)

- Type of product (Substance, Preparation, Article, Polymer etc))

- Typology (Checklist, decision support tool, Management tool etc)

- Regulation specific (specific, or tool from adjacent field of work etc))

- Source (Member State and person with contact details)

- Review results (Workability, Effectiveness. Project reports etc.)

In this paper we will only make one matrix-like document. Later versions can be transformed into a database structure. In this version the items of target group, type of product and typology are left out. 
The matrix version of the compendium will be structured as following:

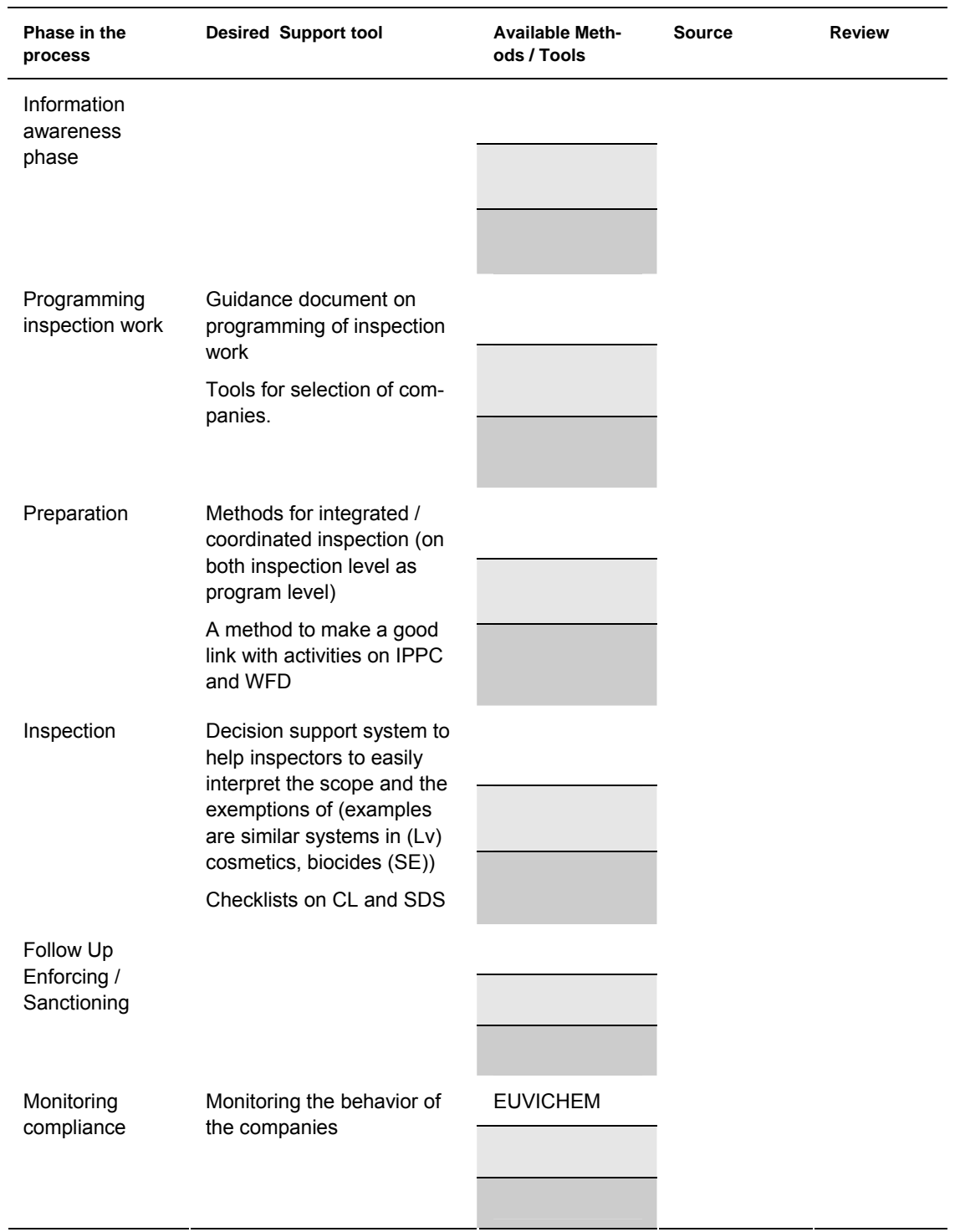

Note that this structure is not the first compendium but only an illustration of the structure. So it is mainly empty.

With respect to the available tools a three-way differentiation is made into REACH specific tools (colour ), tools used under 'old' chemicals legislation (colour $\square$ ) and tools form adjacent fields (colour $\square$ ). This differentiation is marked with a change of background. The first compendium contains only little REACH specific documents. When it evolves the need for displaying tools in adjacent field will gradually fade away. 
Gaps in the final matrix reveal the availability of tools and create a possible basis for Forum projects on the development of working methods and tools.

Issue of language

The first version contains only documents in English. For the spreading of information this is by far the easiest option. It is however an option to also put in non-English documents. This would take more effort but could have the following advantages:

- Firstly, inspectors often speak other languages beside their native language and English. So documents in other languages can still be beneficial with respect to exchanging of information on tools and methods;

- Secondly, if one uses only English documents it gives the impression that other countries don't have anything and this gives the wrong impression of their level of competence. It could also cause a certain unbalance in the exchange in a way that UK and Ireland would be the ones giving most information but receiving the least. (this last aspect can however only be tackled by a consequent translation of other documents).

Issue of confidentiality

The confidentiality can be regulated by creating a restricted area on the CIRCA site that can only be accessed by way of a user code and a password. Decisions on the confidentiality are however a matter of the 'donating' Member State.

\section{Good Practice vs. Best Practices}

In this stage the compendium contains referrals to documents that have only been preliminary reviewed on usability.

Determining the 'best practices', instead of simply exchanging practices, would implicate a normative review which is difficult and delicate one. The difficulty lies within the fact that this would mean a review on the effectiveness, as well as efficiency and side effects of methods. The Forum may have to consider whether how to handle this and whether a project to identify best practices should be launched (and if when). Given the value of such information we recommend the Forum to, in the long term, develop projects on such an issue. 


\section{Work process}

In order to maintain the concept that the compendium is a continuous evolving toolbox, it is not enough to simply make a first version of such a toolbox, but also establish a work process for further elaboration and updating.

In this process we also assign specific responsibilities of the players in order for the process to work. In the figure below we describe such a process. The figure shows that it is a continuous process since it contains a feed back loop. The idea is that methods and tool have to be continuously adapted to the demands. Since the industry and the government will change through time. Also the methods and tools will likely have to be adapted. We recommend that the Forum strives to maintain a principle of continuous improvement.

Idea for a process in order to update the compendium:

Need for tools (Forum)

Work program (Forum)<smiles>[13CH3]</smiles>

Specific Forum Projects on methods and tools<smiles>[13CH3]</smiles>

Execution of projects

Results of Forum project

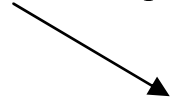

Autonomous activities (MS)

Tools / Methods

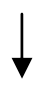

Identification

(individual Forum members)

Translating valuable

documents

Incorporating the documents into the compendium (Forum secretariat)

Use of Tools (Member States)

Reviewing the tools (MS or possible

Forum project) 
Explanation:

The centre of the process is the compendium. This compendium is filled either by working methods and tools developed in Forum projects or by tools developed by individual member States.

The Forum-part of the process starts with establishing the need. If specific needs are established by the Forum, the development is incorporated in the work program and subsequently in projects within the work program. Successful output of these project can than be incorporated in the Compendium (by a working group or by the Forum Secretariat).

The MS-part of the process recognizes that Member States themselves will probably also develop or possibly identify good working methods. Individual Forum Members representing their country are responsible for identification of tools useful for the Forum. When the Forum considers it to be best practice or agrees on the usefulness it can be translated and incorporated.

The process does not stop when a tool or method is being incorporated in the compendium. It is important that methods and tools are continuously evaluated. Changing circumstances and new insights can require adaptation, revision of methods or development of new tools. Reviewing methods could be done either by Member States or by way of a Forum Project. If a review leads to adaptation or revision this could be input for new Forum projects. 


\subsection{Version 1 of the Compendium}

The following matrix is the first version of the compendium. The amount of empty spots in the matrix is quite large. So filling in these gaps will require prioritisation. The project group suggests prioritising the following tools to be either chased for or developed.

- Tool for programming of inspection

- - Methods for integrated inspection

- - General checklist for inspection

- - A Decision Support tool for interpretation of exemptions

\begin{tabular}{|c|c|c|c|c|}
\hline $\begin{array}{l}\text { Phase in the } \\
\text { process }\end{array}$ & Desired Support tool & Available Methods / Tools & Source & Review \\
\hline \multirow{5}{*}{$\begin{array}{l}\text { Information } \\
\text { awareness phase }\end{array}$} & Information to China and & & & \\
\hline & EU about REACH & & & \\
\hline & $\begin{array}{l}\text { Information to inspectors } \\
\text { that they have a duty to } \\
\text { enforce REACH }\end{array}$ & $\begin{array}{l}\text { Guidance Manual for Inspections } \\
\text { under REACH / GHS }\end{array}$ & $\begin{array}{l}\text { Source: Polish Department of Environ- } \\
\text { mental Hygiene }\end{array}$ & $\begin{array}{l}\text { It gives a brief overview of both REACH and GHS which helps } \\
\text { the inspector. For a proper usage the inspector will need a } \\
\text { more thorough working knowledge of the Regulation. }\end{array}$ \\
\hline & & & (in corporation with Austria and the UK) & \\
\hline & & & $\begin{array}{l}\text { Contact: Edyta Miegoc } \\
\text { [E.Miegoc@gis.gov.pl] }\end{array}$ & \\
\hline
\end{tabular}




\begin{tabular}{|c|c|c|c|c|}
\hline $\begin{array}{l}\text { Phase in the } \\
\text { process }\end{array}$ & Desired Support tool & Available Methods / Tools & Source & Review \\
\hline & & & & $\begin{array}{l}\text { The chapter on enforcement gives an overview of items for } \\
\text { inspection. So it describes 'what to inspect'. The document is } \\
\text { for general use so it gives no guidance on 'how to inspect'. The } \\
\text { document also describes other sources of information that can } \\
\text { be useful for an inspector. }\end{array}$ \\
\hline & & & & This guidance document is REACH -specific. \\
\hline \multirow[t]{4}{*}{$\begin{array}{l}\text { Programming } \\
\text { inspection work }\end{array}$} & $\begin{array}{l}\text { Guidance document on } \\
\text { programming of inspec- } \\
\text { tion work }\end{array}$ & & & \\
\hline & \multirow{3}{*}{$\begin{array}{l}\text { Tools for selection of } \\
\text { companies. }\end{array}$} & & & \\
\hline & & Environmental Risk Manual, Issue 8, & $\begin{array}{l}\text { Source: Scottish Environment Protec- } \\
\text { tion Agency }\end{array}$ & \multirow{2}{*}{$\begin{array}{l}\text { In this document is described how the authority determines the } \\
\text { frequency and the duration of inspections for specific opera- } \\
\text { tors. These are determined on the basis of the pollution hazard } \\
\text { and an appraisal of the operator's performance. } \\
\text { This guidance is not REACH -specific nor is it specific to } \\
\text { chemicals legislation. It could however be adapted. }\end{array}$} \\
\hline & & $\begin{array}{l}\text { Environmental Protection Operator } \\
\text { and Pollution Risk Appraisal (EP } \\
\text { OPRA) Version } 3.2\end{array}$ & $\begin{array}{l}\text { Contact: } \\
\text { www.sepa.org.uk/guidance/envriskman } \\
\text { ual/index.htm }\end{array}$ & \\
\hline
\end{tabular}




\begin{tabular}{|c|c|c|c|c|}
\hline $\begin{array}{l}\text { Phase in the } \\
\text { process }\end{array}$ & Desired Support tool & Available Methods / Tools & Source & Review \\
\hline & & & $\begin{array}{l}\text { Source: Environment Agency of Eng- } \\
\text { land \& Wales (United Kingdom) } \\
\text { Information: www.environment- } \\
\text { agency.gov.uk/ >Business > How and } \\
\text { why we regulate > Compliance > } \\
\text { Assessing compliance > OPRA EP - an } \\
\text { introduction }\end{array}$ & $\begin{array}{l}\text { The Environment Agency uses a risk based approach in order } \\
\text { to assign their means towards the worst performing operators. } \\
\text { It combines the complexity of the operators site, the size of } \\
\text { emissions, the use of management systems and the compli- } \\
\text { ance behavior of the operator. } \\
\text { This guidance is not REACH -specific nor is it specific to } \\
\text { chemicals legislation. It could however be adapted. }\end{array}$ \\
\hline \multirow[t]{2}{*}{ Preparation } & $\begin{array}{l}\text { Methods for integrated / } \\
\text { coordinated inspection } \\
\text { (on both inspection level } \\
\text { as program level) }\end{array}$ & & & \\
\hline & & $\begin{array}{l}\text { Annex II of the European inspection } \\
\text { project "European Classification and } \\
\text { labeling of Preparations, including } \\
\text { Safety Data Sheets" (ECLIPS) - final } \\
\text { report }\end{array}$ & $\begin{array}{l}\text { Source: CLEEN } \\
\text { Contact: CLEEN website [www.cleen- } \\
\text { europe.eu } \rightarrow \text { Projects } \rightarrow \text { Past projects ] } \\
\text { or CLEEN secretariat } \\
\text { [helmut.witzani@umweltbundesamt.at ) }\end{array}$ & $\begin{array}{l}\text { Annex II contains a guidance manual with specific checklists. } \\
\text { The guidance manual focuses on classification and labeling } \\
\text { and the Safety Data Sheets of preparations only } \\
\text { The checklist go into specific phases of the inspection work, } \\
\text { i.e.: preparation of the project (paragraph 4.1), Preparation of } \\
\text { company inspections (paragraph 4.2), the inspection itself } \\
\text { (paragraph 4.3), for hollow up on inspections ((paragraph 4.4). } \\
\text { It also contains useful Annexes with FAQ and so-called IQ's } \\
\text { (Interpretative Questions). }\end{array}$ \\
\hline
\end{tabular}




\begin{tabular}{|c|c|c|c|c|}
\hline $\begin{array}{l}\text { Phase in the } \\
\text { process }\end{array}$ & Desired Support tool & Available Methods / Tools & Source & Review \\
\hline & & & & $\begin{array}{l}\text { This guidance is not REACH -specific but can be relatively } \\
\text { easily adapted. All legislation of the project is incorporated in } \\
\text { the REACH Regulation. }\end{array}$ \\
\hline & & & Source: CLEEN & $\begin{array}{l}\text { Appendix } 1 \text { contains a working method guidance manual with } \\
\text { specific checklists. The document focuses on notification, } \\
\text { classification and labeling and the Safety Data Sheets. With } \\
\text { respect to the products there was a specific focus on dyestuffs }\end{array}$ \\
\hline & & & $\begin{array}{l}\text { Contact: CLEEN website [www.cleen- } \\
\text { europe.eu } \rightarrow \text { Projects } \rightarrow \text { Past projects ] } \\
\text { or }\end{array}$ & $\begin{array}{l}\text { The NONS project was the predecessor of the SENSE pro- } \\
\text { jects. How valuable the project was, with respect to the meth- } \\
\text { ods and tools it gives no additional insight in relation to the } \\
\text { SENSE project. }\end{array}$ \\
\hline & & & CLEEN secretariat & \\
\hline & & & [helmut.witzani@umweltbundesamt.at] & $\begin{array}{l}\text { Appendix } 1 \text { contains a working method guidance manual with } \\
\text { specific checklists. The document focuses on notification, } \\
\text { classification and labeling and the Safety Data Sheets and } \\
\text { permitted market quantities. There was a specific focus on the } \\
\text { following types of product: photochemicals, paints, intermedi- } \\
\text { ates, dyestuffs and paper industry chemicals. }\end{array}$ \\
\hline & & $\begin{array}{l}\text { European inspection project on the } \\
\text { Notification of New Substances }\end{array}$ & - & \\
\hline
\end{tabular}




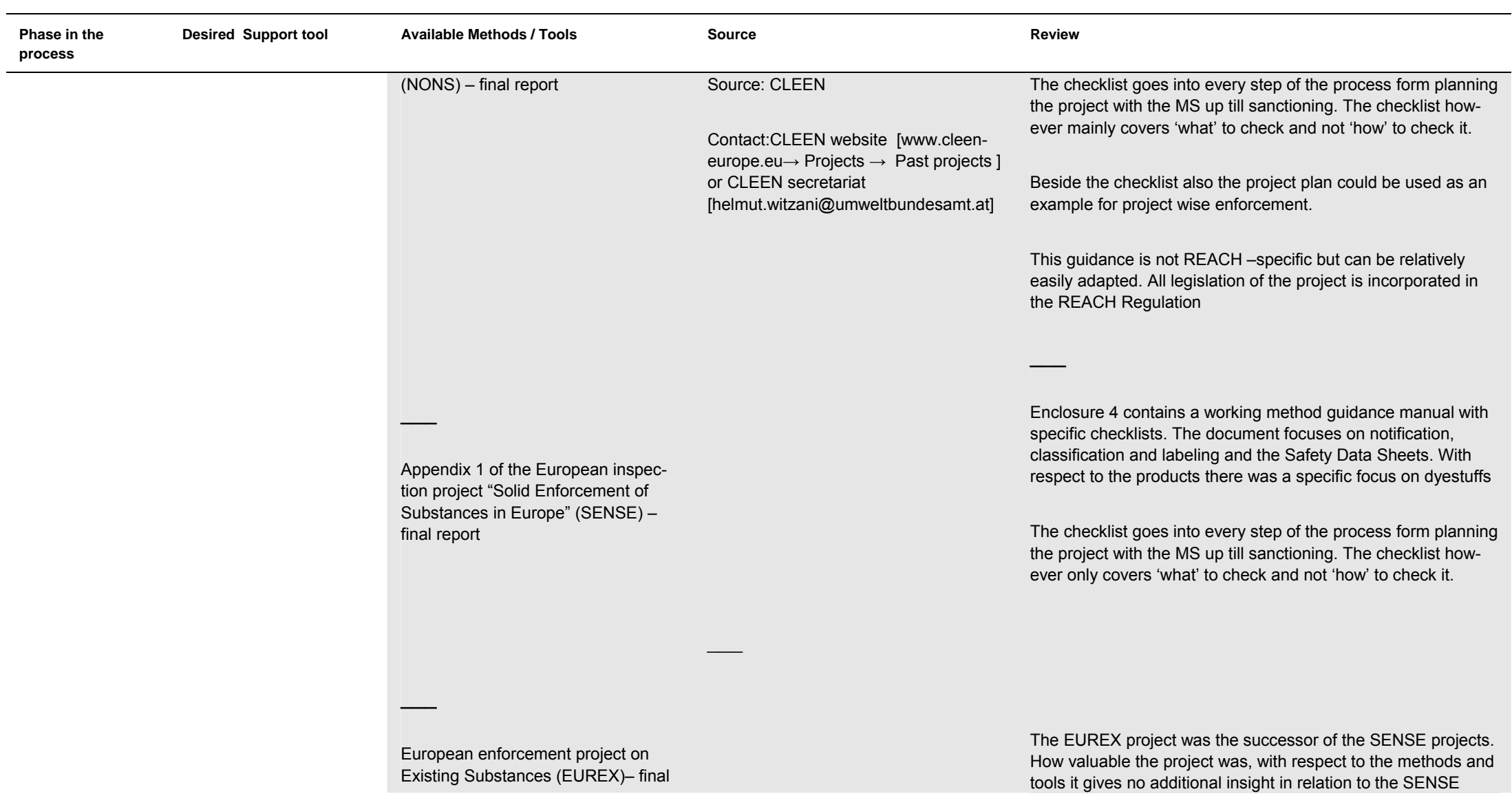




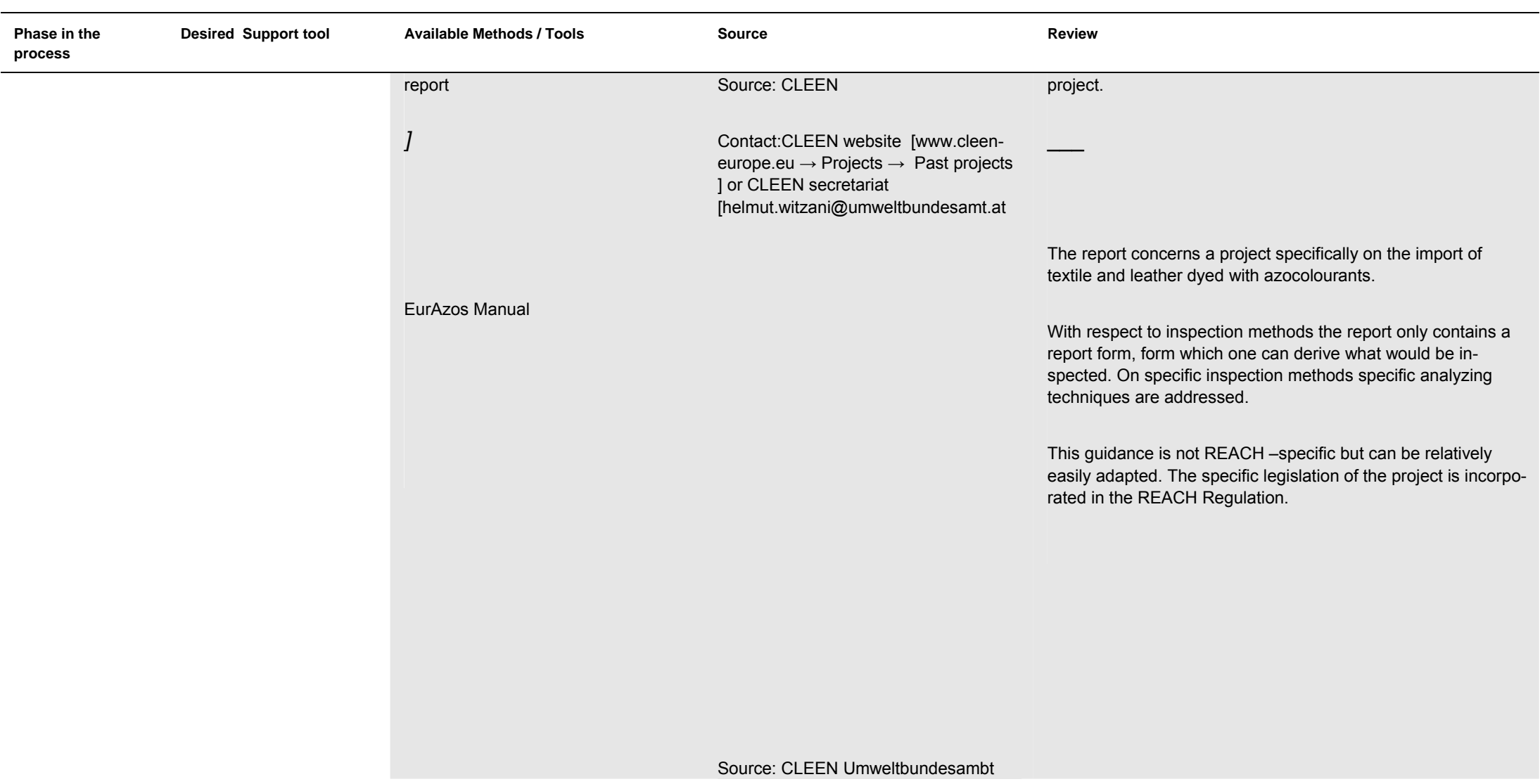




\begin{tabular}{|c|c|c|c|c|}
\hline $\begin{array}{l}\text { Phase in the } \\
\text { process }\end{array}$ & Desired Support tool & Available Methods / Tools & Source & Review \\
\hline & & & $\begin{array}{l}\text { Austria } \\
\text { Information: } \\
\text { Ms. Sabine Cladrowa [sa- } \\
\text { bine.cladrowa@umweltbundesamt.at }\end{array}$ & \\
\hline & \multicolumn{4}{|l|}{$\begin{array}{l}\text { A method to make a good } \\
\text { link with activities on } \\
\text { IPPC and WFD }\end{array}$} \\
\hline & \multicolumn{4}{|l|}{$\begin{array}{l}\text { The use of information } \\
\text { from different sources: } \\
\text { - Site permits }\end{array}$} \\
\hline & $\begin{array}{l}\text { - Registration for taxes } \\
\text { - Risk approach } \\
\text { - Trade registration/ } \\
\text { product registration } \\
\text { Information from other } \\
\text { MS (about trades) }\end{array}$ & Product Registers in Europe & $\begin{array}{l}\text { Source; Nordic Product Register Group, } \\
\text { Nordic Council of Ministers }\end{array}$ & $\begin{array}{l}\text { This document provides no guidance for an inspector but gives } \\
\text { an insight into possible information sources for a product } \\
\text { register. }\end{array}$ \\
\hline & $\begin{array}{l}\text { Other inspectorates/ } \\
\text { stakeholders }\end{array}$ & & $\begin{array}{l}\text { Contact: Rune Eskøy } \\
\text { [rune.eskoy@produktregisteret.no], }\end{array}$ & \\
\hline
\end{tabular}




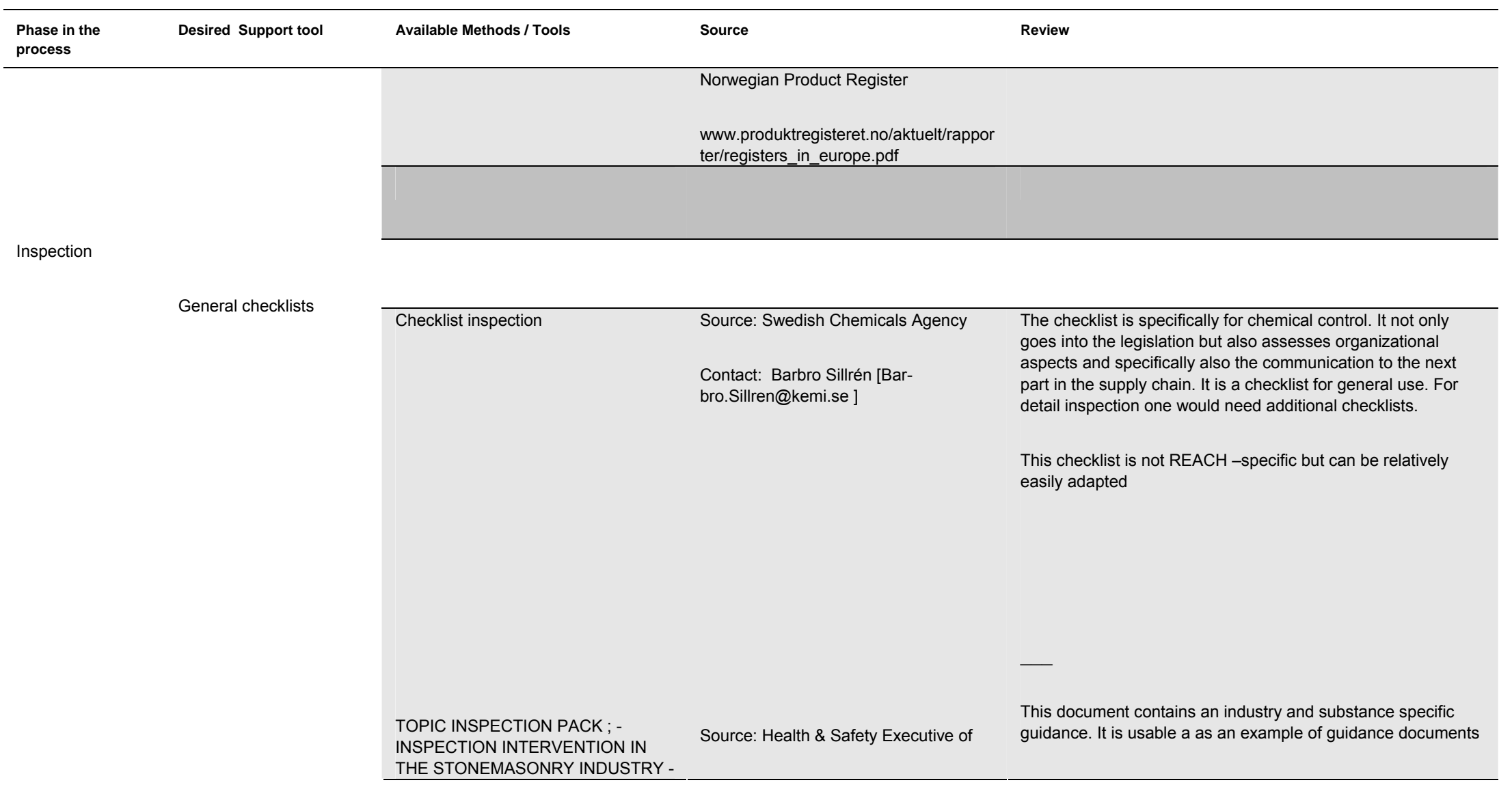




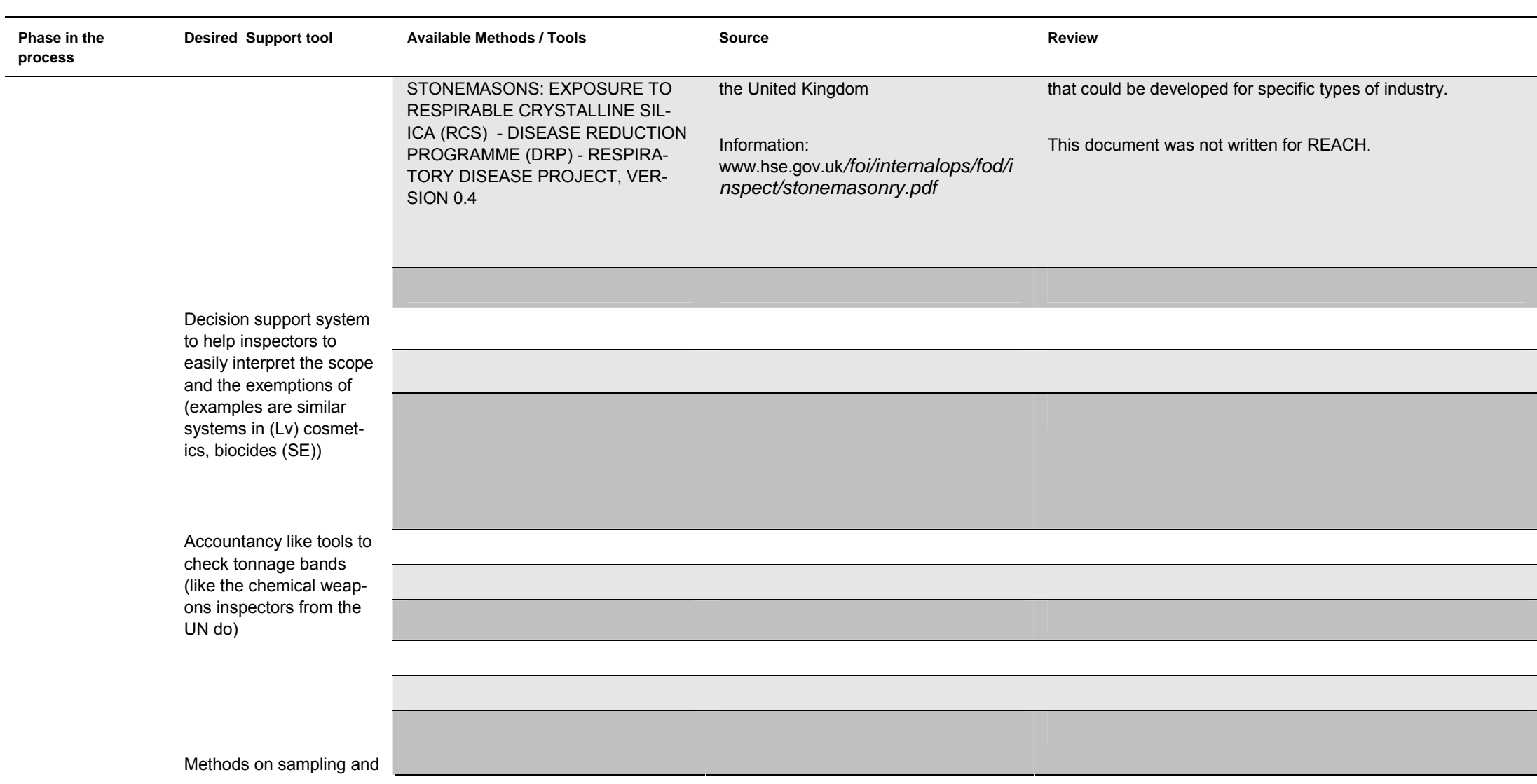




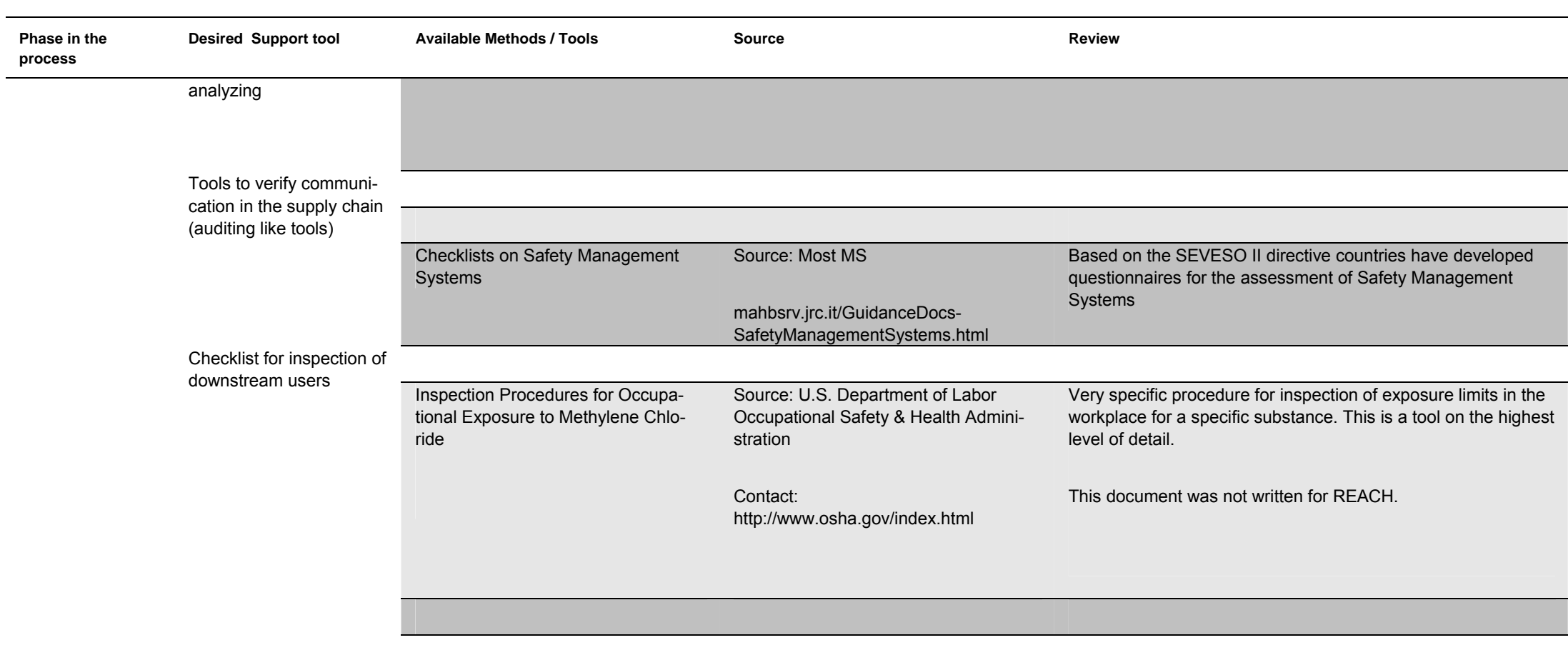

checklists on $\mathrm{CL}$ and
A guide to compiling Safety Datasheets
Source: Polish Department of Environor distributors. It is however very well usable for inspectors who
ons 


\begin{tabular}{|c|c|c|c|c|}
\hline $\begin{array}{l}\text { Phase in the } \\
\text { process }\end{array}$ & Desired Support tool & Available Methods / Tools & Source & Review \\
\hline & & & mental Hygiene & want to control the Safety Data Sheet of a product. \\
\hline & & & $\begin{array}{l}\text { Contact: Edyta Miegoc } \\
\text { [E.Miegoc@gis.gov.pl] }\end{array}$ & This guidance document is REACH -specific. \\
\hline & & $\begin{array}{l}\text { Guidelines for the Preparation of } \\
\text { Material Safety Data Sheets in New } \\
\text { Zealand }\end{array}$ & $\begin{array}{l}\text { Source: Occupational Safety and } \\
\text { Health Service of }\end{array}$ & $\begin{array}{l}\text { This document provides guidance for manufacturers, importers } \\
\text { or distributors. It is however very well usable for inspectors who } \\
\text { want to control the Safety Data Sheet of a product. }\end{array}$ \\
\hline & & & $\begin{array}{l}\text { the Department of Labour, New Zea- } \\
\text { land } \\
\text { Contact: } \\
\text { www.osh.govt.nz/order/catalogue/69.sh } \\
\text { tml }\end{array}$ & $\begin{array}{l}\text { This checklist is not REACH -specific but can be relatively } \\
\text { easily adapted. The added value is however limited, given the } \\
\text { availability of the Polish Document. }\end{array}$ \\
\hline \multicolumn{5}{|l|}{ Follow-up } \\
\hline \multirow[t]{3}{*}{$\begin{array}{l}\text { Enforcing / Sanc- } \\
\text { tioning }\end{array}$} & & Enforcement Policy Statement & $\begin{array}{l}\text { Source: Health \& Safety Commission of } \\
\text { the United Kingdom }\end{array}$ & $\begin{array}{l}\text { The document describes the guiding principles of enforcement } \\
\text { work of the Health \& Safety Executive as well as local authori- } \\
\text { ties. }\end{array}$ \\
\hline & & & $\begin{array}{l}\text { Information: } \\
\text { www.hse.gov.uk/enforce/index.htm }\end{array}$ & \\
\hline & & Enforcement management model, & Source: Health \& Safety Executive of & $\begin{array}{l}\text { This document is not specific for certain legislation. It can be } \\
\text { seen as possible guidance for managers. The character is very } \\
\text { general, so it has limited value for inspectors. Its value lays } \\
\text { mainly in helping management to determine their mindset. }\end{array}$ \\
\hline
\end{tabular}




\begin{tabular}{|c|c|c|c|c|}
\hline $\begin{array}{l}\text { Phase in the } \\
\text { process }\end{array}$ & Desired Support tool & Available Methods / Tools & Source & Review \\
\hline & & $\begin{array}{l}\text { Version } 3.0 \\
\text { HSE PUBLIC REGISTER OF EN- }\end{array}$ & $\begin{array}{l}\text { the United Kingdom } \\
\text { Information: } \\
\text { www.hse.gov.uk/enforce/index.htm }\end{array}$ & $\begin{array}{l}\text { The EMM is a tool for making enforcement decisions. The } \\
\text { model is based on the Enforcement Policy of HSE. The goal is } \\
\text { to help inspectors to be consistent in their decisions, and for } \\
\text { managers to evaluate the fairness and consistency of the } \\
\text { enforcement activities. It also provides guidance for inexperi- } \\
\text { enced inspectors. } \\
\text { It describes an approach in which on the basis of the violation } \\
\text { or risk is determined what course of action is appropriate. The } \\
\text { extent of the risk, the behavior of the operator an the side } \\
\text { effects of the enforcement measure are considered when } \\
\text { establish a choice for a specific intervention measure. This car } \\
\text { vary from a verbal warning up till criminal prosecution. } \\
\text { This guidance is not specific for a certain legislation but spe- } \\
\text { cific for the field Occupational Health and Safety. For use in } \\
\text { REACH it is usable but the scope is too narrow considering the } \\
\text { Fact that REACH also covers risks for the environment and for } \\
\text { consumer health. It could however be adapted. } \\
\text { This site gives details of enforcement notices issued by the } \\
\text { Health \& Safety Executive. }\end{array}$ \\
\hline
\end{tabular}




\begin{tabular}{|c|c|c|c|c|}
\hline $\begin{array}{l}\text { Phase in the } \\
\text { process }\end{array}$ & Desired Support tool & Available Methods / Tools & Source & Review \\
\hline & & $\begin{array}{l}\text { FORCEMENT NOTICES } \\
- \\
\text { HSE PUBLIC REGISTER OF CON- } \\
\text { VICTIONS }\end{array}$ & $\begin{array}{l}\text { Sor United Kingdom } \\
\text { Information: } \\
\text { www.hse.gov.uk/notices/ } \\
\text { Source: Health \& Safety Executive of } \\
\text { - } \\
\text { Source: Health \& Safety Executive of } \\
\text { the United Kingdom } \\
\text { www.hse.gov.uk/prosecutions }\end{array}$ & $\begin{array}{l}\text { This tool is applicable to any legislation } \\
\text { This site gives details of prosecution cases obtained by Health } \\
\text { \& Safety Executive, which resulted in a successful conviction. } \\
\text { This tool is applicable to any legislation. }\end{array}$ \\
\hline & & Enforcement and prosecution policy & Source: Environment Agency of Eng- & $\begin{array}{l}\text { The EPP describe the enforcement policy of the Environment } \\
\text { Agency (for England \& Wales). It contains the direction of types }\end{array}$ \\
\hline
\end{tabular}




\begin{tabular}{|c|c|c|c|c|}
\hline $\begin{array}{l}\text { Phase in the } \\
\text { process }\end{array}$ & Desired Support tool & Available Methods / Tools & Source & Review \\
\hline & & 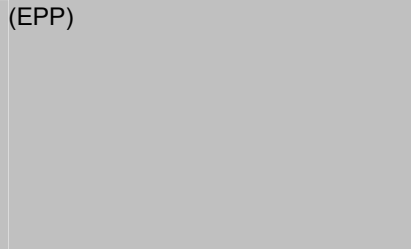 & $\begin{array}{l}\text { land \& Wales (United Kingdom) } \\
\text { Information: www.environment- } \\
\text { agency.gov.uk/commondata/acr- } \\
\text { obat/enfpolicy.pdf }\end{array}$ & $\begin{array}{l}\text { of measures, range in height of sanctions and the choice for } \\
\text { the type of court. } \\
\text { It is very similar to the document of the Enforcement Policy } \\
\text { Statement of the Health and Safety Commission. So it too has } \\
\text { limited value for inspectors and its value lays mainly in helping } \\
\text { management to determine their mindset. }\end{array}$ \\
\hline & & $\begin{array}{l}\text { Enforcement Concordat: Good } \\
\text { Practice Guide for England \& Wales }\end{array}$ & $\begin{array}{l}\text { Source: Department of Trade \& Industry } \\
\text { of England \& Wales (United Kingdom) } \\
\text { Information: } \\
\text { www.cabinet-office.gov.uk/regulation/- } \\
\text { PublicSector/enforcement/enforc- } \\
\text { ement.htm. }\end{array}$ & $\begin{array}{l}\text { It too is very similar to the document of the Enforcement Policy } \\
\text { Statement of the Health and Safety Commission and Enforce- } \\
\text { ment and prosecution policy Environment Agency. So it too } \\
\text { has limited value for inspectors and its value lays mainly in } \\
\text { helping management to determine their mindset. }\end{array}$ \\
\hline & & - & - & - \\
\hline & & Compliance Classification Scheme & $\begin{array}{l}\text { Source: Environment Agency of Eng- } \\
\text { land \& Wales (United Kingdom) }\end{array}$ & $\begin{array}{l}\text { This document describes the type of measure that matches a } \\
\text { violation. It is a classification of the severity of a violation. }\end{array}$ \\
\hline & & & $\begin{array}{l}\text { Information: } \\
\text { www.environment-agency.gov.uk/ }\end{array}$ & $\begin{array}{l}\text { This guidance is not REACH -specific nor is it specific to } \\
\text { chemicals legislation. It could however be adapted. }\end{array}$ \\
\hline $\begin{array}{l}\text { Monitoring com- } \\
\text { pliance }\end{array}$ & $\begin{array}{l}\text { Monitoring effective } \\
\text { control to learn for the }\end{array}$ & & & \\
\hline
\end{tabular}




\begin{tabular}{|c|c|c|c|c|}
\hline $\begin{array}{l}\text { Phase in the } \\
\text { process }\end{array}$ & Desired Support tool & Available Methods / Tools & Source & Review \\
\hline & future & EUVICHEM & $\begin{array}{l}\text { Source: CLEEN } \\
\text { Contact: CLEEN website [www.cleen- } \\
\text { europe.eu } \rightarrow \text { Projects } \rightarrow \text { Past projects ] } \\
\text { or } \\
\text { ms Rosario Alonso Fernández [ralon- } \\
\text { so@msc.es] }\end{array}$ & $\begin{array}{l}\text { This project concerns design of a system for information } \\
\text { exchange. It is not so much a tool for an individual inspector, } \\
\text { but very valuable since it is an information tool which can assist } \\
\text { the focusing of enforcement activities. } \\
\text { This guidance is not REACH -specific but can be very rela- } \\
\text { tively easily adapted. Almost all legislation of the project is } \\
\text { incorporated in the REACH Regulation. }\end{array}$ \\
\hline & $\begin{array}{l}\text { Monitoring the behavior } \\
\text { of the companies }\end{array}$ & & & \\
\hline & & & & \\
\hline
\end{tabular}





\section{Borderlines}

\subsection{Introduction}

On the basis of article 76.1 of the REACH - Regulation a Forum will be established. This specific type of Forum is a new phenomenon in EUlegislation. Never before has enforcement (and specifically the exchange of information and co-operation in enforcement) had such a prominent role in the legal text.

From earlier investigations it was concluded that for many people in the work area of enforcement, the borderlines between existing and new organizations (like ECHA, Forum et cetera) aren't clear. Therefore the project group on enforcement of REACH decided to elaborate these borderlines.

Some aspects will become much clearer when all activities around the regulation are actually going on. So this document is a starting point for further analyses or clarifications.

This paper first goes into borderlines between ECHA and the National Enforcement Authorities in relation to the REACH process. After this the role of the Forum and its tasks is described. In the fourth chapter the interfaces between the various enforcement authorities within a Member State is shortly addressed. The final chapter briefly goes into the helpdesks, i.e. the ECHA helpdesk and the national helpdesks.

\subsection{Borderlines between work by ECHA and by National Enforcement Authorities}

In essence ECHA is responsible for and carries out large parts of the administrative processes of the Regulation. The Competent Authorities (CA's) take part of and support the processes through participation in three committees (MSC, RAC, SEAC) and through written comments. Many of the administrative processes result in legally binding decisions, e.g. concerning registration, evaluation and authorisation. All of these tasks imply no onsite inspection or imposing of sanctions.

Parallel to this work of ECHA and the CA's, National Enforcement Authorities work to verify compliance with REACH, including with these decisions, and as appropriate to impose sanctions.

When do we talk about enforcement? 
The core of the borderline-discussion has to do with the way one treats the definition of 'enforcement-activities'. If one defines enforcement as checking compliance than there is a very vague borderline because ECHA also checks completeness and compliance (articles 20 and 41). The division of task between ECHA and Enforcement organization lies in the fact whether a matter is within or outside the administrative process. This discussion is therefore also influenced by how one has organized enforcement in relation to the task of the competent authorities (CA's).

This means, taking decisions (and all connected actions) in the course of the process of registration, evaluation and authorization is within the scope of ECHA (and the CA's).

Once these different decisions have been taken by the Commission or ECHA they are to be enforced by the National Enforcement Authorities. Sometimes there can be cooperation with ECHA and the CA's.

When a matter is outside this process - which means either no decision is asked (for instance no registration is made), a decision of ECHA is made (either to register or to ask for extra information etc.) or the information was not verified by ECHA - and other parties (Manufactures, Importers, Downstream Users) have to act upon this, then it's the responsibility of the National Enforcement organization to verify compliance and act upon it.

For example if the information required (for instance: SDS or ES) is not distributed down a supply chain, this is a matter for National Enforcement Authorities.

Another example is when the National Enforcement Authority finds out that a Manufacturer / Importer is marketing a substance for uses outside what is in the registration. This might be a matter to inform ECHA and/or the CA about. But the task and the possibilities to act on this lie with the National Enforcement Authorities.

\section{Completeness and compliance check of ECHA}

This particular item causes some discussion among enforcers since the wording 'compliance check' implicates inspection- or enforcing-like work by ECHA. There are clearly overlaps.

Note: ECHA performs selective compliance checks and will not check all items. One should therefore be aware that if additional information is asked on one item, other related items are not evidently in compliance. Also in the case when no additional information is asked one cannot automatically assume that the registration is compliant.

The completeness check is something entirely outside the scope of the enforcers. But the compliance check is something which, in theory, also the enforcement authority could do. Since a thorough compliance check of an entire dossier will be a costly matter, it is unlikely that this latter action by the enforcement authority will happen on a large scale. Whether a check is done by ECHA or by an Enforcement authority, the result stays 
the same. The registrant will have to give extra Information. If the registrant does not comply, this provision (article 41.3) itself can be enforced (beside article 5) by the National Enforcement Authority.

\section{Recalling a registration?}

According to REACH (art. 20.2) the Agency shall reject the registration if the registrant fails to complete his registration within a deadline set as a result of the completeness check. However, REACH don't tell about any such option if the registrant later on fails to carry out a test or to submit further information as required by an evaluation decision. Such information though may be more important to get than certain of the information required to make the registration complete

At first glance recalling a registration would be an obvious enforcement tool like withdrawing a permit can be an enforcement method in IPPC activities. With several enforcers this raises the question whether a registration can be recalled by ECHA. But in fact the question is: "does an enforcer need recalling as a method?"

To be clear on the first question: the REACH regulation does not contain a provision to recall a registration. Only when a dossier is incomplete or when a registrant refuses to comply with its duties with respect to data sharing, no registration is admitted by ECHA. Actual withdrawal is only possible with authorisations. But this authority is in fact not ECHAs but the Commissions. An example is when the National Enforcement Authority finds out that a substance requiring an authorization is being used outside what is covered by the authorization. This is clearly valuable information for ECHA or for the commission when reviewing the authorisation, but the actual enforcement remains a matter for the National Enforcement Authority to deal with. On the basis of article 56 such a use is prohibited. It is the responsibility of the user and/ manufacturer to make sure a proper authorisation is applied for.

But with respect to the second question, i.e.: "Does an enforcer need recalling as a method of enforcement?" the answer is no. A registration is not simply valid because a registrant has a registration number. Article 5 clearly states that the 'no data no market'- principle a registration must be made "..according to the provisions in this title ...". So this means that the registration must be correct. This discussion is however understandable since such a strong connection between having a registration number and being compliant would make it very easy for an inspector to enforce by way of checking the registration number. Alas this is only a superficial check. So when a registrant has submitted a complete but incorrect dossier and they have received the registration, they still don't have the formal right to market the substance. 


\section{Division of tasks / Work process}

When a Members State has separated the tasks of CA within the registration and evaluation process and enforcement tasks, into different organizations (example the Netherlands), they will probably have small problems in establishing the borderline. If however the CA does both evaluation and enforcement - so these tasks are within the same organization - a Members State has to make some clear division of work. This division is not compulsory in REACH and is therefore mainly depended on organizational aspects, enforcement culture and member states specific regulations.

The borderlines are also dependant on the national processes of enforcement. Some European countries adopted a way of working where they notify ECHA and do not enforce until ECHA confirms the noncompliance. When adopting such a work processes, additional borderlines are introduced.

Because of the relation to the process of registration, evaluation etc., the borderlines are described along the process and various titles of REACH.

The Forum and its secretariat and Helpdesk are not in this table because of the characteristics of their role. The role of the helpdesk is the same everywhere. And the Forum secretariat has a very indirect role which is in essence on every part where the enforcer is. So their role doesn't change. 
Note: This table is not intended to be complete but to give a rough overview by way of some examples

\begin{tabular}{|c|c|c|}
\hline & ECHA tasks & $\begin{array}{l}\text { National Enforcement Authority } \\
\text { (NEA) tasks }\end{array}$ \\
\hline Pre registration & $\begin{array}{l}\text { - Receive pre-registrations } \\
\text { - Publish list of pre-registered sub- } \\
\text { stances }\end{array}$ & $\begin{array}{l}\text { Enforcement of those who } \\
\text { market phase-in substances } \\
\text { but have neither pre- } \\
\text { registered, nor registered the } \\
\text { substances }\end{array}$ \\
\hline \multirow[t]{3}{*}{ Registration } & - Completeness check & $\begin{array}{l}\text { - Enforce non-registration or } \\
\text { denied registrations }\end{array}$ \\
\hline & $\begin{array}{l}\text { - Ask for further information } \\
\text { - If incomplete no registration }\end{array}$ & $\begin{array}{l}\text { - Enforce "bad" registrations, } \\
\text { i.e. non-compliance with } \\
\text { various registration provisions. }\end{array}$ \\
\hline & $\begin{array}{l}\text { - Assign registration number } \\
\text { - Take decision on costs of sharing }\end{array}$ & \\
\hline $\begin{array}{l}\text { Data sharing an } \\
\text { avoidance of unnec- } \\
\text { essary testing }\end{array}$ & $\begin{array}{l}\text { - Stop registration in refusal to provide } \\
\text { proof of cost or study results }\end{array}$ & \\
\hline Dossier evaluation & Check and decide on test proposals & $\begin{array}{l}\text { Enforce non-compliance with } \\
\text { decisions on test proposals }\end{array}$ \\
\hline \multicolumn{3}{|l|}{ - test proposals } \\
\hline $\begin{array}{l}\text { Dossier evaluation } \\
\text { - compliance checks }\end{array}$ & $\begin{array}{l}\text { Check registrations and decide } \\
\text { on/require more information }\end{array}$ & $\begin{array}{l}\text { - Enforce non-compliance with } \\
\text { decisions on/requirements for } \\
\text { giving in more information }\end{array}$ \\
\hline \multirow{2}{*}{ - compliance checks } & & Inform ECHA \\
\hline & & $\begin{array}{l}\text { - check compliance outside the } \\
\text { registration process }\end{array}$ \\
\hline Substance evaluation & $\begin{array}{l}\text { Distribution of the different substances } \\
\text { to the MS for evaluation. }\end{array}$ & \\
\hline \multirow[t]{2}{*}{ Authorisation } & $\begin{array}{l}\text { - Check applications and advice on } \\
\text { authorizations. }\end{array}$ & $\begin{array}{l}\text { Enforce non-compliance with } \\
\text { the authorization conditions. }\end{array}$ \\
\hline & $\begin{array}{l}\text { Note: Granting, reviewing or possibly } \\
\text { suspend or withdraw authorizations is } \\
\text { an authority of the Commission }\end{array}$ & \\
\hline $\begin{array}{l}\text { Information through } \\
\text { Supply Chain }\end{array}$ & $\begin{array}{l}\text { Check registrations and decide } \\
\text { on/require more information with re- } \\
\text { spect to information to give in Safety } \\
\text { Data Sheets }\end{array}$ & $\begin{array}{l}\text { - Enforce non-compliance with } \\
\text { the requirements to supply a } \\
\text { SDS (with relevant Exposure } \\
\text { Scenarios). }\end{array}$ \\
\hline $\begin{array}{l}\text { Classification and } \\
\text { labelling }\end{array}$ & $\begin{array}{l}\text { - Receive the classification of the } \\
\text { different substances and make them } \\
\text { public on the ECHA website through the } \\
\text { inventory list. }\end{array}$ & $\begin{array}{l}\text { - Enforce non-compliance of } \\
\text { the classification on the } \\
\text { SDS/label with the classifica- } \\
\text { tion given in the inventory list. }\end{array}$ \\
\hline Downstream users & $\begin{array}{l}\text { - Receive reports on uses outside } \\
\text { conditions described in an exposure } \\
\text { scenario }\end{array}$ & $\begin{array}{l}\text { - Enforcement of non- } \\
\text { compliance with the duties to } \\
\text { apply appropriate measures to } \\
\text { adequately control risks, to } \\
\text { report uses outside conditions } \\
\text { described in an exposure } \\
\text { scenario, to comply with } \\
\text { authorisation conditions. }\end{array}$ \\
\hline
\end{tabular}

Clearly the work of National Enforcement Authorities (NEA) to enforce various registration provisions, and the work by ECHA (with the help of CAs) to check completeness and compliance as well as test proposals, is the item of most possible overlap 
For example: A NEA imposes sanctions on a registrant for not haven taken into account the main obvious risks in a registration (known to the NEA from its enforcement activities). At the same time ECHA does nothing because this registration has not been chosen for compliance check (which only will be made for $5 \%$ of the registrations. A question here might be: should the NEA first ask ECHA to do something? The NEA actually doesn't have to do that. It however would be practical if they can make an arrangement that ECHA checks this registration anyway. In any case it would be good for ECHA to know about the problem, when reviewing similar dossiers.

\subsection{Role of the Forum and of its secretariat}

In the REACH Regulation the main task of the Forum is defined as follows: "The Agency should therefore provide a Forum for Member States to exchange information on and to coordinate their activities related to the enforcement of chemicals legislation".

Furthermore, according to article 77-4 of the REACH Regulation the Forum shall undertake the following tasks:

- spreading good practice and highlighting problems at Community level;

- proposing, coordinating and evaluating harmonised enforcement projects and joint inspections;

- coordinating exchange of inspectors;

- identifying enforcement strategies, as well as best practice in enforcement;

- developing working methods and tools of use to local inspectors;

- developing an electronic information exchange procedure;

- liaising with industry, taking particular account of the specific needs of SMEs, and other stakeholders, including relevant international organisations, as necessary;

- examining proposals for restrictions with a view to advising on enforceability.

The Forum is in essence itself an interface. An interface between the collective Enforcement organizations from all Member States and ECHA and between Enforcement organizations of Member States amongst each other. The forum secretariat gives support to enable this interface to work. The Forum secretariat is part of the ECHA secretariat that also carry out the procedural work of pre-registration, registration and evaluation, but these are entirely different tasks.

In general the greater goal of the Forum is to help the Regulation to work. Its tasks imply the fostering of quality, effectiveness and efficiency 
of enforcement activities by way of information exchange and projects. The Forum itself cannot intervene in actions of ECHA, Member States Competent Authorities or their National Enforcement Authorities. It is a body without formal powers.

For each task we will give a short description:

(a) Spreading good practice and highlighting problems at Community $\underline{\text { level; }}$

This task implies that the Forum has to organise the spreading of good practices and problems on a simple, unified and efficient and for every country accessible manner.

The most relevant information will have to be gathered while the enforcement is being practiced. Involvement of experienced inspectors in the Forum is needed to assure feedback on malfunction of the regulation on the national level. It should not involve only by enforcement of REACH, but experience with other networks (CLEEN, Impel SLIC) should be used.

Grey Area:

There is an overlap with task (d) which also deals with best practices. The question is how one could objectively establish the best practice.

Example:

To spread good practice at community level, the setup of a confidential website amongst MS could be relevant. In such a way information exchange between inspectors could be facilitated.

(b) Proposing, coordinating and evaluating harmonised enforcement projects and joint inspections;

This means that the Forum will have to promote and organize the harmonization of enforcement and joint inspections through out the Member States. These activities will have to be coordinated and evaluated. Evaluation of these projects should be facilitated by clearly formulated criteria. This also applies for the organization of joint inspections; it should be made clear which types of companies are subject to joint inspections and which are not. The results of these projects should also be made available to all Member States by the Forum and in one way or another Member States should be inspired/ motivated to use the same approach. This could be achieved by formulating simple and clear procedures that could be implemented by the National Authorities.

Grey Area:

Evaluation of harmonized enforcement project and joint inspections might also produce information concerning best practices. Thus there is 
an overlap with task (d). The question here is what is a harmonized enforcement project and when will such a project be considered as a best practice?

Carrying out joint inspections could mean that different inspectors from different Member States will enforce REACH together. There is an overlap here with task (c), namely coordinating the exchange of inspectors. Joint inspections could also facilitate the transfer of knowledge concerning best practices after these have been identified. So coordinating joint inspections also has an overlap with task (d). The question here is how can the transfer of the evaluated knowledge be effectively organized?

Examples:

- - Development of a basic training kit to develop skills for enforcement inspectors.

- - Carry out joint inspections in harboring ships coming for example from China.

(c) Coordinating exchange of inspectors;

This task implies that the Forum is there to facilitate the exchange of inspectors through out the Member States.

It is very important that it is made clear why exchange is necessary. Criteria will have to be formulated to evaluate when this is acceptable and when not. Also there should be a budget and staff to facilitate the organization of these activities.

Some Member States might reject having foreign inspectors carrying out their regulative duties. The Forum will have to identify these Member States and respect these decisions.

Grey area:

It is unclear when such an exchange of inspectors is necessary and justifiable and who is responsible for the needed budget and staff needed to coordinate this.

Example:

Exchange of inspections by inspectors from different MS could be carried out to increase understanding of each others methods. The Forum could make an inventory of specific demands and connect Member States.

(d) Identifying enforcement strategies, as well as best practice in enforcement;

This means that the Forum will have the task to collect data concerning the results/ efficiency of certain enforcement strategies implemented by the National Authorities, evaluate these and congregate this knowledge in an overview of best practices. Member States will have to be convinced 
of these best practices in order to stimulate the National Authorities to implement the identified best practices. In addition to this identification of the worst practices will also have an added value.

It seems plausible that the best way to generate the needed knowledge concerning best practices is on a case to case basis while REACH enforcement is put into practice.

Grey area:

It is unclear if it's possible to formulate one general REACH strategy or several different strategies based on a specific field.

(e) Developing working methods and tools of use to local inspectors;

The Forum will have to compile practical manuals, provide trainings and toolkits that can be applied by the inspectors.

Here it is important to let practice show what kinds of guidance, tools etc. are needed by the enforcers and how can existing tools be used and or adapted to enforce REACH.

Grey area:

This task has overlap with tasks (a), (b) and (d). Important is that it should not be imposed on the National Authorities for this might restrict the effectiveness of the approach implemented by the inspectors.

Example:

Development of new working methods (for instance: auditing the communication down the supply chain) and best practice tools for local inspectors in the format of a toolbox. Such information could be stored on a secured website.

(f) Developing an electronic information exchange procedure;

All the relevant information that will be needed by the National Authorities concerning enforcement should be made available by the Forum. It concerns information that the National Authorities can use to enforce REACH. In example information about problems at national and community level, best practices, statistical data, results of projects etc.

Important aspects related to the spreading of needed information are: the system should be internet based, and a specific timeline for the answering of certain questions from National Authorities should be built in.

Grey area:

It has to be clarified which information will be published and how. Which systems can be used to achieve this? Who is the target group and it should also be clear who is responsible for delivering which data, in which format and in which language. 
Such a system could for example be based on the EUVICHEM system (EUropean Voluntary Information exchange system on CHEMicals). In this system an electronic report form was developed as the main basic communication tool of the information exchange system. More on this subject can be read in the project group paper on Alert Systems.

(g) Liaising with industry, taking particular account of the specific needs of SMEs, and other stakeholders, including relevant international organisations, as necessary;

Liaising means maintaining contact with others. The purpose of this is making the regulation work. So it means actively gathering experience and opinions from other stakeholders.

\section{Grey Area}

The regulation does not define what extent of involvement liaising means and whether a Member State has a role in that.

Concerning the division in work between the Forum and an individual Member State it would be workable when the Forum would have this task on a more EU or global level. One can think about the large multinational companies like Shell et cetera, or multinational NGO's like Greenpeace et cetera. These stakeholders could for example help with identifying differences in inspection regimes. The individual Member States are the more appropriate party for stakeholders that are only nationally involved.

With respect to the extent of liaising the general ideas of Member States are that stakeholders should get some feedback on the results on enforcement projects. This would have an effect on better compliance. Liaising could be useful to identify problems in interpretation of regulation in advance. The part of ' $\ldots$ taking particular account of the specific needs of SMEs .." implies that this liaising task can differ per target group.

(h) Examining proposals for restrictions with a view to advising on enforceability.

This task implies that the Forum will have to advise if a certain restriction imposed on a certain substance can be enforced. The main objective is to prevent from creating regulation that cannot be enforced by the National Authorities. Clear procedures to achieve (draft) proposals will have to be laid down.

Grey area:

It still has to be clarified what the specific role of the Forum will be. Also the advice on restrictions is a three way communication. It concerns also the Agency and the Commission. The Commission, the Agency nor the Forum has any influence on the national situation. This questions the 
status of the advice and or proposals done by the Forum. Thus, it is unclear how the Member States will react on the proposals.

Example:

Authorisation may result in a restriction in the use of a substance. It is vital that such a restriction and / or the specific use is formulated in such a way that the enforcer (in a MS) is able to comprehend the restriction and that it is unambiguous.

\subsection{Interfaces between enforcement fields}

This overview is limited to the most relevant enforcement fields. We specifically say enforcement "fields" and not address "organisations" because Member States have organized this differently. So to prevent communication errors in the future work of the Forum one will always have to keep in mind that organisational settings differ but the tasks are the same. So it is best not to refer to organisations.

The proposed selection of related enforcement field is:

Occupational Health and Safety

The scope of the section occupational Health and Safety is to maintain a safe and healthful environment for workers in concert with the mission of the particular institution while ensuring compliance with applicable federal, state and local regulations.

REACH relation: One of the aspects of occupational health is the management of exposure to hazardous chemicals or substances. The use of chemicals and substances often also leads to exposure and therefore demands to take measures with respect to personal protection (gloves, mouth caps et cetera) to work environment (ventilation, closed processes et cetera) or even the prohibition of use. Both the employer and the employee have to know about the risks and have to take adequate measures. The REACH regulation will cover all of these aspects, since exposure scenarios and risks have to be identified and adequate measures have to be communicated to the users (by way of Labeling and Safety Data Sheets). So the field of Occupational Health is quite an overlap with REACH. For the OHS field the DNEL value is of specific importance.

\section{Environment (IPPC/WFD/SEVESO II)}

Environmental enforcement is dedicated to the implementation and enforcement of environmental legislation. The aim of environmental enforcement is to improve compliance with environmental legislation and 
ensure that those who are in violation with the law and cause environmental pollution are held to account.

IPPC refer to the permitting and enforcement activities with respect to discharges from point sources. WFD deals with quality criteria for water resources. SEVEVO II directive tasks concern the permitting and enforcement activities around sites with major hazards. These major hazards are determined mainly by amounts of dangerous substances, therefore these sites will also be very relevant in REACH enforcement.

REACH relation: One of the aspects of environmental protection is the management of exposure to the environment hazardous chemicals or substances. This could be either through the air, waste water or soil. The use of chemicals and substances often also leads to emissions to one or more parts of the environment and therefore demands to take measures with respect to protection of nature, wildlife and / or the surrounding community. For the environment field not the DNEL but the PNEC level is of importance. People that issue permits should take care that the information in the application is adequate and that provisions with respect to the emissions concentrations and the measures are minimally in line with the registration, authorisation and restrictions.

\section{$\underline{\text { Customs }}$}

Customs fulfills three core functions:

- Prevent prohibited goods from entering MS territory, with a view to protecting safety, health, the economy or the environment;

- Ensure that goods entered are kept under supervision until they have been given a permitted destination;

- Ensure that taxes payable upon import are calculated in the correct manner and are actually collected.

REACH relation: The first of these tasks clearly describes the relevance of REACH for their work. Imported goods, being substances or goods containing substances, should pose only acceptable risks to human and environment. Proper registration under REACH is one of the most important ways to assure this goal.

As explained all three fields are related to REACH legislation, but the working fields also have mutual interfaces.

\section{Other authorities}

Finally there are some other authorities that have other enforcement areas that also may need to be considered. One could think of a Consumer Product Safety Authority or Consumer Health Authority, Trade inspection, Regional and even local level inspectors. 


\subsection{Helpdesks}

The name 'Helpdesk' already implies their role. They are there to answer questions and provide information. They don't take decisions and their advice has no legal force. Their role doesn't change over the entire scope of REACH. They have borderlines with anyone, who either asks for information (In theory all stakeholders, but first for manufacturers, importers and downstream users) or gives information (like the CA and the NEA). It is quite thinkable that also people from the NEA's ask the Helpdesk questions on interpretation. Helpdesks are a responsibility of the Competent Authorities.

ECHA itself also has a task of providing information but this is not a helpdesk as meant in the legal text of the Regulation. The 'Helpdesk'-like task that is part of the ECHA secretariat is closely linked to the people that carry out the procedural work of Pre-registration, registration and evaluation. They provide support to the national helpdesks (among others). In theory it would be possible that people in the secretariat perform both tasks, but the responsibilities are different.

To maintain consistency the ECHA secretariat will keep a Manual of Decision and Opinions.

For good and particular, consistent enforcement it is important that enforcers know about the decisions of ECHA and the advice of the helpdesk. Interpretation of REACH raised by national helpdesks or ECHAs helpdesk may need to be discussed either in Forum and/or the Member State Committee and/or the CA meeting, depending on the nature of the question. 



\section{Alert System}

\subsection{Introduction}

REACH Enforcement Authorities have various needs to communicate among each other beside the meetings in Forum:

- Distribution of relevant documents

- A platform for discussion

- Information exchange among few MS

- A system for Rapid alert

Distribution of relevant documents

If a member of Forum wishes to distribute a document to other members he/she could ask ECHA to put the document at CIRCA. Be aware that CIRCA also are open to industry and others?

\section{Platform for discussion}

Forum members possibly want to discuss some issues between the meetings. This could be done at a closed homepage for Forum members only.

Information exchange among few MS

If a MS have a question concerning a company in another MS this question could be send by e-mail to the member of Forum, who will distribute the e-mail to the right person.

\section{Rapid alert systems}

Following systems are relevant:

- RAPEX

- ICSMS

- EUVICHEM

\subsection{RAPEX}

RAPEX (Community Rapid Information System) is a European rapid alert system for dangerous consumer products. It ensures that information about dangerous products identified by the national authorities is quickly circulated between the national authorities and the European Commission Directorate-General for Health and Consumer Protection, with the aim of preventing or restricting the supply of these products to consumers. 30 
countries participate in the system: all the EU countries and the EEA countries: Iceland, Liechtenstein and Norway.

The Directive on general product safety 2001/95/EC (GPSD) provides the legal framework for RAPEX.

According to the GPSD, national authorities notify the Commission, via the RAPEX system, of measures taken to prevent or restrict the marketing or use of consumer products posing a serious risk to the health and safety of consumers.

Both measures ordered by national authorities and measure taken voluntarily by producers and distributors are covered by RAPEX. The common measures are a ban/stop on sales, withdrawal of a dangerous product from the market, providing information to consumers about the risks related to the use of the product, recall of a dangerous product from consumers.

RAPEX is dedicated to consumer products. Consumer products are defined as products, which are intended for consumers and products, which can be used by both professionals and consumers.

A serious risk is defined by the GPSD as one, which requires rapid intervention by the public authorities and includes risks of which the effects are not immediate.

The information is submitted via a standard notification form, which includes details on product identification, risks posed by the product, measures adopted to prevent risks and distribution channels of the product.

The national RAPEX Contact Point submits to the Commission detailed information about dangerous products found on its own market. The Commission examines this information, checks the completeness and quality of the notifications and assesses their compliance with the law and the RAPEX Guidelines. The Commission publishes weekly overviews of notifications from national authorities on its RAPEX Internet pages http://ec.europa.eu/rapex.

Consumer products containing chemicals like toys (phthalates), clothing (azodyes) and cosmetics are often notified by the RAPEX.

\subsection{ICSMS}

ICSMS is a powerful system offering the various users a wealth of practical functionality. Its main task is to provide and exchange product information via the internet.

ICSMS consists of a closed and a public area. The closed area is for the use of market surveillance bodies, customs authorities and the EU Commission - i. e. official agencies. It contains product information, test results, official measures taken, and so on. The public area is for the use of consumers and manufacturers. It contains, for example, official infor- 
mation about dangerous products, as well as voluntary industry recalls and postings made by manufacturers drawing attention to pirated copies. Here the consumer can quickly find reliable information about unsafe products. All the information is presented in an easy to understand form; it is kept up-to-date, and can be accessed via an internet address.

ICSMS enables all users to carry out a specific search. A search can be made, for example, according to individual products, and according to test results for entire product groups. Test results can be obtained for products from specific countries; information can be obtained for products coming under certain directives, safeguard clause notifications, RAPEX notifications, as well as information about manufacturers, importers and dealers. Confidentiality aspects are protected by a complex system of access authorisations.

The market surveillance authorities of the following states are using ICSMS: Austria, Belgium, Estonia, Germany, Luxemburg, Malta, Slovenia, Sweden, Switzerland, The Netherlands and United Kingdom.

\subsection{EUVICHEM}

EUVICHEM (European Voluntary Information Exchange System on Chemicals) is a system for voluntary information exchange on noncompliance of the EU chemical legislation adopted at the $7^{\text {th }}$ CLEEN (Chemical Legislation European Enforcement Network) Conference in Vienna 2006. The notification system is developed by the Spanish Ministry of Health and Consumer Affairs.

The aim of the EUVICHEM project was to develop a useful and simple way of exchanging information of interest between CLEEN countries (EU countries, Norway, Switzerland and Candidate countries) on specific situations of non-compliance of the chemical legislation, that could be of use to improve enforcement activities in the MS and in general, assessment of the single market.

The scope of the exchange system was to cover those chemicals, which present a significant non-compliance of the chemical legislation: Dangerous Substances Directive, Dangerous Preparations Directive, Limitation of marketing and use Directive, Existing Substances Regulation and Biocides Directive.

The information is submitted via a standard notification form, which includes general information, details on chemical/product identification, supply chain information and description of actions performed/measures adopted. The standard notification form is available at CLEEN Internet pages www.cleen-europe.eu.

While it's a voluntary system the reporting country can decide to communicate to another country or to several countries. There is no need 
to report to all countries if the deficiencies may have no consequences in the other countries.

\subsection{Recommendations}

- Use CIRCA for relevant documents

- Establish a homepage for discussions

- Use e-mails between members of Forum

- Use EUVICHEM 


\section{Needs for/access to confidential information in REACH-IT}

This paper is just intended to function as a thought starter for a Forum project on the issue of needs for and access to confidential information in REACH-IT

\subsection{Needs}

Cf. Chapter 3 of this report on REACH enforcement priorities, in which a preliminary analysis also has been made of some of the needs for confidential information from REACH-IT.

The following are some examples of such needs:

- Information in pre-registrations and registrations of substances (on companies, substances, uses, volumes, etc), to be able to enforce both the basic registration provisions and a number of complementary provisions e.g. on updating (e.g. check if actual tonnage, recommended uses, classification, etc fit with the registration), as well as e.g. to check if information in Safety Data Sheets and factual uses at Downstream Users fit with the registration or if art. 31 and or 38 should be enforced

- Information in registrations and notifications of substances in articles, to be able to enforce the provisions in Art 7

- Information in Chemical Safety Reports, to e.g. be able to enforce Art. 31 on requirements for Safety Data Sheets incl. exposure scenarios, and check whether CSR exposure scenarios if respected in fact leads to adequate control at DUs

- Information in reports from downstream users, to be able to enforce art. 38

- Information in evaluation decisions on testing to be conducted and further information to be given in to ECHA, in order to be able to enforce such decisions.

- Information in authorisations (companies, customers, uses, conditions), to be able to enforce the authorisation provisions and individual authorisation decisions 


\subsection{Access options}

Tthis section is an extract from document CWG/33/2007 by COM/DG ENT

Based on the analysis and design of REACH-IT and the discussions held in the Security Officers Network, the Commission services propose to ECHA that external parties can be granted limited access to REACH-IT under strictly defined conditions.

REACH-IT will have several user profiles that can be assigned to external parties. Those profiles precisely define what data the external parties are allowed to access and what actions on this data are allowed or denied. In some cases online access will not be necessary and data can be provided in another form.

An external party in this context of REACH-IT is a person not employed by the European Chemicals Agency (ECHA) or a Member State Competent Authority (MSCA) requiring access to REACH-IT business data that is not available in the public dissemination site. These persons must have been contracted either by the Agency or an MSCA to perform a task for them under the REACH legislation and they therefore require having wider, but defined access than the general public. The contract must also contain a paragraph explaining the secrecy agreement, i.e. that data from the REACH-IT system cannot be used in another context or shared with any other parties.

Enforcement authorities which have a legal obligation to enforce REACH will not be considered to be contracted as external parties but do fall under the definition of external party.

\section{Controlled access of external parties}

The online access of users can be limited so that only parts of a dossier are viewable to them or that they will only be able to access a certain set of dossiers, based e.g. on the location of the production site. Therefore online access to REACH-IT can be granted to an external party requiring it. Granting access to such a user can be achieved exactly the same way that standard MSCA or ECHA users request access to REACH-IT, but their account will only grant them limited access and will only be valid for a short period of time. The MSCA or ECHA user administrator can define this time, when the new user account is created and the role assigned.

In practice this means that external parties must be working in the premises of the Agency or an MSCA, when they require access to REACH-IT. The subgroup on MSCA connectivity discussed in more detail the possibilities that different MSCAs have to gain access to REACH-IT. The identities of external parties will be verified and the MSCA decides what level of access they require. The definition about the 
level of access to business data is partly driven by the external party itself, so that they will request access to a specific data set and the MSCA or ECHA will evaluate if the need is legitimate. As a general rule the external parties will belong to a user group that only has limited access to business data. The exact fields will be identified separately for each external party. In the long run external party access groups can be defined based on gained experiences.

All external parties who will gain online access to REACH-IT must sign "external party access request" and "non-disclosure agreement" forms that will explain them inter alia that data must be kept confidential and that their actions in the REACH-IT system will be traced.

In some cases direct access to REACH-IT will not be necessary when e.g. only a limited subset of the business data is needed to perform the task at hand. For this purpose there will be a mechanism in REACH-IT to create pre-defined Business Object (BO) reports that will have some fields, considered confidential for the current purpose, filtered out. These reports can be generated, by MSCA or Agency staff having the correct role, from the business data and will contain various options to compare different data sets. Exports from the REACH-IT system will be logged and traceable so that it will be possible to see who exported what data and when. Of course once the data is out of the REACH-IT system, it will be beyond its control. Since the information is limited and the external party has signed agreements, the security risk of information leaking out in the form of $\mathrm{BO}$ reports is limited.

All the methods above refer either to online viewing of data or downloading data in the form of business reports. Downloading a full dossier from REACH-IT to be used e.g. in a local IUCLID5 installation can also be an option, but in these cases there must be a clear justification why online view access or BO reports do not cover the needs on the external party in question. An authorisation method for this needs to be defined.

Once the security procedures have been set-up and ECHA is operational it could be foreseen that an auditing firm would be contracted to perform an audit. The purpose would be to verify that agreed procedures regarding access to data are strictly followed in ECHA and MSCAs.

\section{Enforcement authorities}

In the context of REACH-IT the enforcement authorities are considered to be external parties and therefore will follow exactly the same procedure as described above in 0 . However as described above the online access to REACH-IT can only be allowed from the premises of the MSCAs. Therefore the enforcement authorities must also perform their work in the premises of the MSCAs or discuss with the MSCAs to get the information in the form of BO reports. Since enforcement is very much a 
national issue the enforcement authorities must contact their local MSCA for the necessary practicalities. The topic of enforcement has been discussed in more detail in the CWG subgroup on enforcement.

\subsection{Interrelation between organisational structure and access}

To explain this, the situation in the MS participating in the project may be described:

In Netherlands, VROM (the Ministry for Housing, Spatial Planning and the Environment) is the competent Authority for REACH. VROM will be supported in this task by the National Institute of Public Health and the Environment (RIVM).

RIVM has a Bureau REACH which by order of VROM will perform all national REACH tasks and have the access to REACH-IT. The Bureau REACH will make all necessary information out of the REACH-IT system available to the Partnership for REACH Enforcement Alliance (SHR).

SHR is a structure (not entity) for joint enforcement of the REACH regulation, to be executed by the Labour Inspectorate (AI), Inspectorate for Housing, Spatial Planning and the Environment (VI), and the Food and Consumer Product Safety Authority (VWA). There is an REACH Enforcement Steering Group (StHR) consisting of representatives from these inspection services, which will conduct actual enforcement in accordance with agreements made within the StHR.

Note: SHR is considered essential for proper implementation. Examples of functionalities: Updating the enforcement strategy; Drawing up a (long term) enforcement programme in coordination with the enforcement services and advising on the drawing up of concrete project plans; Contact point for the policy directorates on the development of REACH enforcement; Contact point for ECHA and Forum; Monitoring/gathering information on compliance (e.g. from enforcement campaigns and from the help desk); Answering enforcers' queries so as to prevent divergent interpretations of REACH; Providing training for enforcers from VWA, $A I$ and VI; Communication with the enforcers, and the provision of information to them.

In Ireland, the Health and Safety Authority (HSA) is the designated competent authority (DCA) for REACH. In addition the HSA is the enforcement authority for occupational health and safety and currently enforces such legislation e.g. regarding chemicals safety. It is envisaged that

ECHA will give the HSA full access to REACH IT. The HSA has a REACH IT co-ordinator who will determine the various access levels required and its enforcement inspectors (who are based in a number of 
locations) will be given an access level as determined to be appropriate by this co-ordinator.

Other CAs who may require access to REACH IT (such as the Environmental Protection Agency EPA, Pesticides Control Service etc) will have an account with ECHA setting out their access level to REACH IT information. They will have to visit their local HSA office to gain access to REACH IT and they will use their own account No / password to gain the required access.

In Denmark, the Danish Environmental Protection Agency (EPA) is Competent Authority for REACH and will have full access to REACHIT.

Enforcement of REACH will be carried out by the Chemical Inspections Service and the Danish Working Environment Authority. Since the Chemical Inspection Service is a part of the Danish EPA, it will have full access to REACH-IT. The Working Environment Authority though will not have direct access to REACH-IT. It is planned that all necessary information from REACH-IT will be made available for the Working Environment Authority and local Autorities by the Danish EPA on request. There are still no written procedures for the cooperation, but this will be made when access to REACH-IT is a reality.

In Sweden, the Chemicals Agency (KemI) is competent authority for REACH and will have full access to REACH-IT. KemI has been responsible for enforcement of the old chemicals legislation with respect to manufacturers and importers of substances and preparations and is provisionally responsible for REACH enforcement. County Administrative Boards (regional authorities) are responsible e.g. for enforcement of environmental legislation such as IPPC with respect to large companies and for parts of the old chemicals legislation. Local environmental authorities are responsible e.g. for enforcement of environmental legislation such as IPPC with respect to small companies and for other parts of the old chemicals legislation. Work Environment Authority is responsible for enforcement of legislation on occupational safety including chemical hazards and has a regional organisation.

A proposal for how to organise enforcement of REACH will be given by a governmental investigation in June 2008, and might be implemented in 2009. At present, it is not possible to say how this will affect enforcers' access to information in REACH-IT. Though, it is quite possible that responsibilities will be given to a number of the present organisations, which then will have no direct access to the information, unless this can be arranged in some way.

From the above can be understood that the organisational structure for enforcement of REACH has major influence on the possibility for fast/easy access to the information. 


\subsection{Some considerations/conclusions}

From the preliminary analysis made during the work with the report on Priority Articles, it is rather obvious that there will be an extra need of information given in by and/or related to $\mathrm{M} / \mathrm{I}$ and DU in the own MS, and also a rather extensive need for information related to any substance on the market in the own MS or used by a DU in the own MS. There will probably also be needs for follow up actions by ECHA and/or enforcers in another MS towards the M/I (or formulator DU) who did put the substance or preparation on the EU market. This means needs to hand over information on non-compliance (may be of a confidential nature) to ECHA and/or another MS.

To describe the needs more precisely will most probably be necessary, in order to get a basis for discussions on which access options that might be needed. To do this, a number of questions will be necessary to answer, such as e.g.:

- Which is the enforcement situation?

- What question(s) will be raised during that enforcement situation?

- Which information from REACH-IT is needed to answers the question(s)?

- What way to access the information would be most efficient?

- Implications of not being able to access the information in the most efficient way?

Theoretically, a number of ways to access information might be envisaged, such as

- On-line access directly at the Enforcement authority to all or only parts of REACH-IT

- On-line access at the MS CA only, to all or only parts of REACH-IT

- A downloaded "Business Object" (BO) report in the form of a database

- A downloaded "Business Object" (BO) report on paper only

According to the COM proposal mentioned above, direct on-line access at the premises of Enforcement authorities is excluded unless the authority is part of the MS CA. Instead, they will have to work on-line in the premises of the MS CA, or get a $\mathrm{BO}$ report.

The implications for the efficiency of enforcement from such limitations for access to information need to be analysed in depth. However, it seems obvious that where enforcers only have indirect access to the needed confidential information (via the MS CA who will have to retrieve the information from REACH-IT and pass on information in the form of special BO reports), this may lead to a number of problems. 


\section{Proposals for Forum projects}

From REACH Enforcement Workshop 24-25 September 2007:

- Proposals by the discussion group on projects

\subsection{Introduction}

The establishment of the Forum is set out under Article 86 of the REACH Regulation. The tasks to be performed by the Forum are described in article 77.4 of the Regulation. These tasks are:

a. spreading good practice and highlighting problems at Community level;

b. proposing, coordinating and evaluating harmonised enforcement projects and joint inspections;

c. coordinating exchange of inspectors;

d. identifying enforcement strategies, as well as best practice in enforcement;

e. developing working methods and tools of use to local inspectors;

f. developing an electronic information exchange procedure;

g. liaising with industry, taking particular account of the specific needs of SME's, and other stakeholders, including relevant international organisations, as necessary;

h. examining proposals for restrictions with a view to advising on enforceability

A first draft proposal for Rules of Procedures (RoP) for Forum was handed over to the Forum secretariat at ECHA 5 November, after drafting by the REACH EU Enforcement Project and incorporation of viewpoints from the Commission and Member States, including at the last meeting with the sub-CWG Enforcement. Section 8 of the RoP paper outlines proposals for "Working Groups and Projects".

The aim of this new paper is to assist the Forum in its start-up phase and to allow it to select projects as quickly as possible based on proposals from the recent REACH Enforcement Workshop held in Brussels 24/25 September 2007 back-to back with the last meeting with the sub-CWG Enforcement. The workshop was organised by the project, hosted by the Commission, and included e.g. a session on "Ideas on Enforcement Projects for the Forum to Co-ordinate". 


\subsection{Proposed projects}

Project topic to be announced up to one year in advance:

This arose following discussion on the time delay between Forum meetings ( 2 per year). It was suggested that the initial meeting will probably be dealing with Rules of Procedure etc. so that it may be late 2008 before the Forum will be in a position to start projects. To overcome this delay it was suggested that Forum topics be announced as early as possible so that member states could decide early which projects they wished to be performed and which they wished to participate in.

\section{Development of Guidance Document:}

It was suggested that a REACH inspection guidance document be prepared as a Forum project to assist in harmonisation of enforcement as set out in Article 77.4(b). An example was cited of the guidance document prepared by the European Chemicals Bureau for the enforcement of the Seveso (Control of Major Accident Hazards to Man and the Environment) Directive.

Development of a Report Template: (2008)

This was suggested as an early (2008) project for the Forum. Article 117 sets out that each member state must report back to the Commission by 01 June 2010 on the operation of the REACH Regulation. Article 127 says the common issues to be covered in the report shall be agreed by the Forum. The early availability of a report template would ensure each Member State is recording the relevant information to assist in the compilation of the 2010 report.

\section{Project of Co-operation with Customs:}

It was agreed that Customs have a role to play in the successful implementation of the REACH Regulation as they are the frontline point of entry of chemicals to the EU (passing the outer Borderline of the EU). However it was noted Customs Codes refer to product classes and would not be readily able to identify substances to which Registration, Authorization or Restriction apply. A project was suggested for the Forum to develop a process which could assist Customs throughout the EU to identify such substances more easily so inspection of compliance with the REACH regulation can take place.

Comment: Customs will also have difficulties to identify articles affected by the above provisions as well as by the Article 7 and 33 provisions in REACH. The project thus ought to include also identification of articles concerned. 


\section{Harmonisation of Level of Capabilities:}

It was noted that there is differing levels of enforcement capabilities throughout the Member States as there may also be a number of agencies enforcing different aspects of the REACH regulation. A project to assist in harmonization of these capabilities was suggested. Suggestions included

a. transfer of enforcement inspectors between member states and

b. centralised training to be provided by ECHA.

Comment: It should also be noted that there is an ongoing process to review the recommendation for minimum criteria for enforcement/inspections with respect to environmental legislation and that the question has been raised whether it would be beneficial to include such criteria also with respect to REACH. It seems appropriate that this question is discussed by Forum, and potential criteria might possibly be elaborated under the umbrella of a project.

\section{Develop basic Training Kit:}

A project was suggested to develop a basic training kit for enforcement inspectors. This could be in the form of a Proforma type questionnaire.

Proposal for project to Forum on SDS (2009).

It was noted that up to $50 \%$ of existing safety data sheets (SDS) are inadequate. It was suggested that the Forum prepare a project throughout the member states to identify the level of adequacy of SDS and proposal for improvement.

\section{Identification of target groups for inspection}

It was noted importers and SME's (Small, medium enterprises) were difficult groups to target for enforcement of the REACH Regulation. It was suggested that the Forum prepare a project to assist member states in the targeting of these groups.

In addition it was suggested that a project may be prepared focussing on the usage of chemicals in the construction industry to raise awareness in this sector. 



\section{Draft Proposal for Forum Rules of Procedure (31 October, 2007)}

The Forum,

Having regard to article 76.1 (f) of REACH (no 1907/2006), hereafter to be named "The Regulation", which states the establishment of a Forum on exchange of information on enforcement, as a part of the agency (ECHA).

Having regard to article 77.4 which designates specific tasks of the Forum

Having regard to article 86 which specifies how the Forum shall be established, including that it shall draft its own rules of procedures (article 86.4), and that these Rules of procedures have to be adopted by the Management Board of ECHA.

Having regard to that with respect to the membership of the Forum, article 88 provides rules on the publication of the membership and the commitment of the members to their duties and declaration of interests

Having regard to that article 105 states the duties on the matter of confidentiality, and that article 118.1 states that EC/1049/2001 (concerning transparency and accessibility of information) is also applicable to documents of ECHA. Since the Forum is part of ECHA, these rules also apply to the Forum.

Having regard to that articles 106 and 107 open the possibility for participation of third countries and observation of international organisations in the work of the agency and consequently the Forum. These operating procedures describe how the Forum deals which such requests.

Having regard to that specific rules already laid down in the Regulation should not be repeated unnecessarily in these Rules of Procedures.

Having regard to that in performing its tasks the Forum does not make decisions on the use of resources of the Member States. Resources of Member States can only be used on a voluntary basis.

HAS ADOPTED THE FOLLOWING RULES OF PROCEDURE: 


\section{Tasks of the Forum}

The Forum shall, to the best of its abilities perform the tasks described in article 77.4 of the Regulation. These tasks are:

a. spreading good practice and highlighting problems at Community level;

b. proposing, coordinating and evaluating harmonised enforcement projects and joint inspections;

c. coordinating exchange of inspectors;

d. identifying enforcement strategies, as well as best practice in enforcement;

e. developing working methods and tools of use to local inspectors;

f. developing an electronic information exchange procedure;

g. liaising with industry, taking particular account of the specific needs of SME's, and other stakeholders, including relevant international organisations, as necessary;

h. examining proposals for restrictions with a view to advising on enforceability

\section{Composition}

\subsection{Members}

2.1.1. The Forum consists of one Member per EU Member State, appointed by the Member States in accordance with Article 86.1 of the Regulation for a three-year term.

2.1.2. Beside members appointed per Member State, the Forum can appoint up to five additional members, chosen on their specific competence, which are appointed for a three year period.

2.1.3 Before appointing an additional Member as mentioned in article 2.1.2 the Forum shall establish the specific need for expertise.

2.1.4 Any member or the Management Board of ECHA may propose candidates, i.e. parties or natural persons, to fulfil the position of additional Member.

2.1.5 In the appointment of additional members measures are taken to ensure their independency and integrity. When submitted to the Forum, a proposal for a candidate for the position of additional member is adjoined with the declarations of commitment, interests and confidentiality. 
2.1.6 When the independency or integrity of an additional Member has been questioned, the Forum can decide to withdraw its appointment.

\subsection{Replacing the members}

2.2.1. Each member shall have an alternate appointed by the respective institution of origin. Alternates have the same rights as members

2.2.2 Additional members are appointed on the basis of their specific expertise. Alternates can therefore only represent this Member if the Chairperson has approved the replacement.

\subsection{Advisors}

2.3.1. Where appropriate, considering the topics that are foreseen by the Forum meeting agenda, members may be accompanied by technical / scientific advisors.

\subsection{Observers}

\subsubsection{Definitions}

- Observers: All participants of Forum meetings who are not members or their advisors

- Category A observers:

o The executive Director of ECHA or his representative

o Up to three (Note: arbitrary amount) representatives of the European Commission

o Third Countries who have been invited on the basis of article 106 of the Regulation and whose attendance is approved by the Forum (see art 2.4.3)

- Category B observers are all other stakeholders that are invited by members of Forum or the Management Board of ECHA and international organisations who are invited on the basis of article 107 of the Regulation (example: participants representing third countries, representatives of other networks or EC Agencies in adjacent fields of work, acting under or guided by the Commission, and other stakeholders with an interest in the $\mathrm{REACH}$ regulation)

2.4.2. Observers may attend meetings, participate in discussions and access the meeting documents, but cannot vote.

2.4.3 Invitations on the basis of articles 106 and 107 of the Regulation are subject to approval by the Forum.

2.4.4 When considered necessary, members can request the chairman of Forum to close specific parts of meetings and documents for category B observers (and for observers from third countries). Such a decision is subject to (2 options) a majority vote / decision of the Chair 
NOTE: It has to be made clear whether there should be any difference in treatment of third country observers from countries that have adopted REACH via the EEA agreement, and other third countries. Art. 106-107 does not exclude third countries who have not adopted REACH from the possibility to participate as invited observers. Neither does it state that the Forum cannot set preconditions. The fact that its states that agreement is necessary implies that preconditions can be set

\section{Chairperson and Vice-Chairpersons}

\subsection{Selection of the Chairperson and Vice-Chairpersons}

3.1.1. In executing his duties, the Chairperson shall act impartially.

3.1.2. The Chairperson is chosen amongst the members and appointed by consensus or by election for a term of three years with the possibility of re-election. If voting is necessary, to be elected in the first round a member needs a two thirds majority of full members. Should no candidate get the two thirds majority required directly, a second round of full is arranged amongst the two who got most votes. The candidate getting a simple majority of full members present will be elected. At the request of any member the full shall be organized by secret ballots.

\subsubsection{The Chairperson shall be assisted by 2 vice chairpersons.}

3.1.4 The Vice-Chairpersons are chosen among the members and appointed by consensus or by election for a term of one and a half years with the possibility of re-election. If voting is necessary, to be elected in the first round a member needs a two thirds majority of full members. Should no candidate get the two thirds majority required directly, a second round of full is arranged amongst the two who got most votes. The candidate getting a simple majority of full members present will be elected. At the request of any member the full shall be organized by secret ballots

3.1.5 The alternates of the chairperson and the vice-chairperson shall only replace their duties and rights as members and not as a chairperson or vice-chairperson.

3.1.6 When a majority of the Forum agrees that there is reasonable doubt about the integrity or proof on lack of competence of the chairperson or vice-chairpersons, he or she can be removed from his duties. 
3.1.7 In the occasion that the chairperson as well as both vicechairpersons are unavailable, the members will choose an ad-hoc chairperson. This person will only obtain the rights of chairperson for the time the chairperson and the vice-chairpersons are unavailable.

\subsection{Responsibilities}

3.2.1 The Chair, which consists of the chairperson and the two vicechairpersons, and which is supported by the Forum secretariat at ECHA, is responsible for the efficient conduct of the business of the Forum and shall in particular:

1. plan the work of the Forum, including the meeting dates together with the Forum Secretariat and full members;

2. determine the agenda of the Forum meeting

3. chair the meetings of the Forum;

4. ensure that these operating procedures are respected;

5. ensure that at the beginning of each meeting any potential conflict of interest is declared, regarding any particular item to be discussed by the Forum;

6. strive, in close cooperation with the Forum Secretariat, for consistency of the Forum's conclusions;

7. take decisions concerning the participation of Observers in the Forum meetings, considering any objections from the members of the Forum to the observers participation in specific agenda points.

3.2.2. The Vice-Chairperson will take the responsibilities of the Chairperson when the latter is unable to do so. On such occasions, the Chairperson will inform the Vice-Chairperson and the Forum Secretariat as early as possible.

\subsection{Mandate}

The chairperson and the vice-chairpersons are authorized to speak on behalf of the Forum to other parties. Individual Members can be mandated by the Forum to speak on behalf of the Forum for specific issues and / or occasions.

\section{Forum Secretariat}

4.1 The Forum Secretariat will be provided by the ECHA. It shall, inter alia:

- Provide organisational and administrative support to the Forum, its Chairperson and Vice-Chairperson, and its working groups and project groups in particular by 
0 organising meetings of the Forum and its working groups and coordinating their work;

0 ensuring timely availability of draft agendas and meeting documents;

0 preparing the minutes of the meetings in consultation with the Chairpersons and circulating them within the set deadline;

o managing written procedures and report about its result;

o proposing modification of the working procedures if needed;

0 arranging the pre-selection of candidates for additional members;

0 propose effective modes of action.

- Manage the input of ECHA questions (example: on restrictions) towards the Forum.

- Support the preparation of proposals from working groups or projects towards the Forum

- Co-ordinate the work of the Forum with that of the other services of the ECHA and other bodies established under Community law.

- Take minutes of the Forum meetings

- Manage the communication between the Forum and other committees under the Regulation and other EU Networks

4.2 The ECHA will nominate the staff members of the Forum Secretariat. The Secretariat members take part in the Forum meetings.

\section{Meetings}

5.1. The Forum shall normally convene at the ECHA premises. Where applicable and technically possible, other meeting forms than face-to-face may be chosen. On invitation of a Member State, under the condition that this Member State covers the additional organizational costs, the Forum can convene in another location.

5.2. The invitation including the draft agenda of the meeting shall be circulated at least 1 month before the meeting. The meeting documents will be made available at least 14 days before the meeting. Draft agenda and meeting document will be made available at CIRCA / ECHA homepage.

\subsection{Agenda's}

5.3.1 Members can put in requests for matters to be included in the agenda. Requests shall be submitted to the chair (Note: this could be limited in time, when done so article 5.3.2 should be revised or removed. A 
possible text could be: no later than 14 days before the date of the meeting. Later submission of items is subject to approval of the chair)

5.3.2 Items may be added to the agenda at any time before the end of the meeting with the agreement of the chairperson, and items on the agenda may be deleted or carried over to a subsequent meeting.

5.3.3 Any request by one or more members for inclusion, deletion or replacement of an item on the agenda shall state the reasons on which it is based. The chair shall bring any such request to the notice of all Members.

5.3.4 Having taken into account the requests by members for inclusion, deletion or replacement of items, the chairperson shall take the final decision on the agenda.

5.4. Draft minutes will be circulated within 1 month after the meeting.

5.5. When a member of the Forum is unable to participate in a meeting, part of meeting, or in the discussion of a specific topic because of a conflict of interest, he/she has to inform the Forum Secretariat in advance in writing. The Chairperson of the Forum will decide how to handle the issue on a case by case basis. He/she may consult the Vice-Chairperson and the Forum Secretariat. If the Chairperson has a conflict of interest, the first Vice Chairperson replaces him or her.

\section{Written procedure}

6.1. The Forum can agree by written procedure. To this end the Forum secretariat, upon agreement by the Chairperson, shall send the members the draft documents on which their opinion is sought.

6.2. In the context of a written procedure, draft documents are addressed to all members of the Forum, who may comment within a specified time period that normally will be not less than 2 weeks. The Chairperson may request a shorter deadline in duly justified cases. Any full member who does not comment within the set deadline is considered to have given his/her tacit agreement to the document. A document is agreed by consensus when the members have agreed, expressively or tacitly. The majority and minority opinions will be duly recorded in the written procedure report. The chair shall present a full report on the outcome of the written procedure at the following meeting of the Forum.

(Example: Advice on restrictions cannot wait half a year) 


\section{Work program and reports}

7.1 The Forum shall establish a work program for the period of three years. The first work program shall be established before the $1^{\text {st }}$ of October of 2008 (note: this date is arbitrary).

7.2 During the 3-year period the work program must be regularly reviewed and adapted when appropriate.

7.3 When a majority of the Members finds it appropriate the Forum can make a publicly available yearly report on the activities of the year before outside the regular ECHA-report.

\section{Working groups and Projects}

8.1 Where appropriate, the Forum may establish working groups or project groups.

\subsection{Definition}

- Working group: a group with a specific mandate and task going on continuously

- Project group: a group with specific non-recurring tasks within a specified time limit

8.2.1 Working groups are composed of volunteering members of the Forum, their alternates and/or advisors, depending on the required expertise, or third countries invited, and approved, on the basis of article 106 of the Regulation. They are to be chaired by a member of the Forum.

8.2.2 Project groups are composed of volunteering members of the Forum, their alternates and/or advisors from MS, or third countries invited, and approved, on the basis of article 106 of the Regulation, depending on the project.

8.3 Any member can propose working groups or projects with the goal to contribute to the tasks mentioned in article 77.4 or participate in them.

8.4 In order for a project to be adopted by the Forum, and consequently being supported by the Forum Secretariat, at least 3 Member States should participate in this project.

8.5. The mandate and the objectives of each working group or project and the duration of their activity shall be determined and reviewed periodically by the Forum. The decision establishing the mandate and objectives 
of each working group shall also include its composition and will be recorded in the minutes of the related meeting of the Forum.

8.6. Each working group and every project group shall present the results of its work in the Forum meeting either during the meeting or via the written procedure. The minutes of the working group or project group meetings are available to the Forum.

8.7 When a majority of the members find it appropriate the Forum can establish specific operating procedures to perform the tasks stated in article 77.4. (Note: Several countries feel that this should be elaborated in these RoP's similar to art 8.8)

(Option: this article could probably also be placed in operating procedures, see art 10. Several countries however consider projects, and also other tasks of the Forum, of such importance that it should be placed in the RoP's)

8.8 Specifically to tasks under $77.4 \mathrm{sub} \mathrm{b}$ and $\mathrm{c}$ the Forum may establish a format for proposal and reporting of projects, joint inspections and exchange of inspectors. The format for proposals may specifically go in to the objectives, the activities, the added value of these activities above the Members States individual activities and the commitment of participating Member States towards the objectives and the expenditure in time. Also a description of the coordination with other EU Networks (examples: SLIC, Impel, CLEEN, Customs) should be given.

\section{Disbandment of working groups and/or projects}

8.9 The support for projects and working groups by the Forum and consequently of the Forum Secretariat can be halted when a majority of the Forum finds the continuation no longer beneficial to the goals of the Forum. Such disbandment may however be subject to specific agreements with third parties working for a specific working group or project group.

\section{Forum conclusions}

9.1 The Forum will generally draw its conclusions by consensus. If this cannot be realised, conclusions are drawn through voting. The majority and minority opinions will be duly recorded in the meeting minutes.

9.2 Unless stipulated otherwise, when the text refers to a majority, it means a more than $1 / 2$ of the Members. 
9.3 A quorum of at least $1 / 2$ of all Full Members shall be physically present in order for conclusions of the meeting to be valid.

\section{Operating Procedures}

10.1. Where appropriate the Forum may establish operating procedures to ensure the proper course of action. 


\section{Swedish summary - Sammanfattning}

Den nya europeiska kemikalielagstiftningen,Reach, innebär en betydande omstrukturering och utökning inom lagstiftningsområdet för kemikalier, och därmed också för tillsyn. Tidigt uppmärksammades betydelsen av att ett forum för informationsutbyte om verkställighet (kallat Forum) inrättats i och med Reach.

Därför föreslog Sverige på ett CWG-möte (Kommissionens arbetsgruppsmöte för implementering av Reach) i november 2005 att ett Reachimplementeringsprojekt om tillsyn skulle påbörjas. Initiativet ledde till att projektet "Reach EU Enforcement" startades i mars 2006 och att kommissionen inrättade en subgrupp till CWG i syfte att förbereda tillsyn av Reach.

Syftet med projektet (se projektplan, Annex I) var att:

- Identifiera nuvarande tillsyn och nya behov pga Reach

- Undersöka medlemsstaternas förberedelser inför tillsyn samt förbereda Forums arbete

- Utarbeta arbetsfördelning, samarbete och informationsutbyte

- Ta fram ett förslag till "Rules of Procedure" för Forum

- Utarbeta ett kompendium av användbara tillsynsmetoder

För att nå dessa mål utfördes ett antal olika aktiviteter som t.ex. workshops, undersökningar, intervjuer m.m. i syfte att ge Forum en "flygande start".

Projektet har bl.a. resulterat i flera separata rapporter som infogats $\mathrm{i}$ denna slutrapport (kapitel 3-10): Prioritering Reach-tillsyn, Kompetens/utbildning, Metoder/verktyg, Gränsdragningar, Larmsystem, ReachIT, Förslag Forum-projekt samt Förslag"Rules of Procedure" för Forum. Kapitel 1 sammanfattar de individuella rapporterna (se nedan svensk översättning). Bilagt till rapporten finns projektplan, mötesanteckningar från workshops och den den presentation av projektet som hölls på Forums första möte i december 2007. 


\section{Sammanfattningar av kapitel 2-10:}

\section{Bakgrund (kapitel 2)}

Kapitlet innehåller en beskrivning av de krav som Reach ställer på medlemsstaterna samt ECHAs roll då det gäller tillsyn Det innehåller även en beskrivning av det arbete som gjorts i detta projekt.

\section{Prioriteringar Reach-tillsyn (kapitel 3)}

Rapporten går igenom artiklarna i Reach med syfte att bidra till att identifiera de som är viktigast att utöva tillsyn över för att Reach ska fungera tillfredsställande. Rapporten försöker också analysera faktorer (t.ex. tolkningsproblem) som kan försvåra eller omöjliggöra tillsyn, och även identifiera några informationsbehov från Reach-IT. Ett utkast av rapporten användes som underlag för diskussioner i en workshop. Resultaten från diskussionerna har införlivats i rapporten.

\section{Kompetens/utbildning (kapitel 4)}

Denna rapport består av en kort analys av de olika tillsynssituationer/frågor som inspektörer kan komma att ställas inför, samt ger några preliminära reflexioner och slutsatser då det gäller kompetens- och utbildningsbehov för olika typer av Reach-tillsyn. Rapporten baseras bl.a. på diskussioner under workshoparna. Syftet är att bidra till medlemsstaternas uppstart av Reach-tillsyn.

\section{Metoder/verktyg (kapitel 5)}

Denna rapport utgör en första version av ett kompendium om metoder och verktyg som, enligt intervjuer och diskussioner på workshoparna, skulle kunna bli ett användbart verktyg. En process att utveckla och uppdatera kompendiet föreslås. Kompendiet skulle även kunna användas som en referensram då det gäller utbyte av information av bra tillsynsrutiner.

\section{Gränsdragningar (kapitel 6)}

Rapporten beskriver och diskuterar oklara gränsdragningar mellan ECHA och nationella tillsynsmyndigheter i förhållande till Reach-tillsyn. Den diskuterar också Forums roll och gränsdragningar mellan tillsynsmyndigheter inom en medlemsstat. 


\section{Larmsystem (kapitel 7)}

Denna rapport beskriver några relevanta existerande larmsystem; RAPEX, ICSMS och EUVICHEM. Syftet med rapporten är att förbereda diskussioner om behov av ett larmsystem, och existerande alternativ, för att komplettera andra metoder för informationsutbyte mellan tillsynsmyndigheter.

\section{Reach-IT (kapitel 8)}

Rapporten innehåller några första tankar om vilket behov inspektörer har av konfidentiell information i Reach-IT samt möjlighet att erhålla sådan. Den diskuterar också sambanden mellan organisationsstruktur och tillgång till information. Syftet med rapporten är även att fungera som diskusionsunderlag för kommande arbete inom Forum som rör Reach-IT och tillsyn.

\section{Förslag Forum-projekt (kapitel 9)}

Denna rapport sammanställer förslag på projekt att driva under Forum i uppbyggnadsfasen. Förslagen togs fram i andra workshopen i projektet och som exempel kan nämnas: utarbeta ett rapportformat enligt artikel 127 , ta fram ett utbildningskit för inspektörer samt projekt rörande säkerhetsdatablad.

\section{Förslag "Rules of Procedures" för Forum (kapitel 10)}

Rapporten innehåller ett förslag till "Rules of Procedure" för Forum. Under utarbetande av förslaget studerades existerande "Rules of Procedures" och relevanta delar av dessa inarbetades i förslaget. I november 2007, innan Forums första möte, överlämnades förslaget till Forums sekretariat på ECHA. 



\section{Annex I - Project Plan}

Swedish Chemicals Inspectorate July 5, 2006

Ireland Health and Safety Authority

Danish Environmental Protection Agency

Netherlands ministry of housing,

spatial planning and the environment

\section{EU project on enforcement of REACH}

\section{Background}

The REACH proposal of the Commission is a significant restructuring and enlargement in the field of chemicals regulation. It is essential for the function of the common market that necessary market surveillance, in a way as similar as possible, takes place in all member states, to ensure that the regulations are obeyed. Together with the short formulations regarding enforcement that always are part of a proposed legislation, the REACH proposal also contains a new actor, the Forum. (Title IX together with the three articles of title XIII) This is an important statement showing that the Commission has identified the need of a new body in the field of enforcement. It is necessary that the start of the Forum is not delayed; its functions should go along with the start of the Agency. It is especially important that those institutions are well prepared and workable in the first period when REACH enters into force.

An overview of REACH from an enforcement perspective would ultimately also work as guidance to enterprises, especially small and medium sized.

It is not possible to foresee to which extent the Forum will influence enforcement, derived from the tasks formulated for the Forum in the REACH proposal title IX, article 73.4:

4. The Forum shall undertake the following tasks:

a. spreading good practice and highlighting problems at Community level;

b. proposing, co-ordinating and evaluating harmonised enforcement projects and joint inspections;

c. co-ordinating exchange of inspectors; 
d. identifying enforcement strategies, as well as best practice in enforcement;

e. developing working methods and tools of use to local inspectors;

f. developing an electronic information exchange procedure;

g. liaising with industry and other stakeholders, including relevant international organisations, as necessary;

h. examine proposals for restrictions with a view to advising on enforceability.

The companies will both due to mandatory handling regulations but also in many other aspects most certainly typically address the Agency directly. Many handling procedures and decisions like registration and authorization will thereby directly enter into force in the whole common market. The enforcement authorities of the MS act solely on a national basis. This in turn means that decisions of the Agency might be dealt with in different ways by enforcement authorities of the MS. A compilation on enforcement methods of REACH might reduce such problems.

The Forum might become extremely important as an interface in the situations when dealing with cases that have been previously dealt with by the Agency.

\section{PHASE I (pre-project March - June 2006)}

\section{Objectives}

1. Identify state of the art of enforcement at present and new needs due to REACH

2. Plan and prepare for phase II of the project

\section{Tasks}

1. Via the use of a questionnaire to the CLEEN members identify the state of preparation for enforcement under REACH including national projects, identification of appropriate enforcement tools and strategies, education of enforcers, changes to the organisation for enforcement and to the national legislation, etc.

2. Investigate different titles of REACH to identify which new needs of enforcement the REACH regulation will imply, taking into consideration national and other efforts that have already been undertaken to investigate different enforcement aspects of REACH. (Reports from the Nordic Council of Ministers and VROM, NL are available)

3. Report to the June meetings of the CWG subgroup for enforcement ("pre-Forum") and of CLEEN, and discussions in order to launch phase II. 


\section{PHASE II (main project July 2006 to December 2007)}

Objectives

1. Further investigate the state of MS preparation for REACH and start the preparation of the operative work of Forum

2. Elaborate how work division, co-operation, and information exchange could be managed under REACH, including the role of Forum and appropriate tools

3. Make a draft proposal for Forums rules of procedure, as mentioned in art. 85.4. in particularly rules for appointing and replacing the chairman, replacing members and the procedures for delegating certain tasks to working groups.

4. Develop a compendium of efficient enforcement methods in the context of REACH, as to support the MS when carrying out national enforcement activities

Tasks (objective 2)

Part A (from July 2006): Work division, co-operation, information exchange under REACH

- Work division and co-operation under the frame-work of REACH: - Role of the Forum: From the MSs' point of view, what can and should be done, and what not, within the framework of Forum? - Identifying and making clear the borderlines between work by the Agency and work by national enforcement authorities - Work division and cooperation between enforcement authorities affected by REACH such as REACH competent authorities and authorities responsible for enforcement under Occupational Safety legislation, IPPC, Customs

- Information exchange between Agency and MS:- Identify the information needs of various enforcement authorities in Member States with respect to information hold by the European Chemicals Agency (ECA).

o Identify needs of the ECA for information from enforcement authorities in the MS, including on interpretation problems.

o Give ideas for how information-exchange between ECA and the enforcement authorities in the Member States can be designed, included automated exchange via the REACH-IT data system under construction.

- Information exchange between MS:

o Present an outline on how to inform other MS in the form of

0 an alert system, when major deficiencies are found during enforcement with respect to duties related to chemical substances and preparations covered by REACH. 
a) This should include a proposal for an organization of contact points at relevant authorities in the MS. A DRAFT system (EUVICHEM) developed by Spain is already available.

Tasks (objectives 1, 3 and 4) Part B (mainly during 2007): Assistance for the work of the MS enforcement authorities

1. Elaborate a DRAFT compendium of useful enforcement methods, including

0 enforcement strategies

o working methods and tools of use to local inspectors Where possible, it may be useful to indicate experience of competences/resources that might be needed to apply the method.

o The compendium should also include how to record and report

o interpretations and uses of REACH in the MS, especially difficulties to interpret

o the efficiency of various enforcement methods/actions.

0 to the Agency on achieved enforcement results

- Investigate possible new needs of competence (education and/or experience) that enforcement of the REACH legislation might require from inspectors.

- In conducting this task, regard needs to be taken to that REACH

o Includes duties also for DUs of chemicals and for suppliers of articles

o Should result in SDSs that include measures not only to limit exposures in the work environment, but also releases to the environment

o For uses of substances of very high concern may include authorisation conditions comprising measures related to work environment, environment, and consumers.

- Identify what kind of procedures is needed to ensure, that Forum is able to manage the work

1. Elaborate a draft proposal for Forums rules of procedure, which has to be presented and adopted by CWG subgroup before it has to be presented and adopted by the Forum and the Management Board. (to be performed autumn 2007)

- Further investigate the state of MS preparation using the results of phase I and phase II part B, in order to propose methods to perform harmonized enforcement project. 


\section{Part C Workshops}

1. Organise a 1st workshop in Nov/Dec 2006 during a prolonged meeting of the CWG subgroup, in order to have a $1^{\text {st }}$ discussion of the results so far from part A of the work, i.e "Work division, cooperation, and information exchange under REACH"

2. Organise a 2nd workshop in June 2007 during a prolonged meeting of the CWG subgroup, in order to discuss results from both part A and part B

Organise a final workshop in connection to the $1^{\text {st }}$ informal meeting of Forum in the $2^{\text {nd }}$ half of 2007 , to "hand over" the results

Organisation

1. Project Group (SWE, NL, IE and DK. SWE will act as lead within the project

2. CWG sub group acting as a form of steering committee. ES, AT, LV and $\mathrm{NO}$ will act as a more formal reference group in close contact with the project group

3. Informal UK, SLO, and BE will act as a responsegroup.

4. Hired consultant(s) to give administrative support and draft report(s).

\section{Reporting}

All those contributing economically and/or practically, such as e.g. Nordic Council of Ministers and MS in the consortium, to be informed as appropriate on the results.

The CWG sub group to be informed on regular developments of the project and being invited to WS during subCWG meetings.

CLEEN to be informed as well at their annual meetings.

\section{Budget/Financing}

1. Work input and travel to project meetings to be provided for free by project members. Costs to be reduced as far as possible through the choice of meeting time and place.

2. Consultant(s):

o From NKG 40000 Euro for 2006 and possibly the same 2007

o From NL: 10000 Euro for 2006

o From other MS: No promise so far but needed

3. Workshops: To be paid by the Commission pending those meetings of the CWG subgroup on enforcement can be extended to include the proposed workshops. This will be arranged in cooperation with the respective MS in presidency. 
4. Other meetings: Meetings of the CWG subgroup on enforcement, and CLEEN to be organised and paid for by respective responsible organisation. 


\section{Annex II - Minutes from workshop 14-15 December 2006 - Report "Preparing for enforcing REACH"}

\section{Contents}

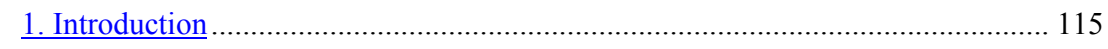

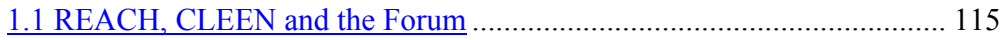

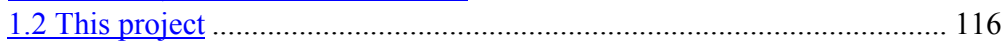

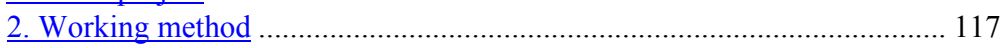

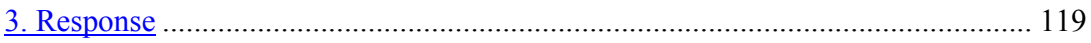

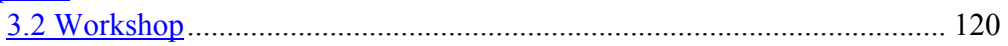

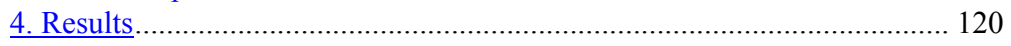

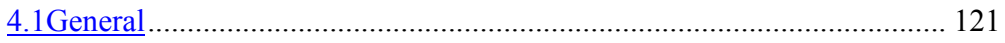

g) Reactions concerning concrete suggestions for the liaising with industry and other stakeholders, including relevant international organisations, as

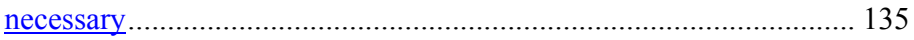

h) Reactions concerning concrete suggestions to examine proposals for restrictions with a view to advising on enforceability........................ 136

4.3 Information Exchange between ECHA and National Enforcement Authorities (NEA) ......................................................................... 142

4.4 Information Exchange between National Enforcement Authorities ........ 145

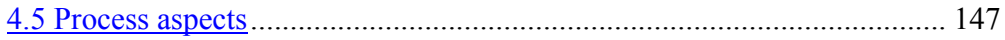

5. Recommendations for the next phase ..................................................... 149

6. Used questionnaire

\section{Introduction}

\subsection{REACH, CLEEN and the Forum}

On June 1st 2007 REACH is expected to come into force. REACH is the Regulation on Registration Evaluation and Authorisation of Chemical Substances and replaces (Parts of) the current directives, like for instance the Dangerous Substances Directive (Directive 67/548/EEC), Dangerous Preparations Directive (Directive 1999/45/EC), the Safety Data Sheet Directive (2001/58/EC) and the Directive on Marketing and Use (76/769EEC).

REACH will require from industry the proven safe marketing and use of chemical substances. The main administrative institute for REACH will be the European Chemical Agency (ECHA), located in Finland. ECHA will be responsible for the overall management of REACH and for 
ensuring the consistent application of REACH by other institutes in the EU. A part of ECHA is the Forum for Exchange of Information on Enforcement, which shall coordinate a network of Member State authorities responsible for enforcement of REACH.

The enforcement of the REACH is to be done by Member State national competent authorities who already are responsible for the enforcement of the current EU chemical legislation. The co-ordination of enforcement activities at a European level is currently undertaken on a voluntary basis by CLEEN, the Chemical Legislation European Enforcement Network. CLEEN is not an official organisation, but CLEEN does foresee a role in preparing for REACH and for the tasks of the Forum.

Participants of the CLEEN network see the opportunity to make use of their existing cooperation in preparing for REACH. By early communication and information exchange the cooperation under REACH can be as good as possible.

\subsection{This project}

Sweden and the Netherlands (both members of the CLEEN network) started up a two-phase project with the objective to establish common understanding of REACH enforcement and to generate rules of procedure and a compendium of enforcement methods. The project group consists of Sweden, the Netherlands, Denmark and Ireland with Sweden acting as project leader. In phase I national preparation activities for REACH enforcement were investigated and the REACH proposal was evaluated for new needs of enforcement.

Phase II has the objective to generate similar measures and tools for REACH enforcement throughout the EU MS. This report is the result of the first part of phase II. The objective of this part was "to elaborate how the work division, co-operation and information exchange could be managed under REACH, including the role of the Forum and appropriate tools". This objective is split-up into three tasks describing relationships between three types of authorities under REACH: ECHA, the MS and the authorities within MS.

The three relationships involved in this project are the following:

- between ECHA and MS;

- between MS;

- between enforcement authorities within MS.

The objectives focussed on the role differentiation, the work division, the cooperation and the communication between the involved parties.

The method of working for this project was by having interviews with CLEEN focal points in EU MS plus Norway, Romania, Bulgaria and Switzerland. The results of these interviews have been presented during a 
workshop of the CWG sub group in December 2006. The results of the interviews and interactive workshop are reported in this report.

\section{Working method}

In cooperation with the project group a list of questions was developed. The questions focused on the ideas that Member States (MS) and other participating countries might have about the role of the Forum and to determine ways of communicating between (1) ECHA and the MS and (2) between the MS themselves (The questions are included in chapter 6 of this report).

The questions were based on a model of the working relations between the various parties. In the following figure these working relations are described schematically.

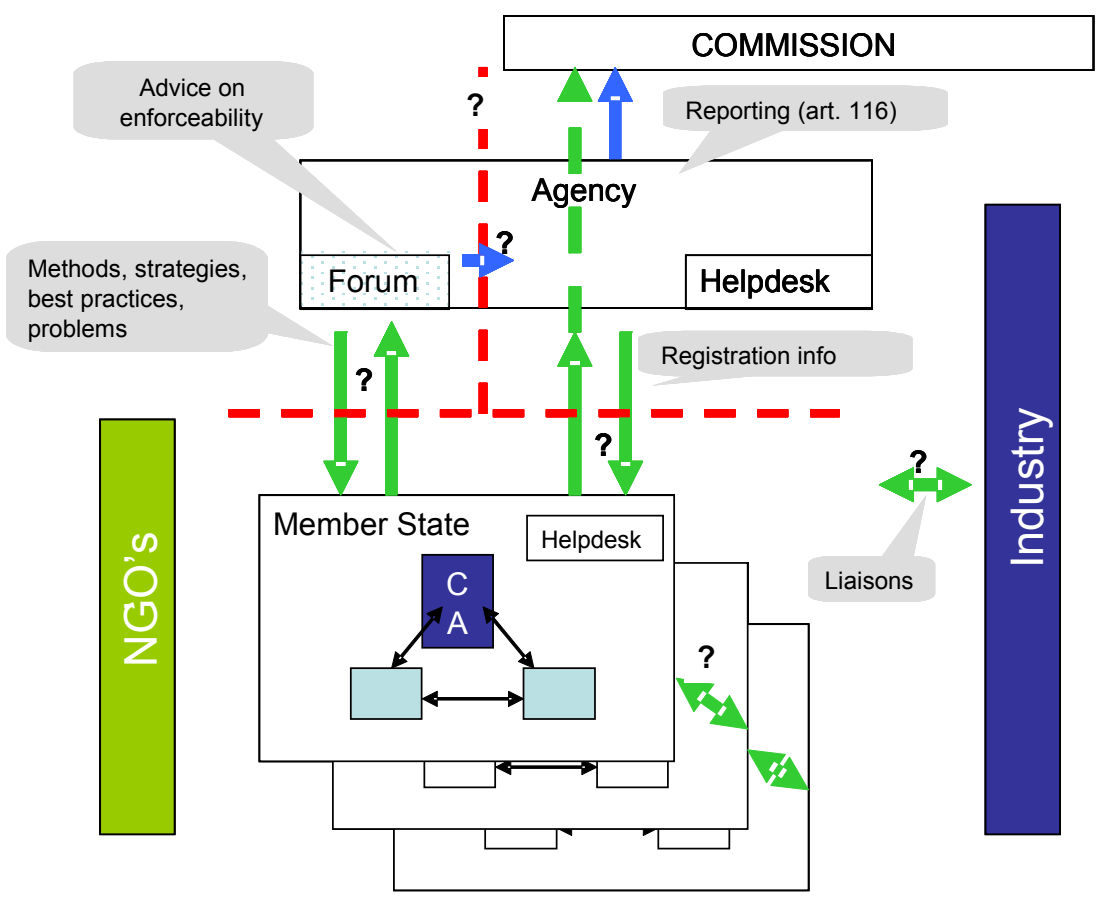




\section{Explanation}

The figure shows the various stakeholders, being: ECHA, the Member States (Enforcement Authority), the Commission and the other stakeholders (industry and NGO's).

The figure shows that the Forum is (according to the text of the REACHproposal) part of the ECHA. The red dotted line shows the borderlines between Forum, ECHA and Member States and the question mark states the uncertainties that appear to be present.

The block Member State shows that even within a Member State there are different parties involved. First there are the Competent Authority (CA) and the Helpdesk. The other blocks represent other authorities with a specific task (for instance Customs or Labour Inspectorates) within the enforcement.

The green arrows reveal communication or information lines. The figure shows that the following information lines are present:

- $\quad$ between Member States;

- between the Forum and the Member States;

- between the other parts of ECHA and the Member States;

- between Member States and the Commission (reporting);

- between the enforcers and the stakeholders (Industry and NGO).

The blue arrows represent specific information lines outside the scope of the Member States.

The list of interviewees was based on the list of CLEEN members. Contact details were listed by the project group. The interviewees were informed by e-mail by the chairman of the project group. After that, all contact persons were contacted to make an appointment for a telephonic interview. Three different consultants from Royal Haskoning conducted the telephone interviews, following an agreed line of questions. Interviews were reported one-by-one and the results of all interviews are put together into this report.

Out of the interviews the various points of discussion could be identified. From these the main issues to be discussed in the workshop were derived. The recommendations out of the interview phase of the projects were incorporated in the agenda the workshop

In order to get answers on the posed question a workshop was held during the meeting of the CWG subgroup on enforcement on the $14^{\text {th }}$ and $15^{\text {th }}$ of December in Brussels.

As recommended the workshop was split up into 2 parts. Part 1, discussed on the $14^{\text {th }}$, was dedicated to questions on a strategic level: looking specifically at the issues of the current phase of the project ('What should we do?"). Part 2, discussed on the $15^{\text {th }}$ was dedicated to the questions on a tactical level, looking forward to the next phase of the project ('How should we do it?"). 
In order to deal with as many questions as possible, the questions were discussed in breakout sessions. A good discussion with input from different angles gives some minimum requirements to the size of the subgroups. Due to the amount of participants, some of the questions as derived form the interviews had to be left out of the discussion.

\section{Response}

3.1 Interviews

In total 22 countries (of 28) participated, of which 17 by telephone interviews and 5 by answering in writing (this is a response of $78 \%$ ). The 22 countries were:

\begin{tabular}{ll}
\hline By telephone: & In writing: \\
\hline Austria & Belgium \\
Cyprus & Bulgaria \\
Czech Republic & Italy \\
Denmark & Slovenia \\
Finland & Spain \\
Germany & \\
Greece & \\
Ireland & \\
Lithuania & \\
Norway & \\
Poland & \\
Romania & \\
Slovakia & \\
Sweden & \\
Switzerland & \\
the Netherlands & \\
United Kingdom & \\
\hline
\end{tabular}

In addition to that, France, Hungary, Latvia, Malta, Portugal and Estonia could either not be contacted during the project time period or had other difficulties in answering the questions. Yet, none of the countries stated that they had no interest in participating in this project.

With respect to the written answers, one questionnaire (of the 22) was received outside the time limit for the report. However the results are covered by the other answers. 


\subsection{Workshop}

In total 19 countries (of 28) participated in the workshop. The 19 countries were:

$\begin{array}{ll}\text { Belgium } & \text { Lithuania } \\ \text { Bulgaria } & \text { Norway } \\ \text { Czech Republic } & \text { Romania } \\ \text { Denmark } & \text { Slovakia } \\ \text { Estonia } & \text { Slovenia } \\ \text { Finland } & \text { Spain } \\ \text { France } & \text { Sweden } \\ \text { Germany } & \text { Switzerland } \\ \text { Ireland } & \text { the Netherlands } \\ \text { Latvia } & \end{array}$

Also some representatives of the Commission participated in the discussion.

\section{Results}

In this chapter the results of the interviews and the workshop are described. Question by question an overview of the answers is given. This means that per question at least 22 answers are summarised to give you insight in opinions, ideas and differences in interpretation.

For each of the questions we did every effort to present the concrete ideas as well as the differences in interpretation and different levels of answers (e.g. strategic versus practical solutions). However, as it was decided not to quote participants literally, it cannot be guaranteed that all answers will be included in the report in detail. For the detailed answers it was chosen not to add them to the report, since some respondents stated that they didn't want to be quoted literally.

If issues have been discussed during the workshop we will present the results of the workshop in a box, see example below. Some workshop results apply to more than one question. In the report the workshop results are only displayed once. So when no box is added under a text this does not necessarily mean that no discussion took place.

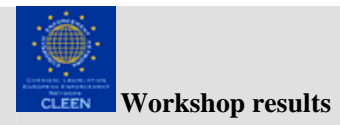

Results of the workshop reflect the common grounds and ideas that have been presented during the workshop 
When describing the results, the participating countries are all designated as 'Member States' (or 'MS'). Technically this is not correct, since some participating countries are not (yet) member of the EU. For reason of semantics, and because some Member States consist of more countries ,combined with the fact that there was not a significant difference in opinion between EU member and Non-EU members, it was decided to use the word Member State.

\subsection{General}

What is your reaction on the initiative to come to a coordinated approach of enforcement?

In general countries are positive about the initiative of the Forum. CLEEN members recognise the tasks of CLEEN and are in favour for an official continuation of the CLEEN tasks. It was emphasised that enforcement is a national issue, but an official Forum to share experiences, to exchange information and to determine enforcement methods is considered to be positive. The official Forum is expected to get more support from the Commission compared to the informal CLEEN.

The fact that enforcement is a national issue is agreed on, but the level of coordination or harmonisation of enforcement is different between countries. Most countries are clear that harmonisation is the wrong word, because enforcement cannot be the same in all countries: industry differs, budgets differ, staff compositions are different etc.

However, agreement on method, on interpretation and reaching a certain minimum standard is good to achieve a similar treatment of companies, which is especially valuable for international companies.

There are countries that want to have equal enforcement or even more stringent enforcement by other countries in order to be no longer "the most stringent" enforcer. 
The following points of harmonization were stated. First we can harmonize the implementation. Specifically the education and training of inspectors is an important item. We can also harmonize the actual enforcement or inspection work. On this theme harmonization through working methods (guidelines), management (setting programmes / setting up project/selecting topics for projects) and competences are to be considered. Harmonization of output or even outcome was mentioned but left out of the discussion.

To what level and what extent should we harmonize?

It was also stated on which we cannot harmonize. Aspects mentioned were: Penalties, fees and National procedures. Also it was stated that harmonization cannot be in details, but only on a general level.

In the process of harmonization we should first formulate minimum criteria for the subjects to be harmonized, and then come to an agreement on criteria for harmonization and last but not least there should be a willingness to harmonize.

Guidelines for specific topics would be a useful way of harmonization. Also general checklists for the work of the inspectors are considered helpful.

\section{What would your country hope to gain by it?}

Various possible benefits of the Forum have been mentioned. These can be divided into categories:

- general benefit of an official EU institute for enforcement;

- information exchange between MS;

- bringing enforcement to a more equal level.

The general benefit is seen in the formal character of the Forum.

The information exchange covers the exchange of enforcement methods and best practices. It also covers sharing information about substances, products and companies. Sharing experiences were mentioned especially with a focus on the new MS and the small MS. A number of MS recognise themselves or others as less experienced in enforcement and therefore foresee an important benefit in learning from more experienced MS.

Also the coordination in enforcement for the purpose of a more smooth enforcement is considered a benefit. Many MS have difficulties in the current system with the fact that enforcement is different between MS. Companies know that penalties are unequal between MS and that the level of enforcement is different between MS. Some countries aim to coordinate enforcement to such extent that these differences no longer appear. 
With respect to the possible benefits the answers reveal a certain difference in perspective. Some MS see it as an approach to ensure a good working of the market, or in other words to ensure a level playing field. Others see it as an approach which leads to efficiency benefits. Some mention both perspectives. It is important to be aware of this difference in perspective since they would lead to different solutions.

\subsection{Work division, role of the Forum}

Which authorities will have responsibilities in the enforcement of $\underline{\text { REACH? }}$

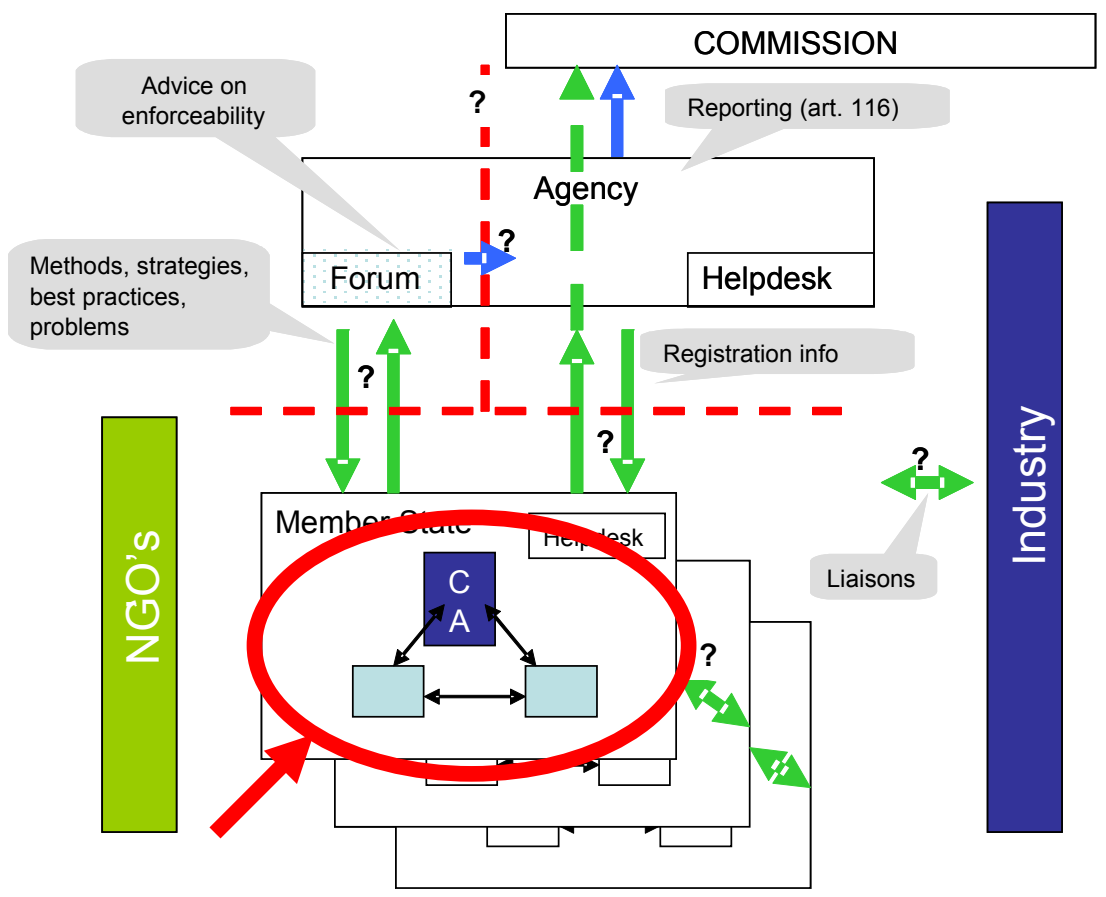

Please note that the answers given to these questions are in some cases based on official choices and concrete ideas, but in many cases based on expectations.

The involved authorities are variable in number and in character. Most of the countries MS will either maintain the current national enforcement structure $(n=6)$ or expand the current structure with new enforcement authorities $(n=9)$. For those that will maintain the current structure, the plan is made $(n=3)$ or the system is ready or not expected to require significant changes $(\mathrm{n}=3)$. The countries MS that are planning an expansion of the structure are mainly in the planning phase $(n=7)$, one country indicated to be ready with that, and one country indicated not to have any plan at all yet. One country has to set up the whole system and that will 
be done in 2007 and three countries MS will probably change their system but that is not clear at all at this moment.

A few of the MS indicated that the enforcement organisation will not be set up or finalised as long as REACH is not final. That means that in 2007 the information about these enforcement organisations might change significantly.

Fields of expertise of the mentioned authorities are the following:

- environment;

- labour;

- public health;

- trade and industry;

- customs.

Most of the MS will enforce REACH in a combination of National Competent Authorities and regional organisations. Three MS only see a role for the National Competent Authorities, partially because of the smaller sizes of the MS.

How will cooperation and information exchange between these authorities be organised?

In most of the MS the information exchange is part of the plan to be developed on enforcement. That means that the methods of information exchange are not clearly determined at the moment. Six of the MS indicate that the information exchange will be the same as in the current system.

Methods of information exchange include:

- One central agency or authority overall responsible for enforcement and therefore for communication with other authorities.

- Rules on tasks, responsibilities and information exchange officially laid down in national law.

- Meetings between the relevant authorities, nationally as well as internationally.

- Information exchange via electronic information: reporting formats, database on companies and compliances and sharing of information via internet.

- A national helpdesk.

- Training of the enforcement officers.

What should, in your opinion, be the first priorities/most urgent tasks of these authorities?

Clearly the first priority for the majority is setting up the enforcement organisation and training of staff, often combined in one answer. Setting 
up the organisation covers different aspects: division of tasks, responsibilities and work, improving cooperation between authorities, capacity building, writing procedures and determining strategies and work programmes for the coming year(s).

Awareness raising and informing industry is mentioned by up to 5 MS.

Regarding specific enforcement ideas three MS state that the focus must first be on registration and pre-registration. One country has the plan to first focus on the requirements that are in the current system, like safety data sheets and existing restrictions. One country uses the strategy towards industry first to focus on giving information and then focus on enforcement.

What is your view on the borderlines between ECHA, Forum and the National enforcement authorities?

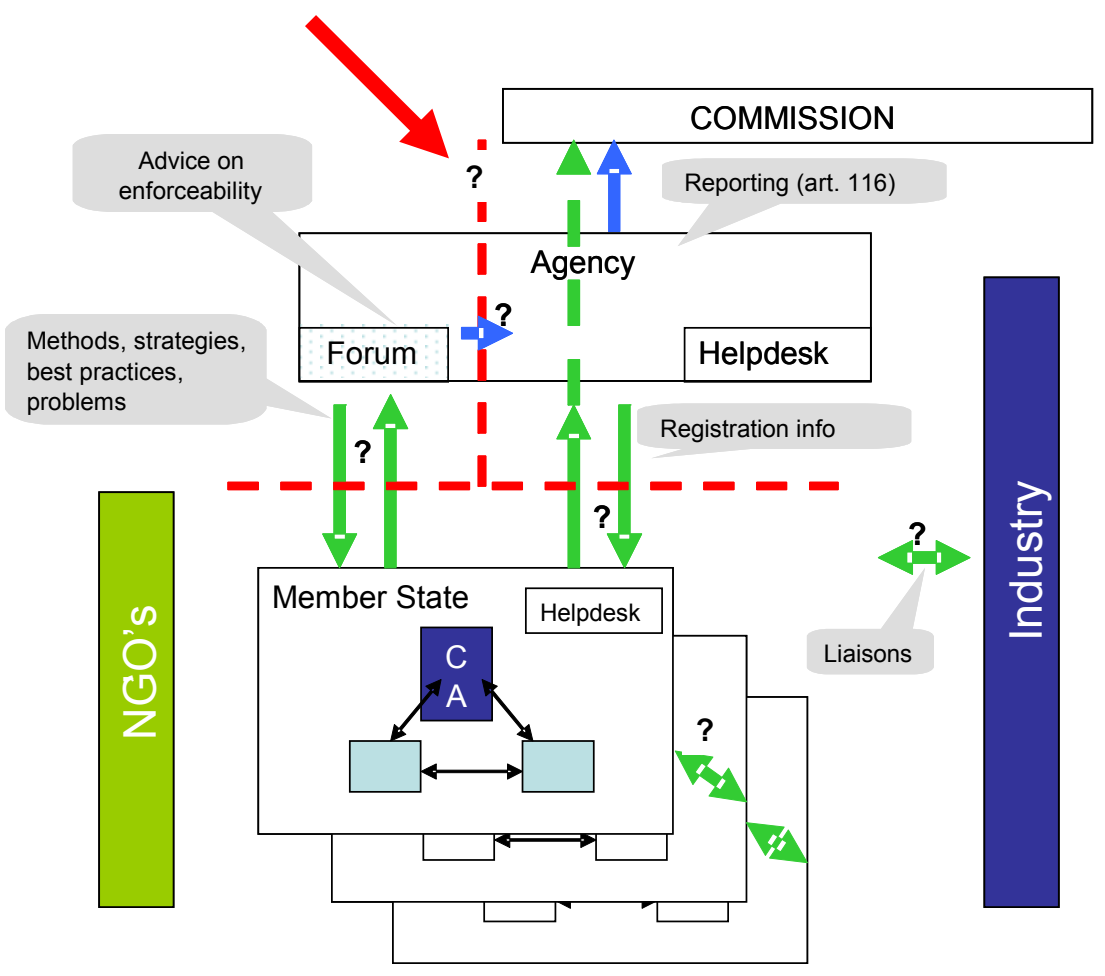

This question resulted in different types of answers. This can be caused by the difficult character of the question, but can also lead to the conclusion that for some countries MS the borderlines between the different organisations are not clear.

In general countries MS agree on the fact that enforcement is a national task; countries MS are responsible for the enforcement. Countries MS indicate that national differences will influence the borderline between the countries MS and the Forum. 
In some cases the distinction between the Forum and the ECHA is not clear and both are considered as the same organisation. Where the distinction is made the ECHA is considered to be responsible for administration, tools, meetings etc. and in some cases as an expert organisation. In those cases the Forum is seen as a working group purely responsible for coordination of the enforcement in the EU.

One country foresees a role of the ECHA as a helpdesk for the MS.

In summary, in general there are two types of answers: either the division of roles is clear or it is not. It shows that clarification of these roles is needed.

\section{Workshop results}

Which borderlines between Forum, ECHA and National Competent Authorities are unclear?

In general it is clear that more clarifications on the borderlines are needed. Specific items that were mentioned are:

- The extent of the legal binding of the registration dossier - legally binding to what extent?

- The matter on the authority and procedures around Interpretation questions - who decides, procedures?

- The cooperation between Help Desk and enforcement.

- The definition of placing on the market with respect to transport between Member states.

- Who has the task on the Interpretation of legislation and in maintaining consistency? The member state or the Forum or even the Help Desk?

How do the differences in National organisation affect the communication between Member States?

Beside this it was also mentioned that a proposal for an idea of confidential electronic communication on enforcement matters should be made. For this proposal one should apply for economic resources from the ECHA.

What is your interpretation of the tasks for the Forum, as stated in REACH article 77.4? Do you have concrete ideas on the implementation? 


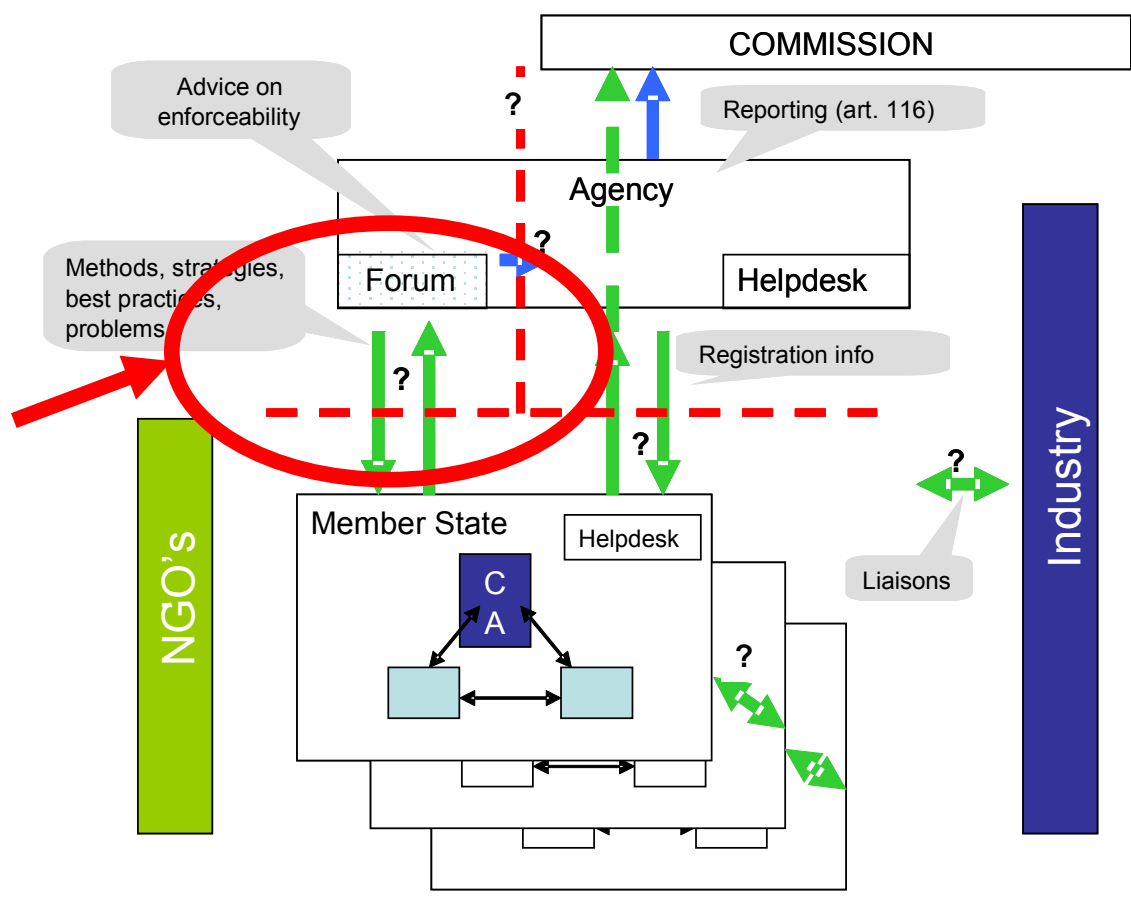

The answers differ per country. Three MS stated that it is too early to have an opinion on the interpretation of the tasks assigned to the Forum while others think that the tasks are correctly formulated and that they already have a clear picture for the implementation. One country in particular thinks that the registration should be the main focus of the Forum in the first 1.5 years, because there will be no time left for other tasks. After that it is possible to apply the gained experience in the future when implementing the other tasks.

Another country stated that the Forum should get a more formal status because it considers the voluntary basis as potentially problematic for the implementation of the relevant tasks assigned to the Forum. On the other hand, there should also be some degree of freedom concerning the implementation.

Some MS see the Forum as a formalisation of CLEEN. Some expect that the tasks of the Forum will be more general and politically loaded and that the practical implementation should be outsourced to CLEEN, which has more practical experience. Several MS have emphasised the need for a practical approach, either by the Forum or by another institute.

The interviewees were also asked to give concrete suggestions for the implementation of the task assigned to the Forum as stated in REACH article 77.4. Their reaction is as follows:

a) Reactions concerning concrete suggestions for the spreading of good practice and highlighting problems at Community level 
Remarks by the interviewed MS are:

- The most relevant information will have to be gathered while the enforcement is being practiced. Participation of experienced inspectors in the Forum is needed to assure feedback on malfunction of the regulation on the national level.

- Communication should take place via regular meetings on an EU and on a national level, also internet applications should facilitate this, i.e. make use of electronic guidance documents or an REACH Manual, websites, workshops, or electronic newsletters that have been translated.

- Spread the experiences with CLEEN to the inspectors via meetings and collect information on new approaches.

- Enhance the dialogue between agencies.

- Report results of (joint) implementations by inspectors, make use of a separate system helpdesk.

- Unify the reporting of practice.

- Start with enforceability; make use of simple methods, models and checklist. Begin with simple projects. Also respect the differences in national enforcement.

It appears that the interviewees would like to organise the spreading of good practices and problems on a simple, unified and efficient and for every country accessible manner. It also seems important that gained experience with CLEEN should be used in the enforcement of REACH.

b) Reactions concerning concrete suggestions for proposing, coordinating and evaluating harmonised enforcement projects and joint inspections

Remarks by the interviewed MS are:

- Formulate clear procedures and criteria and identify proper common targets;

- This aspect has a second priority, maybe an executive body can take care of this by looking at trends and statistics.

- Use the experienced gained with CLEEN.

- Sufficient funding is needed for the exchange of information by inspectors and for the assurance of the staff to carry out the needed activities. Also, make clear who will lead process and therefore who is responsible for the finance.

- Exchange information via email, as it currently takes place within CLEEN.

- Mind the differences in national legislation, this will make it difficult. Joint inspections are acceptable at multinationals but will not be practical for small and medium enterprises (SME's). 
- Formulate a program describing the percentage of joint inspections and the percentage of the inspection that will have to be implemented by the national authorities.

- Define "enforcement projects" better and choose specific objectives and themes and integrate these into the inspections.

It appears that the interviewees would like that the coordination and evaluations of harmonised projects and joint inspections will take place via clear procedures. It should be clear who is responsible for what. The experience gained with CLEEN is once again seen as an important starting point. The financial aspects / responsibilities, the acceptance of foreign inspectors by companies and the difference between national legislation seem to have high priorities.

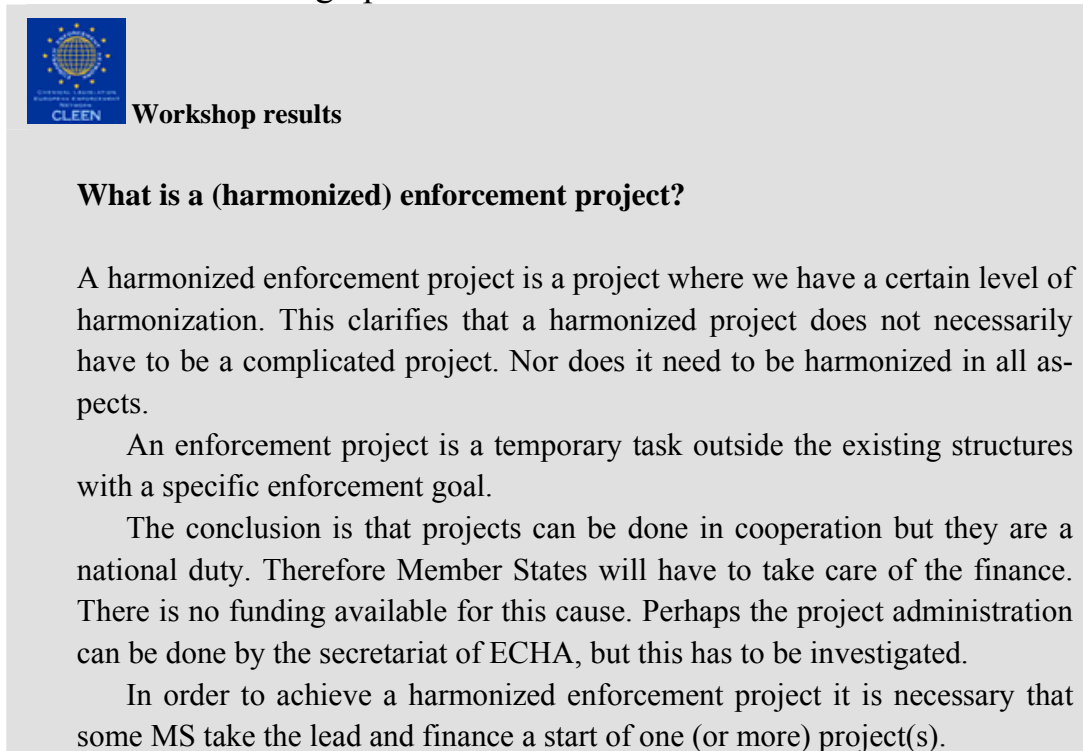
some MS take the lead and finance a start of one (or more) project(s).

\section{Workshop results}

Who proposes a project? The MS through the Forum or the Forum itself?

For this question the following figure was drawn up:

The following general principles were laid down:

Start this process on a "case by case" basis. One should consider a learning period.

The information should be provided proactively.

A Forum Website could be a useful tool; specifically on the advise on revision of current restriction or new restriction.

A working group should be established to fill in the technical and / or practical things for the Forum. 


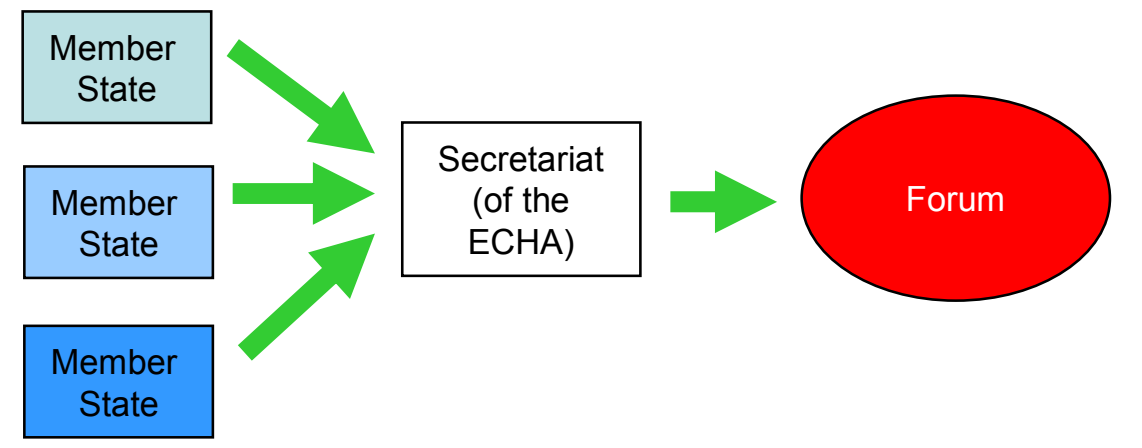

c) Reactions concerning concrete suggestions for co-ordinating the exchange of inspectors

Remarks made by the interviewed MS are:

- Coordination of the exchange of inspectors could be managed by the ECHA. The main problem is the needed budget and staff. Also relevant is who will be responsible for financing the exchange of inspectors.

- No obstacles unless the operators agree on having foreign inspectors as observers during inspections. Companies must accept these observers, guaranteeing confidentiality and the integrity of the inspectors are important issues.

- Constant exchange of information via a confidential website amongst MS.

- Some MS will not accept foreign inspectors to do the inspection, but they will be allowed to exchange information with local inspectors.

- Mind the language barrier.

- Organise a database, obstacles will most likely be made clear on a case to case basis.

- Use an informal approach because then no formal barriers can be expected.

Coordinating the exchange of inspectors seems to be accepted by some MS but rejected by others. This rejection has most importantly to do with the confidentiality and integrity of the inspectors and with national laws. Other expected main problems seem to be the finance and the language barriers. 


\section{Workshop results}

How do we achieve a working exchange system for exchange of inspectors?

The starting point for a possible exchange should be proper justification. Questions like 'Why is the exchange necessary?' 'Is there an actual demand?' should be answered first. The exchange should be made in a mutual agreement and with mutual benefit.

So an exchange of inspectors needs to be:

- $\quad$ Planned (and specified within a project plan);

- Justifiable;

- Necessary.

The necessity can be either training purpose or sharing experience. It in order to really learn feedback from the project is needed. On the basis of this feedback, better decisions on new exchange can be made.

d) Reactions concerning concrete suggestions about the identification of enforcement strategies, as well as best practice in enforcement

Remarks made by the interviewed MS are:

- National enforcers should give feedback on obstacles with strategies based on experience of MS with the enforcement of the current regulations.

- Some CLEEN strategies can be applicable and formalised under the Forum.

- Strategies can only be formulated for specific fields, this will make it difficult to formulate general REACH enforcement strategies.

- The Forum will work on an abstract level; therefore it could be useful to assign an additional working group to focus on practical matters with the Forum as approving body.

- Make use of enforcement strategies and best practices with joint inspections in GMP within the pharmaceutical field.

- Make use of bad practices, there is a lot that can be learned here also.

- Formulate long and short term strategies, create a central database and maintain a difference between international and national strategies.

- Best practices should be viewed very broadly, give needed information on all relevant aspects to assure compliance. In addition; working through branch associations could also be very useful. 
The identification of enforcement strategies and best practices is seen by most MS as a job for the national enforcers. Once again CLEEN is seen here as an important source of practical information. One country stated that the bad practices could also be the source of valuable information for the enforcement of REACH. An important aspect concerning the identification strategies also seems to be the idea that the best strategies can only be formulated on a case to case basis. It is also seen as important by MS that companies will have access to all the information that they will need to be compliant.

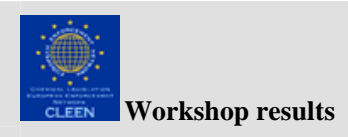

How do we achieve a common guidance document (compendium of useful enforcement methods, including enforcement strategies, working methods and tools of use to local inspectors)?

When considering making a guidance document a distinction should be made between guidance for 'real inspection activities' and guidance for the preparatory activities on management level.

For the design of guidance documents the REACH Implementation projects (RIP's) could provide useful examples. The RIP's were either made in house or made external by a) consultant and/ or stakeholders or b) by project management-groups. For a later period a Forum subgroup could be the party to make further guidance documents.

For the EU project in 2007 the following was stated. In the first half of 2007 the Member States must prepare their national activities. Therefore the discussion focused on how to use the information out of EU- project.

The following steps were laid down: The first proposals or plan should be discussed in an interactive way like a workshop.

Whether companies or specific target groups should be involved in some way in the design of methods, was point of discussion. The opinions differ in this matter.

The above mentioned ideas and recommendations from the workshop on the exploration of enforcement strategies have been incorporated in the recommendations for the next phase see chapter 5 .

- Identify new and old activities for enforcers due to REACH; also identify the timeline constraints

- Make an inventory of other guidance documents that might be useful

- CLEEN products / CLEEN expertise;

o Experience in MS

- Analyse this documents and incorporate them into a reference book

- When we know the tasks and the methods we can make proposals for harmonization 
e) Reactions concerning concrete suggestions for the development of working methods and tools of use to local inspectors

Remarks made by the interviewed MS are:

- The needed tools will be shown in practice, different tools will be needed for different situations.

- Manuals or guidelines on how to be an inspector for REACH may help.

- Training of the inspectors at the central level by ECHA.

- Basis for new tools lies in the existing tools, it should be up to CLEEN to identify these tools and the Forum can then adopt them.

- Make use of a reference or toolkit and beware not to impose methods.

These suggestions seem to indicate that the MS have a need for practical manuals, trainings and toolkits which can be applied by inspectors. CLEEN is once again mentioned as a valuable information source.

f) Reactions concerning concrete suggestions for the development of an electronic information exchange procedure

Remarks by the interviewed MS are:

- The EUVICHEM reporting form could be used as a suitable starting point.

- It should be simple and effective and in English.

- The tool should facilitate communication about illegal products with the country of origin, compare this with RAPEX.

- Only generate information that is of use/interest for other MS. For the flow of information it would be better to connect it with REACH-IT.

- Make use of internet Forums.

- There must be a link to the central IT-system. One person should be responsible for the procedure.

Internet plays a central role in the exchange of information. The EUVICHEM, RAPEX and the REACH-IT systems have been mentioned as possible starting points. There is also a need for a clear procedure stating who is responsible for what. It seems also important that only the information that can be used by other MS will be gathered and exchanged. 
Workshop results

What type of system of information exchange (on problems, best practices, project results) would we like to establish/use?

What kind of information should be exchanged?

In general terms it was stated that all available or agreed information should be exchanged. Problems, best practices and project results were mentioned as valuable information.

How should we exchange the information?

A first priority would be that the exchange should be safe and electronic. Several methods were named: SLIC, RAPEX, CLEEN homepage, EUVICHEM a REACH-Enforcement homepage similar to CLEEN homepage.

It was specifically stated that a timeline for the answering of questions should be built in. Also it was stated that it should not only be in English.

\section{Workshop results}

\section{How do we achieve a working system of exchange of enforcement data?}

With respect to this question the relation with REACH-IT was remarked as important. Their time path is critical. Before taking actions we should first have an insight in the report on the access of REACH-IT for enforcers/enforcement authorities. This report is scheduled to be discussed in the CWG in March 2007.

First it was stated that two levels of exchange can be identified:

- Exchange of statistical data;

- Quick exchange on problems and questions etc.

The different levels might require a different approach. The following steps were identified:

1. Start with further analyzing:

- $\quad$ Existing available systems;

- The specific target group for exchange;

- The technical possibilities with Member States and within REACHIT.

2. From this analysis a discussion paper can be formulated and brought into an interactive process. 
g) Reactions concerning concrete suggestions for the liaising with industry and other stakeholders, including relevant international organisations, as necessary

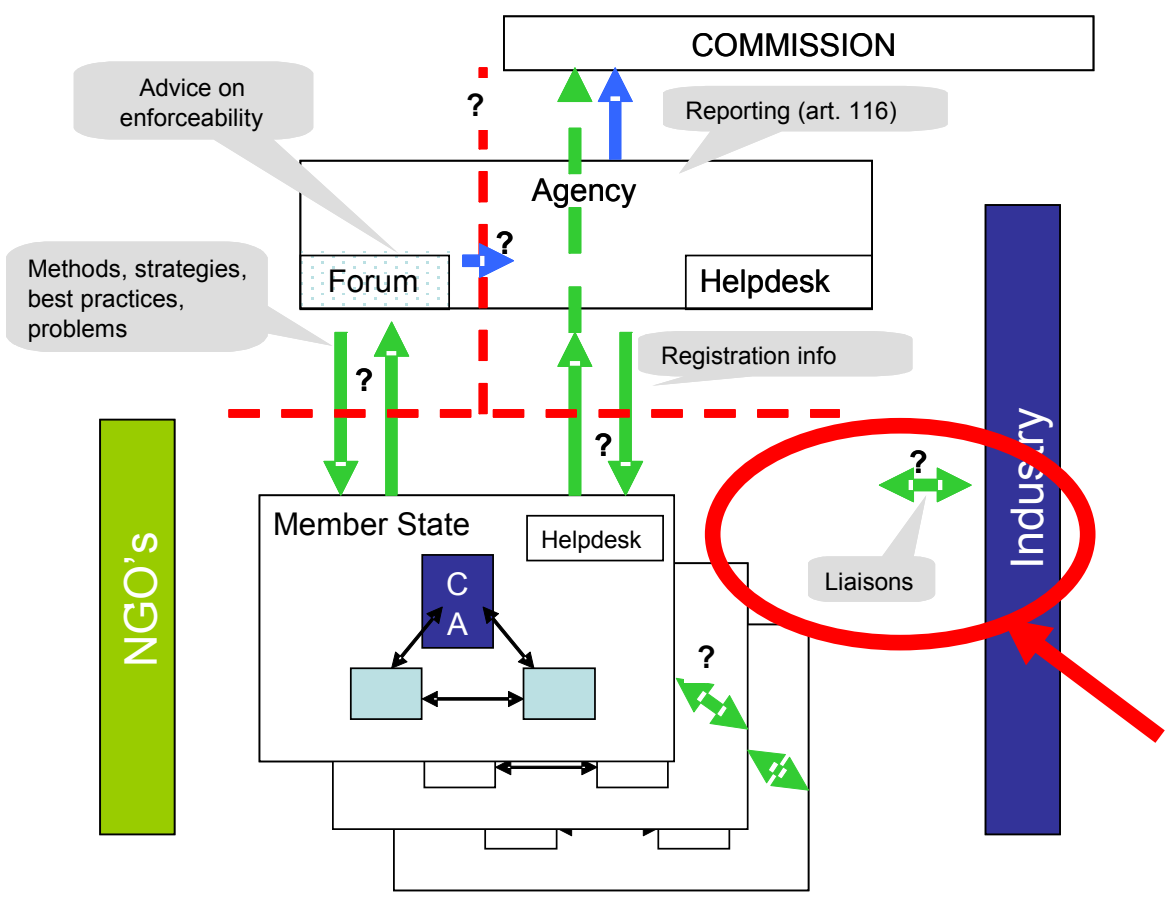

Remarks by the interviewed MS are:

- Make clear what the role of the Forum will be and the language should at least be in English.

- Organise meetings with companies and trade organisations where knowledge, plans and experiences are shared between authority, enforcement and industry.

- Consider involving them in creating rules of procedures for the Forum.

- Try to create open discussions where applicable.

- Liaising on a European level will not have much added value. It is more important to liaise with the industry on a National level.

- Industry should be involved in support groups (not actually in the Forum). The task should largely be done on a national level.

- Organise meetings in each country. There should be things as bulletins, helpdesk and information could be spread by conducting inspections.

- Liaising is not a matter of the authority but for the policymaker. One should not mix these roles. Also liaising should be done on an international level, not a national. 
- For the national companies this should be done by MS, for the international industries this should be done by the Forum, there should be a strong link between the two.

- This has to be developed on a case-by-case basis: there should be a coordination of exchange.

Most MS agree that communication with industry and stakeholders is an important issue. But some MS think that at an international level it won't be very useful, this should be done mostly at the national level. Other MS think the exact opposite. There is also a country that considers liaising with the industry and other stakeholders at both the international as well as on the national level.

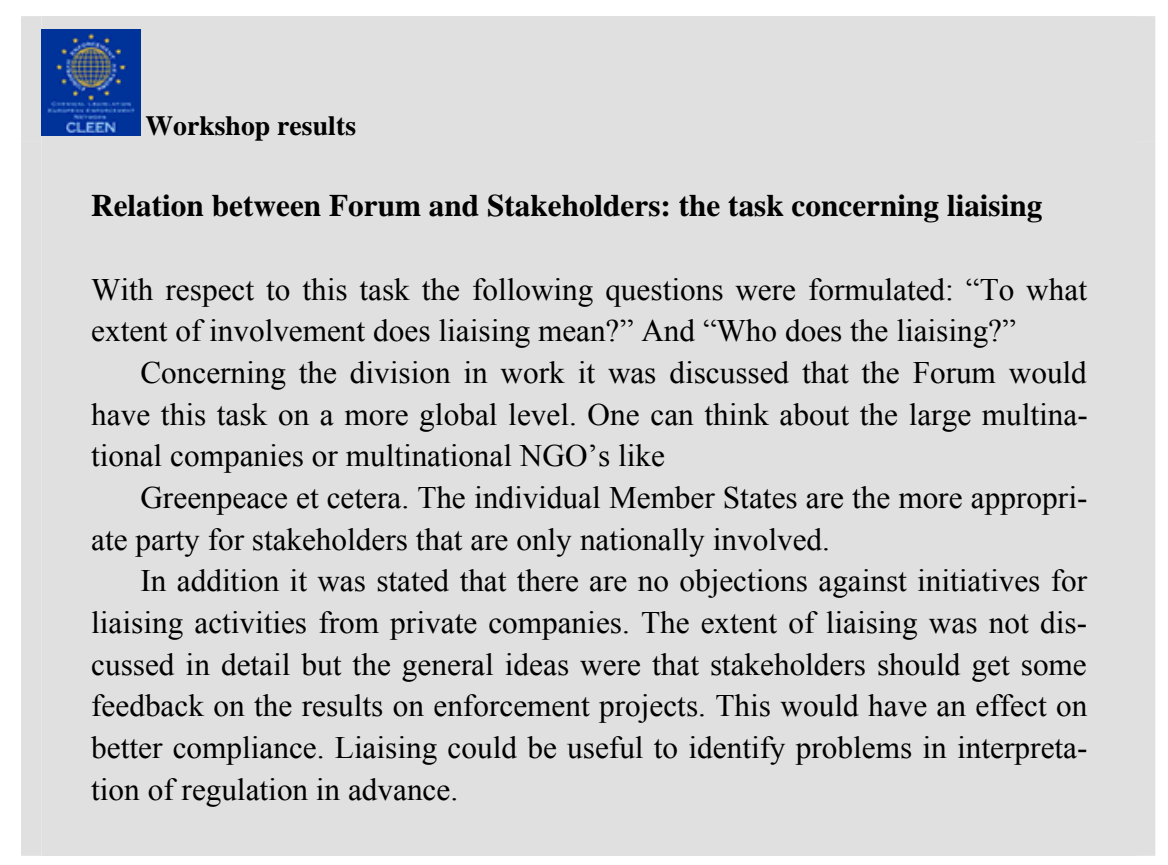

\section{h) Reactions concerning concrete suggestions to examine proposals for restrictions with a view to advising on enforceability}

Remarks by the interviewed MS are:

- The Forum should only do proposals or support other bodies in deciding.

- Prevent the implementation of unenforceable regulations by early communication.

- The Forum could play a role as a consultant for the Commission.

- Assessments of proposals for restrictions should be done by an interministerial Commission including representatives from the Regions and the industry. 
- This will be dependant on the country and the expertise they have, this is more a role for the policymakers and/or also of the enforcers.

- Use the outcome of earlier restrictions in MS as a basis.

- Use a representative for the MS as a negotiator.

- Mind the possible difference in point of views between MS and the Forum.

- Make use of a two way approach: political aspects for the Forum, practical aspects for CLEEN.

- Let the Forum consist of members who are in the national competent authority; they will have their own enforcement groups.

The opinions of the interviewed MS, concerning the examination for proposals of restrictions and advising seem to be divided. Some do not see this as a task for the Forum but for national authorities, enforcers and/ or policymakers. Others seem to accept the Forum as an advising body on this matter.

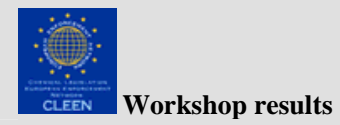

Advice on enforceability of restrictions

How do we prevent or deal with differences in opinions between the Forum and the MS's? (Specifically differences in national restrictions?)

The advice on restrictions is a three way communication. It does not only concern the Forum and the Agency but also the Commission.
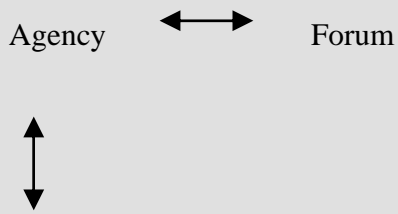

Commission

The rules of procedure for the Forum (see also results of workshop at paragraph 4.2.7) should cover this specific question.

What should the approach of the Forum be (advising, proposing, requesting)?

Most of the interviewed representatives of the MS ( $\mathrm{n}>10)$ agree that the attitude of the Forum approach should be advising, proposing and not requesting. The main storyline is that Forum will have no influence on programs, penalties and fees. Participation in a project is always on a 
voluntary basis. The European Commission cannot influence a national situation.

Only about three MS think that requesting is possible. Only one country thinks that requesting should be the most important role of the Forum. This country pleads that the Forum should get a more formal status. Participation in projects should not be exclusively on a voluntary basis. If the legislation appears to be unworkable the Forum will need to have a stronger voice than 25 different MS individually.

Concerning the language that should be used in the documents almost all MS stated that they would prefer English. Because it will be less time consuming and more cost efficient. But some MS think that documents in English won't work, because not all of the MS speak English. They propose a combination; certain documents should be in English and others in their own language.

Is it desirable and achievable to use one language in order to speed up the
process and save costs? (Is it open to discussion?)
It was stated that the language issue is a big problem on a local level. The street
level of inspectors is not always able to use documents in English. Therefore
translation of documents by the Forum will be necessary. However the costs
for translations in this stage are not in the budget of the Forum. This leads to
the conclusion that practical circumstances force the Forum to work in English.
The Member States will have to translate the most important documents them-
selves. The cost of translation of important guidelines could perhaps be paid by
ECHA.

How do you expect your country will react upon proposals from the Forum?

All the MS have in general a positive attitude towards proposals. But they are also very critical. They believe that the acceptance of proposals will depend on the nature of the proposals on a case to case basis. For example if the proposal has a too directive nature, MS will most likely reject them because enforcement is seen as a national issue. The acceptance is also dependant on how the proposals are brought forward and if they are applicable on the national situations. It also seems important that the proposals should be the result of an open democratic process. 


\section{Workshop results}

How do we achieve a draft proposal for Forums rules of procedure?

To achieve a proposal for the Rules of procedure of the Forum the following path was laid down:

1. The existing Rules of Procedure for other, similar organisation should be studied en analysed for useful elements.

2. The road Map as mentioned in the CWG-meeting of Nov-06).

3. Also the standard rules use buy the Commission (Com) should be studied and analysed for useful elements.

4. From this the extra's or additional aspects for the Rules of Procedure can be identified.

An important question was: Who will do this work and when, with respect to the communication of such a proposal. A draft version should be submitted to the CWG and forwarded to the Forum.

In the Rules of Procedure meeting frequency, selection of 'functions' and the contact between member of the Forum and its Member State (including the timing) should be incorporated

What competences would you consider necessary for Forum-members? According to the representatives of the MS members of Forum should have the following competences:

- Practical experience within the field of inspection/enforcement of chemical legislation.

- Good understanding of REACH and GHS.

- Trained in IUCLID-IT.

- A background in natural science, chemistry, administrative, toxicology, ecotoxicology and risk evaluation fields.

- Able to read and interpret legislation correctly.

- Knowledge of situations in different MS.

- An own network of contacts, thus: a good communicator.

- Knowledge of the formulation of strategies and policymaking on an international level.

- A willingness for progress.

- Concerning persons should be well authorised within national laws.

- No politicians and/or policymakers.

Most Members States think that it would be a good idea to let some CLEEN members become Forum Members, because of the experience they already have on the practical as well as on the strategic level. 
Workshop results

What competences with respect to skills and attitude (beside the knowledge and experience) do we find necessary for a Forum-member?

With respect to this question the following competences were mentioned. He or she should have:

- $\quad$ knowledge of the enforcement organisation in other Member States;

- $\quad$ good knowledge of REACH;

- a clear mandate from it's Member State.

With respect to the skills it was mentioned that REACH has a very broad perspective. It cannot be covered within one person. The five extra delegates will have to fill in the possible gaps in knowledge on that part. 
In line with the above:

How do we achieve a common perspective on the competences of the inspectors within the REACH-diretive
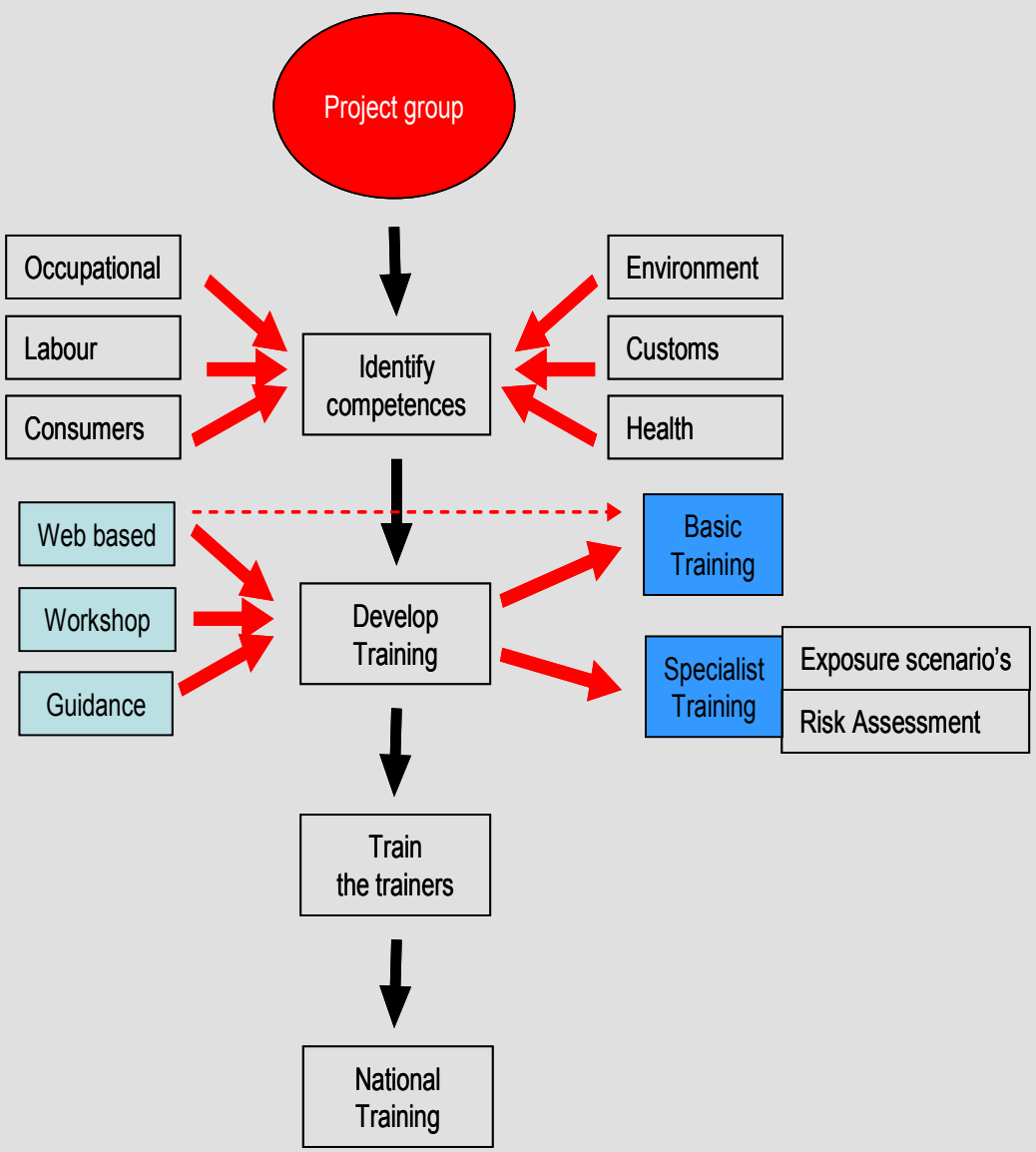

\section{Explanation}

In order to identify the competences, the perspective of all disciplines concerned should be taken into account. The task within REACH should be analyzed from all these perspectives.

For the training it is expected that different levels of training will be needed: a more basic training for a large number of inspectors and a more specialist training for a smaller group. The basic training could perhaps be done through so-called 'webinars'. This would save valuable travelling time. For the specialist training, however a more intensive interaction through workshops or even direct guidance will still be needed.

The idea is that the training program involves the training of trainers per country. These trainers should then do the training towards their National situation. 
Are there any national guidelines/examples for working methods and strategies that could be used for the enforcement of REACH?

About ten of the interviewed representatives of the MS stated that at the moment they do not have any guidelines/examples that could be used for the enforcement of REACH. About eight of the interviewed MS do have some suggestions/examples. Some of these MS have enforcement guides/guidelines; one mentioned a central database with access to all companies. There was also suggested to use guidelines for the classification and labelling of hazardous substances, or to cluster the guidelines thematically around inspection. Another example to support the enforcement of REACH could be a specific system of rating the HSE performance used for prioritising inspection regimes.

\subsection{Information Exchange between ECHA and National Enforcement} Authorities (NEA)

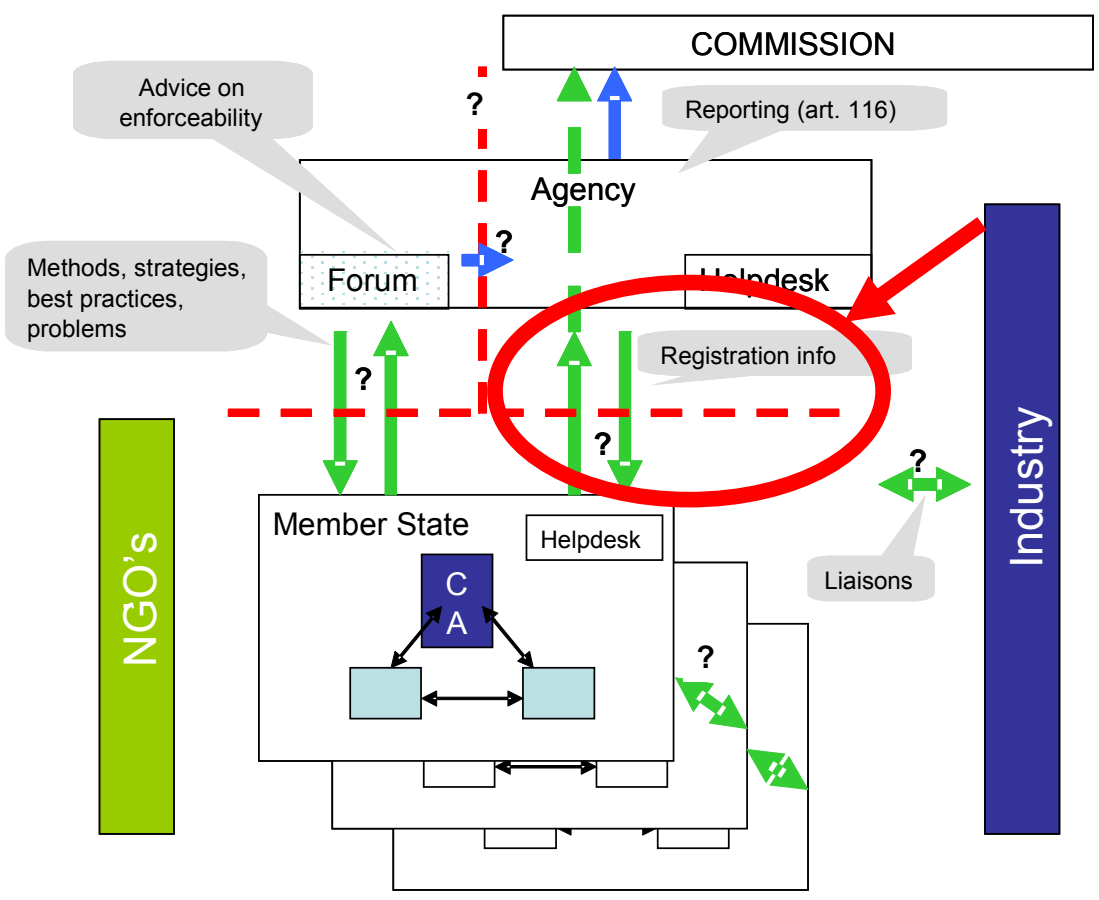

What information does the enforcement authority (or authorities) need from ECHA?

A large majority of the MS (more than 75\%) ask for registration information (the registration as well as the underlying documents like CSR) to be accessible to the inspector.

Some respondents would like additional or other information. The following information needs were mentioned:

- guidance;

- a helpdesk; 
- REACH interpretation;

- composition of consortia;

- non-compliances in registration.

How frequent and how fast would they need this information?

Not all answers are of the same type. Most MS require continuous up-todate information. One country states that a time lapse of a few days is acceptable. Another respondent states that it is too early to give an answer on this.

One respondent specifically states that this information should be available as soon as enforcement starts. Others mention that the database of ECHA will gradually be filled with data.

How / What way of access to this information is required?

Practically all respondents want direct access to the database. One country mentions that this access could be limited to one or a few coordinating persons.

Concerns with respect to confidentiality were expressed by some respondents.

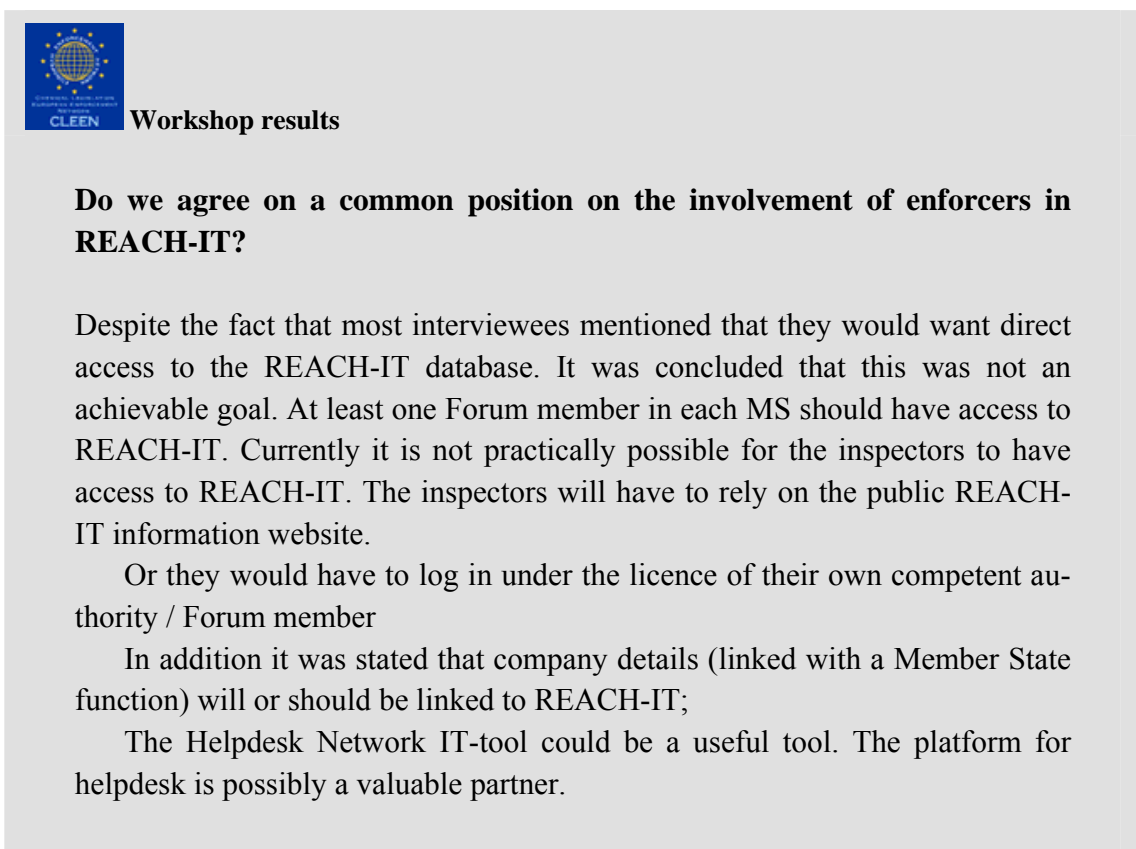

What is your idea on the reporting (as requested in articles 125 and 126)? Is the usage of an agreed format (to be developed by the Forum) acceptable and workable for you?

A large majority (90\%) of the respondents is positive to the idea of a unified format. Some (around 10\%) are neutral in their answer. One respondent state that the articles are clear enough and no further elaboration of a format is necessary. 


\section{What are your ideas for this report format?}

Most respondents have no specific ideas on the report format. It shows that they think it is not a big problem. Some MS give specific recommendations. The following suggestions were made:

5. Number of inspections, imposed sanctions, results of the sanctions imposed, involved other parties (e.g. customs).

6. It should be short (3 to 4 pages). Arranged at type of products/industries and the associated problems.

7. Look at the New Substance Directive and the Biocides Directive for ideas. Another good example is the annual report for the Directive 2037/2000 (Ozondepleting substances).

8. The form must be comprehensive and feed-back must be given to the people delivering the information.

One respondent suggests that this report should be made up more frequently (twice a year) but on a more informal basis.

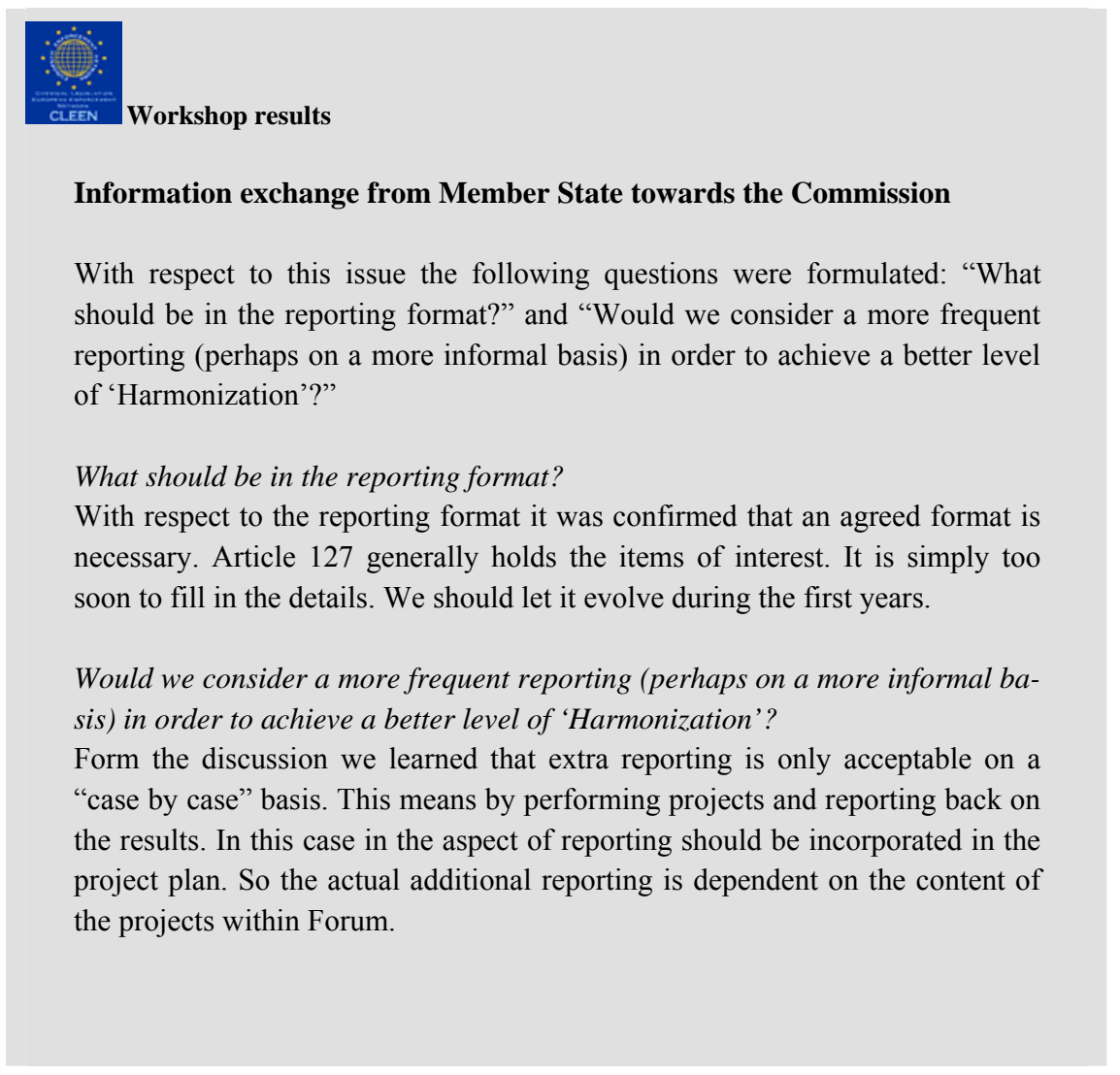

Do you know the REACH-IT data system? If yes, does it cover your need for information?

Most of the respondents have not seen the REACH-IT system (since it is not ready yet). Some however mention that they are confident that it will 
cover all needs. Others express their concerns that the system is stable and workable for the inspectors.

\subsection{Information Exchange between National Enforcement Authorities}

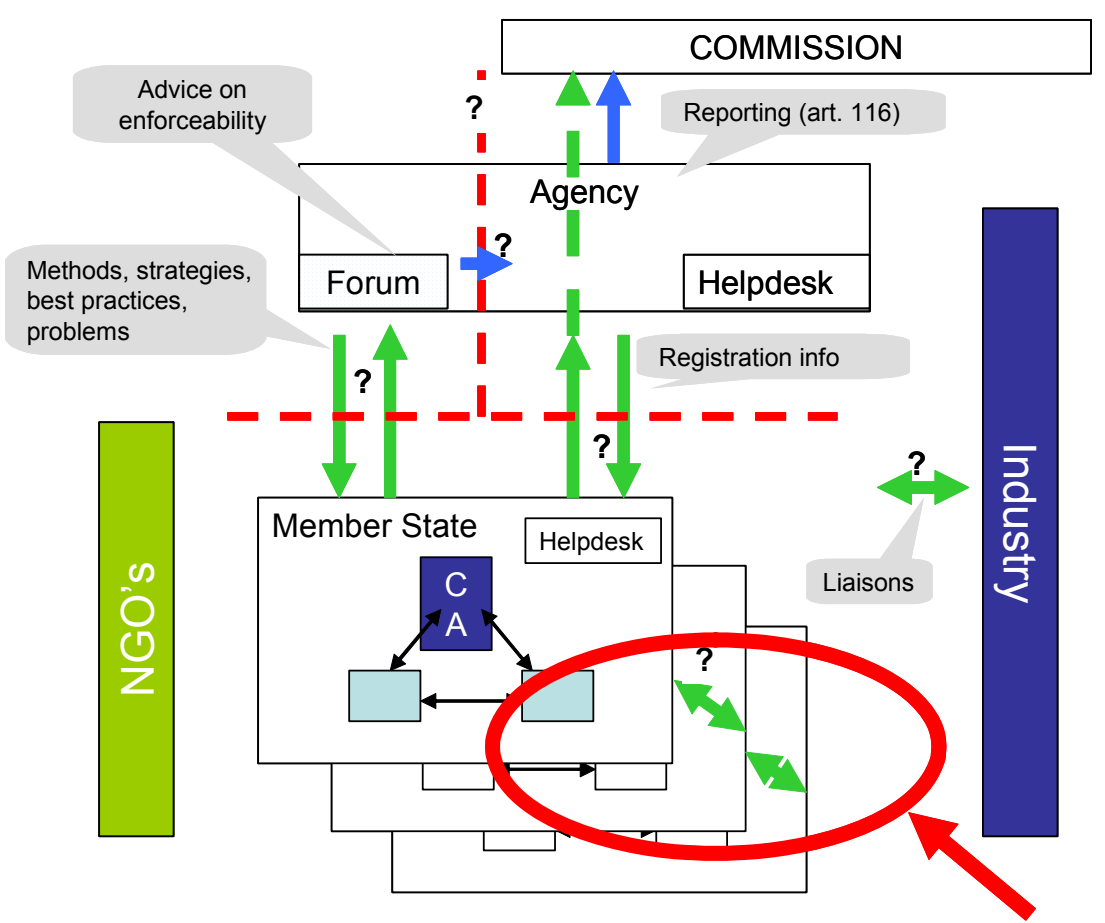

What information will you need from other MS National Enforcement Authorities?

For about one third of the respondents it is too early to give a specific answer on this. The majority of the other respondents answer that they would need inspection information in specific cases of non-compliance. The extent and level of detail however differs. The most mentioned are: company information, results of inspections, action, sanctions and fees.

Specific needs that were mentioned additionally are:

- information on the consortia;

- the supply chain;

- chemicals crossing borders.

One respondent expresses its concern for information overload. Some also mention items that are more general of character, such as experience with specific supply chains or specific target groups and encountered difficulties when inspecting.

Several respondents mention the use of RAPEX or a RAPEX-like system. One respondent mentions that RAPEX is not interactive enough for 
this purpose. Note that another respondent mentions a system (ICSMS) that is derived from RAPEX and is better and more open.

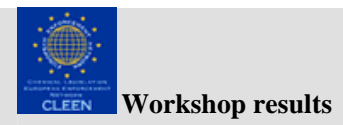

What information do we agree on to exchange?

The question was raised whether it is an (rapid) "alert"-system or is it an information exchange system. The different purposes lead to different requirements. Generally it was concludes that the current REACH-IT platform is the best starting point for any system. Other questions that came up were whether it should only concern substances or also articles.

How should information exchange be carried out?

Most of the respondents consider an electronic system. The majority of them mention e-mail some would want a more automatic system like an internet accessible database. Others do not explicitly mention an electronic system but simply state that it should be simple. For a few MS it is too early to answer this.

EUVICHEM and RAPEX (and the follow-up system ICSMS) are mentioned as possible systems.

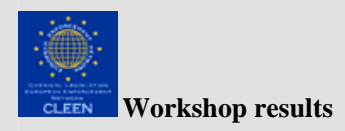

\section{How (RAPEX or EUVICHEM or ICSMS or ?)}

The answer was 'As simple as possible!' Whether it should be RAPEX or EUVICHEM simplified was not considered a big issue at this moment. If one is simply prepared to help each other that is the most important point to start with.

Which pace / Timing do we consider to implement this?

The design and implementation is closely linked to the development of the helpdesk-IT system. Only when the latter is ready, the necessary adaptations for the exchange of information between Member States can be made.

What type of organisation or procedures should be in place for this exchange?

For a lot of respondents this question is difficult to answer. However most of them think this is not a big issue. 'Just start on an informal basis and evaluate later' is given as a message. The secretariat of the Forum is named as the organisation that could be the central point for this. An important condition that was mentioned is that confidentiality and security measures have to be in place. 
One respondent mentions that the organisation and procedures could be the same as used for RAPEX.

Do you know the EUVICHEM data system? If yes, does it cover your need for information?

Nearly $25 \%$ of the respondents were not familiar with the EUVICHEMsystem. From the ones that did know it, most of them consider it as a good starting point. Some of them recommend that it should be expanded to cover all REACH requirements. One respondent on the other hand, finds the system too detailed and time-consuming.

Important to note is that some respondents mention the legal aspects of exchanging this information: 'Is there a legal basis?' Also confidentiality and security matters should be taken into account when using a specific system.

Note that in the first questions, respondents give suggestions for alternative systems (RAPEX or ICSMS). These suggestions do not always imply that they do not know the EUVICHEM-system or it is disapproved by these respondents.

\subsection{Process aspects}

Which difficulties do you anticipate in the building of the enforcement organisation and information exchange, specifically to achieve a harmonised enforcement in the entire EU?

The expected difficulties cover a range of possible pitfalls. However most of the interviewees mention the national legislative process and implementation processes within the MS. Some expect that management issues, like budget and staff, might pose limitations on the possibilities to cooperate or harmonise. Differences in the time schedule of implementing REACH were also mentioned as a factor that would limit these possibilities. Among these differences some mention the differences in culture and mentality.

A few respondents point out that we should not try to achieve a fully harmonised enforcement. Harmonisation should not mean 'the same' but similar. This implies that it is important to specify what harmonised enforcement means and up to which level we consider it appropriate to harmonise.

One respondent expresses its concern that there will be a decrease in level of protection in the first few years.

Which parties have to be involved to ensure the success of this project on coordinated enforcement?

Several types of answers are given here. The main groups are:

- Enforcement authorities (up to street level and including customs); 
- European networks SLIC and IMPEL;

- the Commission and ECHA;

- the helpdesks;

- Industry;

- NGO's (including consumer organisations).

With respect to involving industry the opinions differ. About a quarter of the respondents point out that it would be useful to involve industry. One suggests involving them partly. The following reasons for involving them were mentioned: it would help improve enforceability and they have an interest in consistent enforcement.

The helpdesks are mentioned only by a few respondents. Maybe most of the respondents do not see them as a different organisation. Specifically NGO's are not often mentioned (only 2 respondents). It seems that they are not considered important.

Some respondents specifically point out that the non-EU states (Norway, Switzerland, Romania and Bulgaria) should be involved. One respondent remarks that not only enforcers should be involved but also policymakers and legal advisors

Do you think it would be useful to expand the scope of the Forum apart from REACH?

The answers to this question can be summarised in the following four main categories of answers:

$\left.\begin{array}{lc}\hline \text { No, not at all } & 43 \% \\ \text { No, not now but in the future } & 19 \% \\ \text { Yes, with GHS (see comment) } & 24 \% \\ \text { Yes, beside GHS also other chemicals legislation (e.g. biocides) } & 14 \%\end{array}\right\} 62 \%$

The respondents who answer 'no', on average, point at that the current scope is difficult enough. Some of them point out that the mandate is laid down so that there is no room for expansion of the scope. Some of the respondents who answered 'no' however, point out that the Forum should keep an eye to adjacent fields.

Some respondents remark that expansion of the scope could also be done in an informal manner.

Comment:

From the respondents who answer 'yes' most of them mentioned GHS. It was pointed out that the Forum is already in the GHS-proposal. To others that was not clear. This means that a 'yes, with GHS' for some respon- 
dents leads to answering 'no' because they think GHS is already in and that this is not under discussion.

\subsection{Additional remarks}

Beside all the other answers some (three) MS gave additional remarks. One respondent points out that REACH for them is a drastic change of the system after only a short period of time using the current system. This specific country expresses its need for a strong ECHA that could support the organisation and implementation of REACH in the country. Only with clear legislation and clear requirements they can internally work on expanding their national inspection organisation. However they remark that on the other hand REACH will have limited effect as their chemical industry is small. More effect is expected from GHS as the current system for classification and labelling is already in place.

One respondent points out that the interaction between REACH and CLEEN should be taken into consideration. It would be useful to cover the entire scope of chemicals legislation.

One respondent expresses its concerns about the IT-system. The respondent recommends that the project group tries not to be too detailed and that the objective (level playing field) should be kept in mind.

\section{Recommendations for the next phase}

\subsection{Conclusions form the workshop}

The main conclusion form the workshop is that a high ambition is not appropriate. The state of preparation of the various MS is too different. Several questions are just one step to far. The relative vagueness of some of the answers from the workshop reveals that people simply haven't got elaborate ideas on these items. They probably have more pressing matters to deal with.

During the interviews and even more in the workshop a development on a case by case basis was mentioned a lot to be the most achievable method of making things clear, harmonizing specific aspects and creating new experiences and share them. Projects are flexible and often mentioned as a good development method; they can easily be made tailor made to specific goals and contain low thresholds compared to more structural approaches

A good analysis of articles in REACH is needed to know the tasks, and this is the basis to get any idea for competences, projects and programming.

A lot is already done in other adjacent fields (RIP's, other RoP's, CLEEN etc.) and it would be unwise to reinvent al this material. 


\section{Used questionnaire}

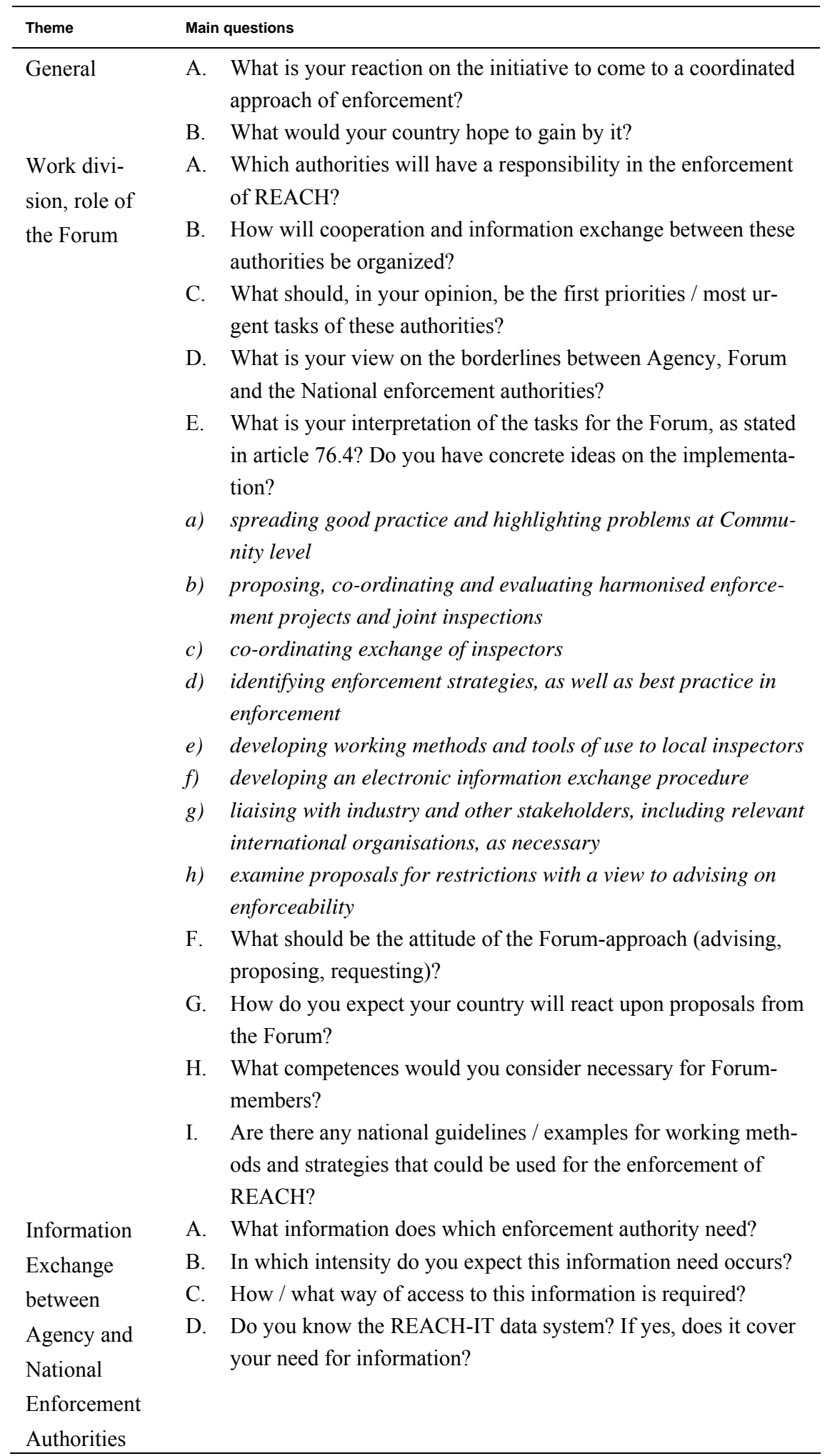




\begin{tabular}{|c|c|}
\hline Theme & Main questions \\
\hline \multirow{5}{*}{$\begin{array}{l}\text { Information } \\
\text { Exchange } \\
\text { between Na- } \\
\text { tional En- } \\
\text { forcement } \\
\text { Authorities }\end{array}$} & A. What information will you need from other Member States \\
\hline & National Enforcement Authorities? \\
\hline & B. How should information exchange be carried out? \\
\hline & $\begin{array}{l}\text { C. What type of organization or procedures should be in place for } \\
\text { this exchange? }\end{array}$ \\
\hline & $\begin{array}{l}\text { D. Do you know the EUVICHEM data system? If yes, does it } \\
\text { cover your need for information? }\end{array}$ \\
\hline \multirow[t]{3}{*}{$\begin{array}{l}\text { Process } \\
\text { aspects }\end{array}$} & $\begin{array}{l}\text { A. Which difficulties do you anticipate in the building of the en- } \\
\text { forcement organization and information exchange? Specifically } \\
\text { to achieve a harmonized enforcement in the entire EU? }\end{array}$ \\
\hline & $\begin{array}{l}\text { B. Which parties have to be involved to ensure the success of this } \\
\text { project on coordinated enforcement? }\end{array}$ \\
\hline & $\begin{array}{l}\text { C. Do you think it would be useful to expand the scope of the } \\
\text { Forum apart from REACH (for example GHS)? }\end{array}$ \\
\hline
\end{tabular}





\section{Annex III - Minutes from workshop 24-25 September 2007}

\section{Welcome and Introduction}

The participants were welcomed by Otto Linher on behalf of the Commission who hosted the workshop, and by Lars Gustafsson on behalf of the REACH EU Enforcement Project who arranged the workshop. Lars Gustafsson then as chair pointed out that the general goal of the workshop was to get closer to a common understanding of the challenges for enforcement of REACH and what the priorities should be.

The following discussion themes for the workshop had been defined by the project group:

- Analysis of prioritisation needs and problems

- Methods/tools for enforcement and competence/education needs

- Ideas on enforcement projects for the Forum to coordinate

- Needs for confidential information from REACH IT

The first two themes were then each discussed in three separate groups with a main focus on REACH Titles II-VII, and the last two themes were discussed in one group each. The results of the discussion sessions will be input for papers to be worked out by the project as contributions to a quick start of Forum.

\section{Discussion Theme 1: Analysis of prioritisation needs and problems}

\section{Introduction}

The first theme discussion was to reach common understanding about the most important titles and articles of REACH to enforce and identify problems and needs for information from REACH-IT in relation to those articles. Before starting the discussions a presentation (c.f. Annex 1 to the minutes) was made by Lars Gustafson of a thought starter/report on Priority Articles.

The three separate groups each had certain Titles to address in their discussion, this way all Titles were discussed in the workshop sessions.

Group 1: $\quad$ Titles II, III, VI

Group 2: $\quad$ Titles IV, V, VII

Group 3: $\quad$ Free choice of Titles 


\section{Summary of the discussion and individual results}

\section{Title II, III and VI}

The conclusions from the workshop are that Articles $\mathbf{5}$ and $\mathbf{6}$ are the most important articles and of highest priority, all other articles are subordinated! But many exemptions and time-limits will make enforcement difficult in the beginning. Pre-registration should not be seen isolated and is a part of the registration requirements in Article 5 and 6. In future when most of the registrations are done, it can be a problem with false information in the database as only $5 \%$ of registrations will be evaluated. This is also a reason why access to REACH-IT is necessary for enforcers for controlling if the data in REACH-IT is in correlation with the data presented at an inspection and that there is a system to give feedback to the ECHA.

As the REACH regulation covers many competences, cooperation between authorities dealing with environment and work environment is needed (often different CAs) as different backgrounds of inspectors will be needed (environment/chemical/health etc).

Most countries have not yet decided if administrative and/or criminal penalties will be used for sanctions. Probably might threat of withdrawal of the product help in getting the companies to comply with the regulation. Many countries considers that the first year should more consist of information and guidance/education rather than sanctions and to focus on small companies since the larger often already know their obligation. A problem can be that companies that do not comply today with the legislation will probably act in the same way in future.

More results from workshop concerning Title II, III and VI:

- It is important to notice that the non-phase in substances (the very new substances) also requires a registration.

- If the substance has an ELINCS-number, another manufacturer/importer has to register even if the substance is considered as registered (only registered by a specific manufacturer/importer).

- It will be difficult to get information from companies (especially from importers) as the definition of substance could be difficult to interpret (e.g. mono-constituents, multi-constituent, reaction products)

- Stocks - difficulties to prove when manufactured/imported. There is a need to check supply chain, tonnage, time when M/I.

- Article 7: Need final decision of definitions e.g. is it an article or a substance in a container? Customs need guidelines/defined role if they shall enforce Article 7, especially the relation to the custom codes.

- Article 7.2 applies for all articles, also "intended release" articles 
- Article 7.7 - note that candidate list is not present until June 1, 2011

- Art. 8.2 - Only representatives - system needed of information MSMS (could be a Forum duty?).

- Article 9,17and 18 - need to add article 49 (strictly controlled conditions etc.). Notification and PPORD conditions can be enforced. Information needed from CA to enforcers and from enforcers to CA.

- Article 10 does more belong to evaluation as it is a part that the ECHA controls. Article 12 and 14 are also connected to evaluation (tonnage, CSR). Tonnage also relates to Article 6.

- The labour inspectors need training as they usually have little or no knowledge of REACH if they have to compare the SDS with the CSR (Article 14).

- Article 20.2 and the evaluation articles - enforcement has to be triggered by the ECHA (via MS CA). The national CA will only be contacted in those cases where ECHA does not get a response in the communication with the company. Otherwise the correspondence is only between the ECHA and the company.

- Article 22 - updating (tonnage, status, new uses etc.). Low priority, rather simple to enforce (easy to create simple checklists). New uses can probably be identified when DU is inspected.

- Article 23, concerning deadlines, has to be enforced together with articles 5 and 6

- Suggestion to add Article 50 to evaluation articles.

Title IV

The conclusion after the workshop was that Article 31 is the main priority this Title. This article has some new requirements - e.g. SDS for $\mathrm{PBT} / \mathrm{vPvB}$, added exposure scenarios. When controlling the SDS, the content shall be in compliance with Annex II of REACH. Results from earlier controls are that $>50 \%$ of SDS content is incorrect and the future controls will show if this will be better with REACH. If the SDS should be compared with the CSR, there is a need to have access to the CSR via REACH-IT in some way. If the MS/CA will give information of CSR to enforcement authorities, they will become some kind of "gatekeepers".

A discussion at the workshop was if the requirements to deliver a SDS are fulfilled with links in an e-mail to customer to available SDS on the company's website. No conclusion was reached.

All the countries are checking SDS as this has been an enforcement duty since many years, but none is punishing the companies for not having changed place on headings 2 and 3. 
More results from workshop concerning Title IV:

- Article 32.- If the format for SDS is used for information according to Article 32 - there is a need to state in the SDS that this is information according to this article

- Article 33 - high priority but difficult to enforce - no guidance on what information to give, what safe use means, what is application to whole lifecycle and interpretation of $0,1 \%$.

- Article 36 - Low priority could be difficult to enforce

\section{Title V}

A main conclusion from the workshop was that DUs consists of a variety of companies. Therefore there is a need for cooperation between REACH enforcers, e.g. OHS and environmental law enforcers. There could then be some problem if there are different requirements in different legislation - should you follow the highest level of protection? (Example: DNEL - OHS limit)

More results from workshop concerning Title V:

- What do if DU has told use to $\mathrm{M} / \mathrm{I}$ but get no recommendations back? What can be required of DU? This may end up in difficulties to know who has the responsibility

- COM legal service analysis of 37.2, 37.4 should be brought into attention

- Difficult to check if SDS for a preparation is in line with SDS for constituents/components

- Need to prioritise formulators, but difficult to reveal if they have "done their job"

Title VII

The conclusions from the workshop were that Article 56 is the main priority as it states the core provisions of authorisation. As authorisation will be a work in progress and new authorisations or changed/withdrawn authorisation will occur continuously, the enforcers need updated information, preferably via REACH-IT/or by MS/CA.

More results from workshop concerning Title VII:

- Art 60.10 - low exposure as possible - (very) difficult to enforce

- Art 61.4 - EQS might be monitored by those enforcing WFD (feedback to ECHA/COM)

- Art 62 - enforcers should control applications only in extraordinary cases (false data might lead to sanctions or to review of authorizations, unclear what priority review will be for COM

- Art 65 - labels rather difficult to know when a label is needed (for which substance, or which substance in a preparation?) 
- Art 66 - controlling DU notifications is a simple duty, but it could be better (?) to first check which DUs using "Annex XIV substances" and then control if conditions are complied with and a notification made.

\section{Theme 2: Methods/ Tools for enforcement and} Competences/ education needs

\section{Introduction}

The second theme was introduced by Jos van de Berg (The Netherlands) (c.f. Appendix 1 to the minutes) and focussed on how we need to develop enforcement methods and tools and what we must think about regarding to competences and educational needs. Again the discussion sessions were in three groups:

Group 1: $\quad$ Titles II, III, VI

Group 2: $\quad$ Titles IV, V, VII

Group 3: $\quad$ Free choice of Titles

Summary of the discussion

In the discussion possible information sources as well as specific needs or preconditions were stated.

- Information sources

- Use good practice from ECLIPS - a CLEEN project concerning CL and SDS;

- Info out of NONSE/ SENSE Project (Eurex)

- $\quad$ RIP 3.5

- Needs

- Methods:

- Site visit versus desk study (depends on subject of inspection)

- specific branch checklists

- Need for checklists on CL and SDS

- Tools for selection of companies

- The use of information from different sources:

- Site permits

- Registration for taxes

- Risk approach

- Trade registration/ product registration

- Information from other MS (about trades)

- Other inspectorates/ stakeholders

- Need for a list of authorizations 
- Importer needs to have their own inventory of substances contained in products from outside EU

- Information to China and other countries outside EU about REACH

- Information to inspectors that they have a duty to enforce REACH

- Monitoring effective control to learn for the future

- Monitoring the behavior of the companies

- Make an inventory of companies that don't follow the regulations

- Guidance document on programming of inspection work

- Decision support system to help inspectors to easily interpret the scope and the exemptions of (examples are similar systems in (Lv) cosmetics, biocides (SE))

- Accountancy like tools to check tonnage bands (like the chemical weapons inspectors form the UN do)

- Methods on sampling and analyzing

- Tools to verify communication in the supply chain (auditing tools)

- Checklist for inspection of downstream users

- Methods for integrated / coordinated inspection (on both inspection level as program level)

- A method to make a good link with activities on IPPC and WFD

- Overall guidance on inspection

- Compilation (example: Seveso)

Preconditions

- Information should be in English (this narrows the possibilities)

- Use CIRCA for upload information about good practices

- A proper treatment of confidential information

These needs and preconditions form the basis for the design of a compendium; this will be worked out by the project group in a paper on this topic.

Suggestions on competences and education:

- Depends on tasks/ national approach

- Use information from the past (e.g. info about polymers)

- Exchange of inspectors (as done for Seveso)

- Support of ECHA for training the trainers

- Service from ECHA to assist

- One MS gives a training open for other MS

- Attention for chemistry/ engineering process

- Specialist support is necessary

- Legal advisors

- Toxicology

- Training on the job/ not only theoretical 
- Different approach in different countries:

- Country 1: Inspectors from 3 different authorities trained to enforce all titles of REACH

- Country 2: To inspect SDS you need to ask 5 different authorities to enforce the different sections

- Knowledge in detail of REACH

- Knowledge of Legal affairs

- Knowledge how to inspect a company

- Knowledge of processes and companies

- Knowledge of chemistry (especially title V)

- Knowledge of administrative and criminal law

- Auditing skills (specialists)

- Training to use checklists

- Use of database (short).

\title{
Individual results of groups
}

\author{
Group 1: Title II, III and IV
}

Discussion leader: Barbro Sillrén

Registration of Substances

- Info out of NONSE/ SENSE Project (Eurex)

- Differences M/I versus placing on the market

Selection of companies

Use of different sources:

- Site permits

- Registration for taxes

- Risk approach

- Trade registration/ productregistration

- Information from other MS (about trades)

- Other inspectorates/ stakeholders

Suggestion: pilot project for the co-operation with customs

Good practices from MS

- Main points: much information but not in English!

- Use circa for upload information about good practices

- Also use circa for exchange information about violations (platform)

Methods:

- Site visit versus desk study (depends on subject of inspectation)

- MS check specific branches and share information to Forum/MS 
Competences / education

Suggestions:

- Depends on tasks/ national approach

- Use information from the past (e.g. MOD/ info about polymers)

- Exchange of inspectors (as done for Seveso)

- Support of ECHA for training the trainers

- One MS gives a training open for other MS

- Attention for chemistry/ engineering process

- Specialist support is necessary

- Legal advisors

- Toxicology

- Training on the job/ not only theoretical

\section{Group 2: Title IV, V and VII}

Discussion leader: Lars Gustafsson

Methods/Tools - general information

- Information to inspectors that they have a duty to enforce REACH

- Selection of companies to enforce for compliance with REACH is very important

- Monitoring effective control to learn for the future

- Monitoring the behavior of the companies

- Make an inventory of companies that don't follow the regulations

- Information to inspectors that they have a duty to enforce REACH

- Selection of companies to enforce for compliance with REACH is very important

- Monitoring effective control to learn for the future

- Monitoring the behavior of the companies

- Make an inventory of companies that don't follow the regulations

Methods/Tools - Title IV

- SDS should be better with REACH than before

- Need of access for information/data is crucial

- Composition

- Exposure scenarios (CSR)

- Some countries have a product register

- REACH-IT?

- Use good practice from ECLIPS - a CLEEN project concerning CL and SDS ( $>50 \%$ SDS incorrect)

- Will the quality of information in SDS suffer where tonnage is smaller?

- In some countries different authorities inspect the SDS at different companies - need for communication between authorities 
- Need for checklists

Methods/Tools - Title VII

- Need for a list of authorisations

- Again, product register is a tool

- Imported consumer products seen as a big problem

- Importer needs to have their own inventory of substances contained in products from outside EU

- Information to China and other countries outside EU about REACH

Competence/Education

- Different approach in different countries:

- Country 1: Inspectors from 3 different authorities trained to enforce all titles of REACH

- Country 2: To inspect SDS you need to ask 5 different authorities to enforce the different sections

- Knowledge of REACH

- Knowledge how to inspect a company

- Knowledge of processes and companies

- Knowledge of chemistry (especially title V)

- Knowledge of administrative and criminal law

- YOU NEED A TERMINATOR!

A proposal for Forum to make a training and education program about $\mathrm{REACH}$ for police, lawyers and public prosecutors 


\section{Group 3: Free choice}

Discussion leader: Armand Dohmen

\begin{tabular}{|c|c|c|}
\hline Process & Methods/ Tools & Competences \\
\hline Programming inspection & Guidance document & \\
\hline \multirow[t]{4}{*}{ Scope/ exemptions } & \multirow{4}{*}{$\begin{array}{l}\text { Decision support system (Uk } \\
\text { cosmetics, biocides (SE)) }\end{array}$} & Legal knowledge \\
\hline & & General \\
\hline & & Specialist (legal adv.) \\
\hline & & Basic knowledge of systems \\
\hline Tonnage & $\begin{array}{l}\text { Chemical weapons 'accountancy' } \\
\text { like tools }\end{array}$ & \\
\hline \multirow[t]{4}{*}{ Quality of information (SDS, CSR) } & Product register (preparations) & Training toxicology \\
\hline & SDS-checklists (ECLIPS) & (specialists) \\
\hline & \multirow[t]{2}{*}{ Sampling / analysis } & .. \\
\hline & & Possible service by ECHA \\
\hline $\begin{array}{l}\text { Communication Downstream } \\
\text { /upstream }\end{array}$ & Tools to verify & Auditing skills (specialists) \\
\hline $\begin{array}{l}\text { Application the info (DU) control } \\
\text { measures }\end{array}$ & Checklist & $\begin{array}{l}\text { Training to use checklist } \rightarrow \text { knowl- } \\
\text { edge (chemistry/ occupational } \\
\text { health/ env. Etc.) }\end{array}$ \\
\hline \multirow{4}{*}{$\begin{array}{l}\text { Application the info (DU) control } \\
\text { measures }\end{array}$} & \multicolumn{2}{|l|}{ Integrated/ cooperation inspection } \\
\hline & \multicolumn{2}{|l|}{ - inspection level } \\
\hline & \multicolumn{2}{|l|}{ - programming level } \\
\hline & \multicolumn{2}{|l|}{$\begin{array}{l}\text { Make a good link with IPPC per- } \\
\text { mits }\end{array}$} \\
\hline \multirow[t]{5}{*}{ General } & Overall guidance on inspection & General training \\
\hline & Compilation (ex. Seveso) & Basic (NL, LV) \\
\hline & \multirow{3}{*}{$\begin{array}{l}\text { Treatment of confidential informa- } \\
\text { tion }\end{array}$} & Elaborate \\
\hline & & Specific training \\
\hline & & Use of database (short) \\
\hline
\end{tabular}

\section{Theme 3: Ideas on enforcement projects and REACH-IT}

\section{Introduction}

The theme was introduced by Birte Børglum (Denmark) (c.f. Appendix $1)$.

This time all participants were divided in two groups:

Group 1: Projects

Group 2: $\quad$ REACH-IT

Lars Gustafsson gave a more detailed presentation for Group 2 of and handed out two short papers which. 


\section{Summary of the discussions}

The short discussion of projects resulted in some specific project ideas and suggestions on how to propose and select projects. This resulted in a vision on development of a guidance document and report template. Furthermore ideas were launched on projects of Co-operation with Customs, a proposal for a project on targetgroup SME / Importers, a proposal for a project on building chemicals and a proposal for project to Forum on SDS. Also projects can be launched to reach Harmonisation of Level of Capabilities and to develop a training kit for enforcers.

The short discussion of REACH-IT to a large part was used for presentation by Lars Gustafsson of two draft short papers on needs for and access to information in REACH-IT (will be used as starting point for a paper from the project on REACH-IT and enforcement), and by explanations of the work with REACH-IT given by a COM representative. The main result of the discussion was the conclusion that more work is needed to more precisely identify and explain the needs for confidential information including e.g. how fast and in what way the information is needed. At the time of the discussion, COM pointed out that there is still a possibility left to influence the so called Query Tool for retrieving information from REACH-IT.

\section{Individual results of groups}

\section{Group 1: Projects}

Discussion leader: Tom O’Sullivan

In the workshop the following ideas were suggestion concerning projects and on specific ideas for projects.

1: Project topic to be announced up to one year in advance:

This arose following discussion on the time delay between Forum meetings ( 2 per year). It was suggested that the initial meeting will probably be dealing with Rules of Procedure etc. so that it may be late 2008 before the Forum will be in a position to start projects. To overcome this delay it was suggested that Forum topics be announced as early as possible so that member states could decide early which projects they wished to be performed and which they wished to participate in.

\section{2: Development of Guidance Document:}

It was suggested that a REACH inspection guidance document be prepared as a Forum project to assist in harmonisaton of enforcement. An example was cited of the guidance document prepared by the European 
Chemicals Bureau for the enforcement of the Seveso (Control of Major Accident Hazards to Man and the Environment) Directive.

3: Development of a Report Template: (2008)

This was suggested as an early (2008) project for the Forum. Each member state must report back to the Commission in 2010 on the implementation of the REACH Regulation. The early availability of a report template would ensure each Member State is recording the relevant information to assist in the compilation of the 2010 report.

\section{4: Project of Co-operation with Customs:}

It was agreed that Customs have a role to play in the successful implementation of the REACH Regulation as they are the frontline point of entry of chemicals to each member state. However it was noted Customs Codes refer to product classes and would not be readily able to identify substances to which Authorization or Restriction apply. A project was suggested for the Forum to develop a process which could assist Customs throughout the EU to identify such substances more easily.

\section{5: Harmonisation of Level of Capabilities:}

It was noted that there is differing levels of enforcement capabilities throughout the Member States. A project to ensure harmonization of these capabilities was suggested.

6: Develop basic Training Kit:

A project was suggested to develop a basic training kit for enforcement inspectors. This could be in the form of a Proforma type questionnaire.

7: Proposal for project to Forum on SDS (2009).

It was noted that up to $50 \%$ of existing safety data sheets (SDS) are inadequate. It was suggested that the Forum prepare on project throughout the member states to identify the level of adequacy of SDS and proposal for improvement.

\section{8: Proposal for a project on targetgroup SME / Importers}

It was noted in earlier discussions during the workshop that the risk of non compliance is larges in the group of small- en medium size importers. Therefore designing a specific project for this target group was suggested. It however could also be done in a way that they receive special attention in other projects.

\section{9: Proposal for a project on building chemicals}

The idea was raised by the Polish delegate to the workshop. In Poland such a project was defined because of the great amount of activities in this sector. 


\section{Group 2: REACH-IT}

Discussion leader: Lars Gustafsson

As input for the workshop discussion a handout on the access to REACHIT for enforcers was reached out (see Appendix 3a). Also a short introduction on REACH-IT has been given by Commission Member from REACH-IT management. In the workshop some questions on the need for confidential information from REACH-IT were used as discussion points (see Appendix 3b).

REACH-IT system collects data from users, stores this in databases and then provides information to other users. The system should support activities of ECHA. Technically there are no problems to implement the system. The problem is how to define and specify what information is needed. The REACH-IT management team is building a query tool at this moment, input or requests are welcome from all MS. First version is expected in December 2007 and end result should be available in March 2008.

Conclusion of the workshop is that it's necessary to further specify needs and requirements, specify which information and why. In October the project group will get down more specific questions and request and send these as input for the Query tool of REACH-IT.

The following suggestions concerning REACH-IT can be summarised as resulted out of the workshop:

9. Specify the information needs

10. Project group makes short paper

11. 30 reports might be searchable data batches

12. More solutions could eventually be found

13. REACH Query Tool is still worked on, specific requests are welcome!

14. Forum project later on?

\section{Closure}

Lars Gustafsson closed the workshop and thanked everyone for their valuable inputs.

The resbults of the workshop will be included in papers from the project group regarding

- Priority Articles

- Methods/tools

- Competence/education

- Project ideas

- REACH-IT and enforcement 
All these papers, together with papers on borderlines and alert systems, and the draft Rules of Procedure for Forum elaborated by the project, will be included in a final report from the project, planned for handover to Forum members in January/February 2008.

\section{General remarks:}

1) MS were asked to send more information on available methods/tools to share with other MS.

Minutes from the Workshop were to be distributed the WS participants.

2) The Netherlands have made an official start on implementation of REACH. They established three documents, among which an enforcement strategy. This strategy is translated to English and can be send to interested MS. Contact Jos van de Berg for more information.

\section{Appendix 1: Introduction to the themes}

Theme 1 Prioritisation needs: introduction by Lars Gustafsson

Background and report

- All MS to establish priorities, sanctions

- Common views may contribute to efficient enforcement / REACH functioning well

- Draft to be used as thought starter

- Open questions + similar/different views

- Need for views of more MS and others, then make a "final" draft

- Might facilitate discussions and conclusions in MS

Focus for report:

Titles with new/extensive obligations

- Identify articles that seem most important to enforce to make REACH work appropriately

("what happens if article not implemented?")

- Identify problems with these articles that may make enforcement difficult

- Identify some specific common needs for confidential information from REACH-IT

Registration (II)

- "Core" Registration articles (5-7)

- - enforce just these? what to do with 7? 
- Articles on what, how, and when to make an "ordinary" Registration including CSR (e.g. 10,12,14,23) - enforce separately?

- Articles on PPORD + special Registrations + update $(9,17,18,22)$ - enforce separately?

- Problems e.g. exemptions, substance identity

Data Sharing and Avoidance of Unnecessary Testing (III)

- "Pre-Registration" (28)

- Other duties, e.g. to share test data (30)

- Articles fitted for enforcement? Which?

- Relation to registration?

- Enforce art 5 if neither pre-reg nor reg?

Evaluation (VI)

- ECHA check test plans/complience, require tests to be made/more information $(41,42)$

- Urgent to enforce evaluation decisions?

- (possible to stay on market in spite of very bad registrations?)

- What can ECHA do, what can MS do?

- MS do substance evaluation, require more information, reveal needs further action (46)

Information in the Supply Chain (IV)

- Add Exposure Scenarios in SDS (31)

- when will Reg. lead to better SDSs

- need to check SDS against CSR?

- Give info on Substances in Articles (33)

- prioritise in spite of unclarities?

- Assemble/keep all info for 10 years (36)

- benefits from enforcing this? Downstream Users (V)

- DUs always ensure adequate control. If own approach: reporting/CSR duties $(37,38)$

- Importance versus M/Is duties?

- How decide whether a use is inside/outside the "conditions" described in the SDS?

- Check against DNEL/PNEC? (adequate control irrespective of if inside/outside??

- Coordinate with enforcement of work / environment legislation?

Authorisation (VII)

- General provision on SVHC (56)

- What should be enforced besides, e.g.

- Ensure lowest exposure (monitor)? (60)

- Check against EQS (monitor)? (61)

- False data in applications?(62) 
- Notifications to ECHA?(66)

- Co-ordinate with enforcement of work / environment legislation?

Other Titles - examples

- Restrictions (VIII):

- Same as before but now a Regulation

- Implications on enforcement?

$\bullet$

- Classification/Labelling (XI):

- Less harmonisation

- Implications on enforcement?

$\bullet$

Theme 2 Methods/tools and competences - introduction by Jos van den Berg

How to develop/where must we think about?

- Use good practices from Cleen-project

- Examples: Eclips, Eurocad and Euroazos

- Use good practices from MS

- Reaction was recieved from pg-members and Poland

Where must we think about?

- Methods/tools for

- General approach and selection of companies

- Site visit and fysical inspection (e.g. stock and proceses)

- Administrative inspection

- Sampling and analysis

What needs a good enforcer?

- Knowledge of REACH legislation

- Knowledge of processes and companies

- Knowledge and skills to inspect a company

- Knowledge and skills to check administration processes

- Knowledge and skills to give penalties (administrative and criminal law)

Which needs for educations are there?

- Depends of the existing knowledge and experiences (custom made education)

- Examples for education:

- Detailed information of the regulation

- Development of inspection skills

- Development of behavior skills 
- NL will have in a month a national programme for

- Education in 2008/2009

Theme 3 REACH -IT and projects: introduction by Birte Børglum

\section{REACH-IT}

What do we need of information to enforce REACH?

Projects

Ideas on enforcement projects for Forum to coordinate

\section{REACH-IT}

15. Information about substance registrations of a company

16. Information about the basis of the classification of a substance

17. Information about CSR

18. Information about the supplier chain

\section{PROJECTS}

- SDS

- Pre-registrations

- Registrations

- Authorisation

- Restrictions

\section{Appendix 2}

Theme 1 Analysis of prioritisation of Articles, needs and problems

- Results from the individual group discussions

Group 1: Titles II, III and VI

Discussion leader: Jos van de Berg

Title II Registration of Substances

- Article $5+6$ highest priority $(\uparrow \uparrow \uparrow)$, all other articles are sub-ordinate to these

- Non-phase-in substances (very new)

- ELINCS- number

- $\quad$ Article 8.2

- Only representatives (Forum duty?)

- Article 7

- Need final decision on definitions 
- Customs role need for good guidelines

- Candidate list has to be present, but not implemented until 1/6 2011

What to do with Stocks?

- Article 10 (connected to evaluation)

- ECHA checks

- Article $12+14$

- Tonnage (12:reg. level and 14:CSR)

- Article 20.2

- Enforcement triggered by ECHA

- No registration yet!

- Article 22 (low priority: simply to enforce) updating (conditions may chance)

- Check: tonnage, status, new users

- Article 23 : Deadlines

- Enforce in combination with art. 5/6

- Exemptions (Art. 9,17,18,49)

- In combination with art. 5/6

- Article 9 - conditions PPORD

- Article 17, 18 (49) - strictly controlled conditions

Title III Sharing of Data

- Pre-registration Article 28 (part of 5 / 6)

- Article 30.6 Penalisation has to be clarified

Title VI Evaluation

- Article 40.4, 41.4-5, 46.2, 49, 50

- Enforcement Triggered by ECHA or CA

- Concerns further information and testing proposal submission

Group 2: Titles IV, V and VII

Discussion leader: Birte Børglum

Title IV - Information in the Supply Chain

- Art 31 main priority, has new requirements

- SDS for PBTs etc (31.1b-c), add exposure scenarios (31.7)

- Also need to check Annex II on SDS

- Need to check what RIP 3.5 says on 31-32

- $\mathrm{M} / \mathrm{I}$ might make SDS available on website via link in e-mail - is this $\mathrm{OK}$ ?

- $50 \%$ SDS content incorrect today, tomorrow?

- With respect to REACH-IT access, only CAs will be able compare SDS with CSR

- CAs cannot refuse to give info to enforcers (?), will become gatekeepers 
- If SDS format is used for Art 32, need to state that this is art 32 info

- Art 33 high priority, but for now difficult to enforce - no guidance on what info to give, what 'safe use' means, application to whole lifecycle, and interpretation of $0.1 \%$ (?)

- Art 36 hard to enforce, probably not focus

Title V - Obligations of Downstream Users

- What do if DU has told use to M/I but get no recommendations back? What can be required of DU? May end up in difficulties to know who has the responsibility

- COM legal service analysis of 37.2, 37.4 should be brought into attention

- Difficult to check if SDS for a preparation is in line with SDS for constituents

- Need to prioritise formulators, but difficult to reveal if they have "done their job"

- If different requirements from different legislation, follow the highest level of protection? (example: DNEL - OHS limit)

- Need for co-operation between REACH enforcers - e.g. OHS and environmental law enforcers

Title VII - Authorisation

- Art 56 ("core provision") the clear priority

- Need to inform enforcers continuously

- 60.10 on as low exposure as possible (very) difficult to enforce

- 61.4 on EQS might be monitored by those enforcing WFD (feedback to $\mathrm{ECHA} / \mathrm{COM}$ )

- 62 on applications only in extraordinary cases (false data might lead to sanctions or to review of authorizations, unclear what priority review will be for $\mathrm{COM}$ )

- 65 on labels rather difficult to know when a label is needed (for which substance, or which substance in a preparation)

- 66 on DU notifications simple duty, but maybe better (?) to first check which DUs use Annex XIV substances and then are conditions respected + notification made?

Other

- One of the first Forum projects might be to have enforcers reporting back problems with some selected REACH articles

- One optional tool could be to have a list (on ECHA/CA/other website?) with questions enforcers will ask during inspections, might influence the behaviour of companies 
Group 3: Free Titles

Discussion leader: Tom O'Sullivan

\begin{tabular}{|c|c|c|c|c|}
\hline Article & Priority & Severity & Obstacles & Direction of solution \\
\hline \multirow[t]{6}{*}{5} & \multirow[t]{6}{*}{ High } & \multirow[t]{6}{*}{ High } & & \multirow{2}{*}{$\begin{array}{l}\text { Data decision support } \\
\text { system }\end{array}$} \\
\hline & & & Amounts (workload) & \\
\hline & & & \multirow{2}{*}{$\begin{array}{l}\text { Finding 'non registrants' } \\
\text { Access to REACH-IT }\end{array}$} & $\begin{array}{l}\text { Cooperation between au- } \\
\text { thorities }\end{array}$ \\
\hline & & & & \multirow{2}{*}{$\begin{array}{l}\text { Checklists for customs } \\
\text { offices }\end{array}$} \\
\hline & & & $\begin{array}{l}\text { Only } 5 \% \text { registrations checked (false } \\
\text { info?) }\end{array}$ & \\
\hline & & & Operator awareness of REACH & $\begin{array}{l}\text { Information campaigns for } \\
\text { smaller companies (semi- } \\
\text { nars etc) }\end{array}$ \\
\hline \multirow[t]{2}{*}{14} & \multirow[t]{2}{*}{ High } & & \multirow[t]{2}{*}{$\begin{array}{l}\text { Different backgrounds of inspectors } \\
\text { (env./chem./health...) }\end{array}$} & $\begin{array}{l}\text { Integrated checklists to be } \\
\text { distributed }\end{array}$ \\
\hline & & & & $\begin{array}{l}\text { Number of enforcers visit } \\
\text { site together? }\end{array}$ \\
\hline
\end{tabular}

\section{Appendix 3a}

Extract from document CWG/33/2007 by COM/DG ENT (Brussels, 14.08.2007)

Proposal on how to control the access of external parties to REACH-IT (CWG subgroup: Security Officer Network)

\section{External party definition}

An external party in this context of REACH-IT is a person not employed by the European Chemicals Agency (ECHA) or a Member State Competent Authority (MSCA) requiring access to REACH-IT business data that is not available in the public dissemination site. These persons must have been contracted either by the Agency or an MSCA to perform a task for them under the REACH legislation and they therefore require having wider, but defined access than the general public. The contract must also contain a paragraph explaining the secrecy agreement, i.e. that data from the REACH-IT system cannot be used in another context or shared with any other parties.

Enforcement authorities which have a legal obligation to enforce REACH will not be considered to be contracted as external parties but do fall under the definition of external party. 
Proposal

Based on the analysis and design of REACH-IT and the discussions held in this subgroup, the Commission services propose to the Interim Executive Director of ECHA that external parties can be granted limited access to REACH-IT under strictly defined conditions.

REACH-IT will have several user profiles that can be assigned to external parties. Those profiles precisely define what data the external parties are allowed to access and what actions on this data are allowed or denied. In some cases online access will not be necessary and data can be provided in another form.

Below there are some examples of each of the different categories in a registration dossier.

Never confidential

EINECS or ELINCS

C\&L

Guidance on safe use

DNEL and PNEC

Analytical methods if requested in accordance with Annexes IX or X

Always confidential (unless urgent action is needed to protect human health or the environment such as emergency situations)

Full composition of a preparation

Precise use including its precise use as an intermediate, function or application of a substance or preparation

CSR

Precise tonnage of the substance or preparation manufactured or placed on the market

Links between a manufacturer or importer and his distributors or DU

Potentially confidential

IUPAC name

Trade name

Degree of purity of the substance

Identity of impurities that are known to be dangerous

Additives that are known to be dangerous

Total tonnage band within which a substance has been registered

Study summaries and robust study summaries

"Grey zone"

Company name

Company contact person

Production site 
Controlled access of external parties

The online access of users can be limited so that only parts of a dossier are viewable to them or that they will only be able to access a certain set of dossiers, based e.g. on the location of the production site. Therefore online access to REACH-IT can be granted to an external party requiring it. Granting access to such a user can be achieved exactly the same way that standard MSCA or ECHA users request access to REACH-IT, but their account will only grant them limited access and will only be valid for a short period of time. The MSCA or ECHA user administrator can define this time, when the new user account is created and the role assigned.

In practice this means that external parties must be working in the premises of the Agency or an MSCA, when they require access to REACH-IT. The subgroup on MSCA connectivity discussed in more detail the possibilities that different MSCAs have to gain access to REACHIT. The identities of external parties will be verified and the MSCA decides what level of access they require. The definition about the level of access to business data is partly driven by the external party itself, so that they will request access to a specific data set and the MSCA or ECHA will evaluate if the need is legitimate. As a general rule the external parties will belong to a user group that only has limited access to business data. The exact fields will be identified separately for each external party. In the long run external party access groups can be defined based on gained experiences.

All external parties who will gain online access to REACH-IT must sign "external party access request" and "non-disclosure agreement" forms that will explain them inter alia that data must be kept confidential and that their actions in the REACH-IT system will be traced.

In some cases direct access to REACH-IT will not be necessary when e.g. only a limited subset of the business data is needed to perform the task at hand. For this purpose there will be a mechanism in REACH-IT to create pre-defined Business Object (BO) reports that will have some fields, considered confidential for the current purpose, filtered out. These reports can be generated, by MSCA or Agency staff having the correct role, from the business data and will contain various options to compare different data sets. Exports from the REACH-IT system will be logged and traceable so that it will be possible to see who exported what data and when. Of course once the data is out of the REACH-IT system, it will be beyond its control. Since the information is limited and the external party has signed agreements, the security risk of information leaking out in the form of BO reports is limited.

All the methods above refer either to online viewing of data or downloading data in the form of business reports. Downloading a full dossier from REACH-IT to be used e.g. in a local IUCLID5 installation can also be an option, but in these cases there must be a clear justification 
why online view access or BO reports do not cover the needs on the external party in question. An authorisation method needs to be defined.

Once the security procedures have been set-up and ECHA is operational it could be foreseen that an auditing firm would be contracted to perform an audit. The purpose would be to verify that agreed procedures regarding access to data are strictly followed in ECHA and MSCAs.

\subsection{Enforcement authorities}

In the context of REACH-IT the enforcement authorities are considered to be external parties and therefore will follow exactly the same procedure as described above in 0 . However as described above the online access to REACH-IT can only be allowed from the premises of the MSCAs. Therefore the enforcement authorities must also perform their work in the premises of the MSCAs or discuss with the MSCAs to get the information in the form of $B O$ reports. Since enforcement is very much a national issue the enforcement authorities must contact their local MSCA for the necessary practicalities. The topic of enforcement has been discussed in more detail in the CWG subgroup on enforcement.

\section{Appendix 3b}

Swedish Chemicals Agency

Draft, 21 September 2007

Lars Gustafsson

\section{Example(s) of how to describe a need for confidential information from REACH-IT}

\section{Which is the enforcement situation?}

Control of that DUs who manufacture preparations make appropriate SDSs, and that the DUs where obliged to do so notify uses outside conditions to ECHA and prepare a CSR.

\section{Will your request for information be common?}

Yes, very common, a large number of DUs manufacturing preparations will be inspected.

\section{What exactly is it that you need?}

1. To check with the CSR for a number of substances used in the preparations, to reveal

a) if the DUs uses are inside or outside of the conditions, with respect to the M/Is assessments and recommendations, the DUs uses as well as the recommendations for uses in conditions in the SDSs made by the DUs are appropriate, and 
b) if the uses/conditions recommended in the DUs SDS is outside the uses/conditions recommended in the M/I SDS

2. Where uses outside the conditions in the M/Is SDS are observed, check whether a notification to ECHA has been made

\section{Why?}

5. How do yo wish to access the information: on-line at your MSCA or via a $B O$ report?

Neither, because

- Working in the premises of the MSCA would mean that....

- A Business Object (BO) report is not an alternative for checking against various parts of a number of CSRs made by M/Is in various MS, since.

- A BO paper report on notifications made by DUs in my MS would mean too much work with manual checking. Instead, we would need a searchable data file, to be able to run our list of names of companies and names of substances - the use of which we consider are outside $\mathrm{M} / \mathrm{Is}$ conditions - against data in REACH-IT 


\section{Annex IV - Presentation of the project at 1 st Forum meeting 11 December 2007}

\section{"A FLYING START" \\ Proposals for the Forum on enforcement of REACH}

Report on the REACH EU enforcement

On behalf of the project group Jos van den Berg, Dutch VROM - inspectorate

Helsinki,

Helsinki,
12 December 2007

\section{Contents}

- Background

- Project contents and results (based on tasks Forum)

1. Rules of Procedure

2. Prioritisation of articles and information needs

3. Methods \& tools for inspector

4. Competence \& Education for inspectors

5. Access to REACH -IT

6. Alert syste $\mathrm{ms} /$ in formation exchange

7. Borderlines/Interfaces between involved organisation s

8. Suggestions for projects

- Recommendations of the project group 


\section{Background}

- With in CLEEN it was early clear that REACH would mean a significant restructuring and enlargement in the field of the chemicals regulation

- Also the significance of the Forum - including a good start for it - for a good implementation of REACH was recognised early

- Therefore, at the CWG meeting in November 2005 a new REACH Implementation Project (RIP) on enforcement was proposed by Sweden (but not accepted)

- This lead to start of REACH EU Enforcement Project in March 2006, and of sub-CWG Enforcement in June 2006

"A elsinki,
12 December 2007 Proposals for the Forum on enforcement of REACH"

\section{Background}

- Financial support for this project has been arranged by Nordic Council of Ministers and Netherlands

- Commission has been able to give indirect support (meeting rooms, travel costs), since project workshops and sub-CW $\mathrm{G}$ meetings have been held back-to back

- Project group: Denmark, Ireland, Netherlands, and Sweden (lead); Consultant: Royal Haskoning (NL)

- Referral group: Austria, Norway, Spain, Belgium, Latvia, Slovenia, and United Kingdom

- Steering group: sub-CW G Enforcement 


\section{Background}

Overall Project objectives:

- Identify present enforcement and new needs due to REACH

- Investigate the state of preparation of the Member States and start preparing for the operative work of Forum

- Elaborate work division, co-operation and information exchange

- A draft proposal for Rules of procedure

- Develop a compendium of enforcement methods

Helsinki,

12 December 2007 "A FLYING START"

\section{Background}

- To achieve this several activities (workshops, investigations, etc.) were carried out

- All with the purpose to give the Forum a 'flying start'

- Today we present an overview of the results

- The written report will follow in February 2008

- Draft reports are already available on request

\section{Subject 1:}

\section{Rules of Procedure}

- The initiators of the project early considered the significance of these RoP's and decided to formulate a proposal

- During the process towards this proposal - Other RoP's were studied

- Relevant Issues and demands were determined

- Drafts were made and revised

- Multiple consultation and discussion rounds were held

- A proposal was handed over to ECHA 
Subject 2: Prioritisation Focus for the report

- Identify articles that seem most important to enforce to make REACH work appropriately

- Identify problems with these articles that may make enforcement difficult

- Identify some specific common needs for confidential information from REACH-IT

\begin{tabular}{l}
\hline Helsinki, \\
12 December 2007 \\
"A FLYING START"
\end{tabular}

Subject 2:

Highest priorities / challenges

- Articles 5 and $6 \quad$ No data - No market

Duty to register

- Article 31 (31.7) Duty to add ES to SDS

- Articles 37 and 38 Implement ES or

- Article $56 \quad$ Use of SVHCs according to authorisation

- Article 67.1 Restrictions 


\section{Conclusions from the analysis of articles}

General, returning conclusions:

- Biggest challenge for inspectors: establish whether a substance is within the scope of $\mathrm{REACH}$

- Information from ECHA is essential

- Coordinate with enforcement of work / environment legislation?

- Further analysis needed

\section{Subject 3}

\section{Methods \& Tools for the inspector}

- There is a clear need for guidance on every level (Management as well as inspectors).

- Members States recognize the usefulness to exchange information but do not want to be prescribed how to act: Harmonization has its maximum

A compendium was the desired solution

- There is much available but not in all languages and not all REACH specific

- First needs were identified 


\section{Subject 3}

\section{Methods \& Tools for the inspector}

The concept for the compendium

- In order for all the different user groups, with changing interest, we propose to create a database-like structure. This means that any tool or method is labelled according to specific items:

\section{A continuously evolving toolbox}

- This information can be placed on Circa

- The first paper version is a large table

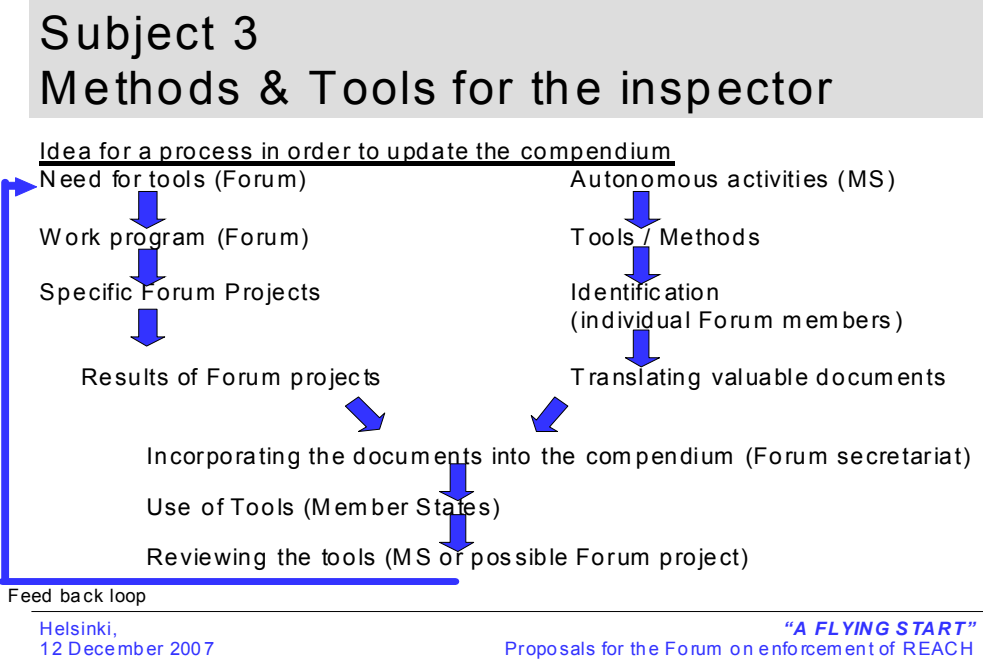

\section{Subject 4}

Competence \& education of inspector

- $\mathrm{REACH}$ requires new knowledge of the inspector

- Main issues:

- Knowledge of REACH

- Knowledge of chemistry, processes and industry

- Specific knowledge on Toxicology, Auditing, Accountancy, IT-systems

- Recommend to harmonize level of capabilities (like Impel) 


\section{Subject 5:}

\section{Access to REACH-IT}

- Access to confidential information in REACH-IT is vital for enforcement

- Depending on how enforcement is organized there may though be problems to access the information efficiently

- More analysis/experience needed to enable drafting of standard questions and "Business Object Reports"

How to get the information?

- Situation is different in every country depending on the relation / level of cooperation between enforcers and the CA (Specifically difficult in federal states)

- Advice to monitor problems

\section{Subject 6}

\section{Alert systems / information exchange}

\section{Various needs}

- Hands on exchange of views between inspectors

\section{a discussion forum on CIRCA}

- Exchange of actual data to identify possible problems

$\longrightarrow$ Implement the use of EUVICHEM as a start

\section{Subject 7}

Borderlines between work by ECHA, CA and National Enforcement Authorities (NEA)

A paper was made to start to describe these borderlines / interfaces in two levels (ECHA-MS and with in MS)

1. Main issues ECHA-MS

- Completeness and compliance check of dossiers by ECHA vs. compliance check of a registrant by an Inspector

- Differences in own way of division between CA en NEA and own work process can create extra borderlines (different in MS!)

- Presumptions / lack of clarity on possibilities of ECHA 


\section{Subject 7}

Borderlines between work by ECHA, CA and National Enforcement Authorities (NEA)

2. Main borderlines in a MS are with:

- Occupational Health \& Safety

- Environment (IPPC, SEVESO, WFD)

- Customs

- Beside these also others (Food, Product authorities etc) can be relevant

- Organisations and division of work differ per country

- Need for good coordination / cooperation and lor a certain level integration in inspection work. Forum can promote this in identifying or developing methods

\section{Subject 8:}

\section{Suggestions for Forum projects}

1. Development of Guidance Document

2. Development of a Report Template art 117 (2008)

3. Project of Co-operation with Customs

4. Harm on isation of Level of Capabilities

5. Develop basic Training Kit

6. Proposal for project to FORUM on SDS (focus based on tonnage and CMR) (2009)

7. Identification of target groups for inspection

Helsinki, "A FLYING START"

\section{Summary:}

\section{Recommendations of the project group}

- Adopt the ideas developed in the project

- Beside these:

- Give follow up to the discussion of priorities taking account to the tim eline of REACH

- Follow up on the need for good coordination / cooperation between en forcement authorities

- Adopt and develop the (concept) of compendium of Methods \&

- Discuss and elaborate borderlines as well as access to REACHIT and monitor problems with in these areas

- Implement EUVIC HEM and create a discussion forum on the internet 


\section{Annex V - Abbreviations}

\begin{tabular}{|c|c|}
\hline CA & Competent Authority \\
\hline CIRCA & Communication \& Information Resource Centre Administrator \\
\hline $\mathrm{CL}$ & Classification Labeling \\
\hline CLEEN & Chemical Legislation European Enforcement Network \\
\hline CMR & Substances that are carcinogenic, mutagenic, toxic for reproduction \\
\hline COM & Commission \\
\hline CSA & Chemical Safety Assessment \\
\hline CSR & Chemical Safety Report \\
\hline CWG & Commission Working Group \\
\hline DNEL & Derived No Effect Level \\
\hline DU & Downstream Users \\
\hline EC & European Community \\
\hline $\mathrm{ECHA}$ & European Chemical Agency \\
\hline EQS & Environmental Quality Standard \\
\hline ERP & Enterprise Resource Planning \\
\hline ES & Exposure Scenario \\
\hline EU & European Union \\
\hline EUVICHEM & European Voluntary Information Exchange System on Chemicals \\
\hline I & Importer \\
\hline IMPEL & $\begin{array}{l}\text { The European Union Network for the Implementation and Enforcement of } \\
\text { Environmental Law }\end{array}$ \\
\hline IPPC & $\begin{array}{l}\text { Council Directive } 96 / 61 / \mathrm{EC} \text { of } 24 \text { September } 1996 \text { concerning integrated } \\
\text { pollution prevention and control }\end{array}$ \\
\hline M & Manufacturer \\
\hline$M / l$ & Manufacturers and Importers \\
\hline MS & Member States \\
\hline NEA & National Enforcement Authority \\
\hline $\mathrm{OHS}$ & Occupational Health and Safety \\
\hline RAPEX & Community Rapid Information System \\
\hline $\mathrm{REACH}$ & $\begin{array}{l}\text { Regulation on Registration Evaluation and Authorization of Chemical Sub- } \\
\text { stances }\end{array}$ \\
\hline RIP & REACH Implementation Projects \\
\hline ROP & Rules of Procedure \\
\hline PBT & Persistent, Bio-accumulative and Toxic \\
\hline PNEC & Predicted No Effect Concentration \\
\hline PPORD & Process and Product orientated Research and Development \\
\hline SDS & Safety Data Sheet \\
\hline SIEF & Substance Information Exchange Fora \\
\hline SLIC & Senior Labour Inspectors' Committee \\
\hline SOP & Standard Operating Procedure \\
\hline Sub CWG & Subgroup of Commission Working Group \\
\hline $\mathrm{SVHC}$ & Substances of very high Concern \\
\hline vPvB & Very Persistent, very Bio-accumulative and Toxic \\
\hline WFD & Water Frame Directive \\
\hline
\end{tabular}

